
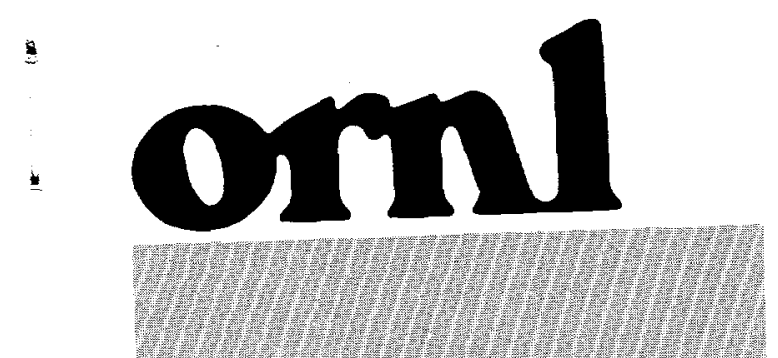

OAK RIDGE

NATIONAW

WABRATORY
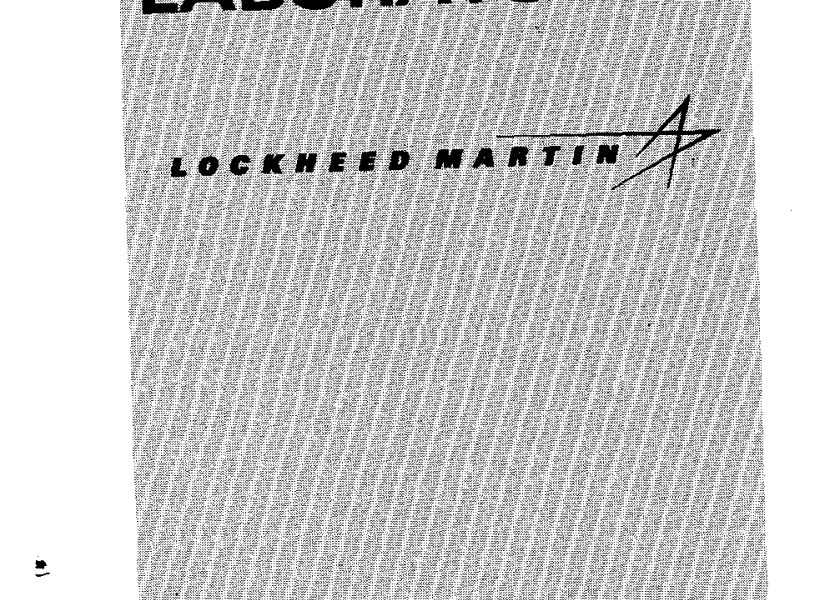

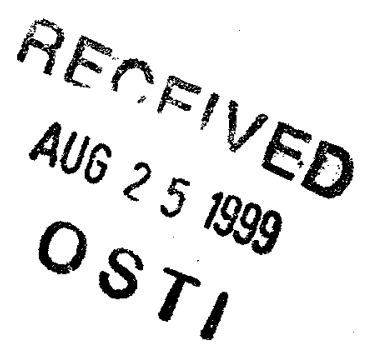

Y-12 Uranium Exposure Study
K. F. Eckerman

G. D. Kerr
WANAGED AND OPERATED BY LOCKHEED WARTN ENERGY RESEARCH CORPORATION FOR THE UNTEO STATES DEPARTUETT OF ENEREY 
This report has been reproduced from the best available copy.

Reports are available to the public from the following source.

National Technical Information Service

5285 Port Royal Road

Springfield, VA 22161

Telephone 703-605-6000 (1-800-553-6847)

TDD 703-487-4639

Fax 703-605-6900

E-mail orders @ ntis.fedworld.gov

Web site http://www.ntis.gov/ordering.htm

Reports are available to U.S. Department of Energy (DOE) employees, DOE contractors, Energy Technology Data Exchange (ETDE) representatives, and International Nuclear Information System (INIS) representatives from the following source.

Office of Scientific and Technical Information

P.O. Box 62

Oak Ridge, TN 37831

Telephone 423-576-8401

Fax 423-576-5728

E-mail reports@adonis.osti.gov

Web site http://www.osti.gov/products/sources.htm!

Reports produced after January 1,1996 , are generally available via the DOE Information Bridge.

Web site $h$ ttp://www.doe.gov/bridge 
Life Sciences Division

\title{
Y-12 URANIUM EXPOSURE STUDY
}

K. F. Eckerman and G. D. Kerr

August 5, 1999

\author{
Prepared for \\ Radiological Control Organization \\ Y-12 Plant \\ Oak Ridge, Tennessee 37831 \\ managed by \\ LOCKHEED MARTIN ENERGY SYSTEMS, INC. \\ for the \\ U.S. DEPARTMENT OF ENERGY
}

\author{
Prepared by \\ Oak Ridge National Laboratory \\ Oak Ridge, Tennessee 37831 \\ managed by \\ LOCKHEED MARTIN RESEARCH CORPORATION \\ for the \\ U.S. DEPARTMENT OF ENERGY \\ under Contact No. DE-AC05-96OR22464
}




\section{DISCLAIMER}

This report was prepared as an account of work sponsored by an agency of the United States Government. Neither the United States Government nor any agency thereof, nor any of their employees, make any warranty, express or implied, or assumes any legal liability or responsibility for the accuracy, completeness, or usefulness of any information, apparatus, product, or process disclosed, or represents that its use would not infringe privately owned rights. Reference herein to any specific commercial product, process, or service by trade name, trademark, manufacturer, or otherwise does not necessarily constitute or imply its endorsement, recommendation, or favoring by the United States Government or any agency thereof. The views and opinions of authors expressed herein do not necessarily state or reflect those of the United States Government or any agency thereof. 


\section{DISCLAIMER}

Portions of this document may be illegible in electronic image products. Images are produced from the best available original document. 


\section{CONTENTS}

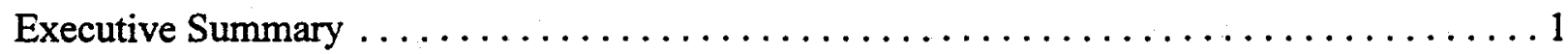

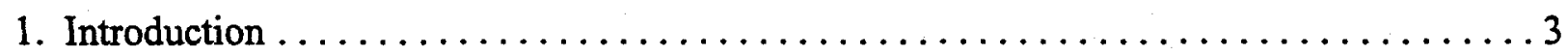

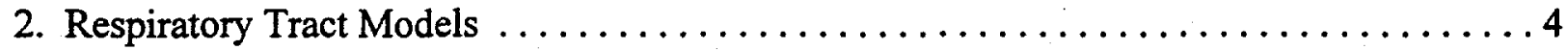

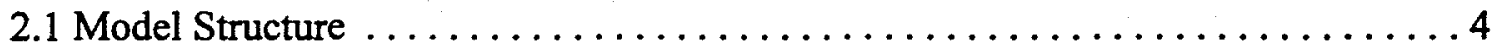

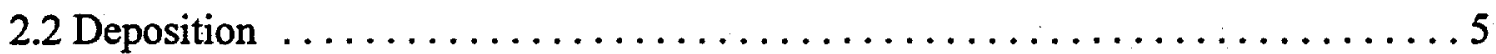

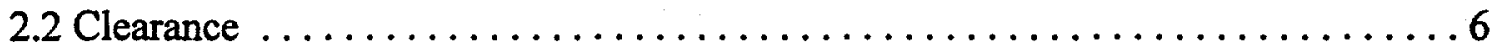

2.3 Dosimetric Considerations . . . . . . . . . . . . . . . . . . . . . . . . 9

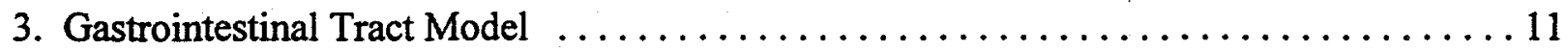

4. Biokinetic Models . . . . . . . . . . . . . . . . . . . . . . . . . . . . . . . 12

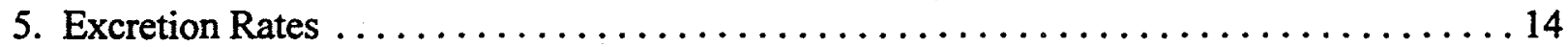

6. Dosimetric Models ........................................ 15

7. Y-12 Intake and Dose Calculation Practices ............................... 16

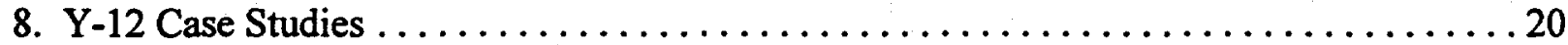

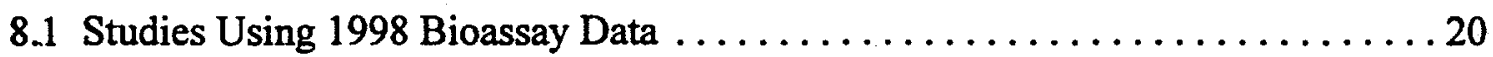

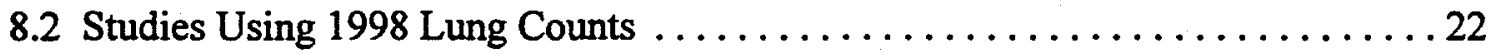

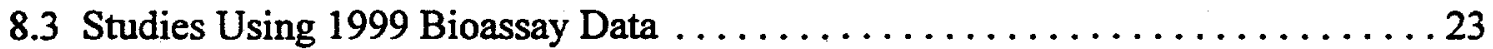

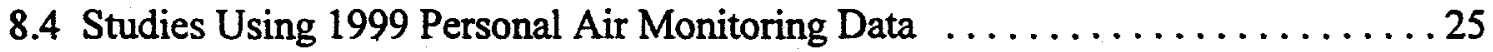

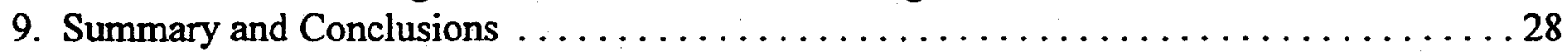

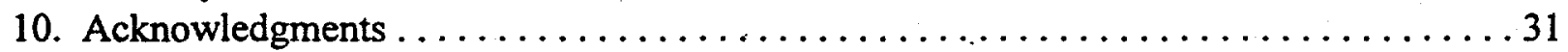

11. References .............................................. 33

Appendix A. Summary of 1998 Bioassay Data for Selected Employees ............. 37

Appendix B. Plots of 1998 Bioassay Data and Estimated Intake Rates . . . . . . . . . . . . 47

Appendix C. Summary of 1999 Bioassay Data for Selected Employees ..............66 65

Appendix D. Summary of 1999 Personal Air Monitoring Data for Selected Employees . . . 71

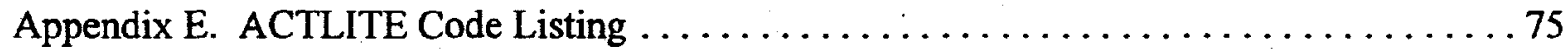

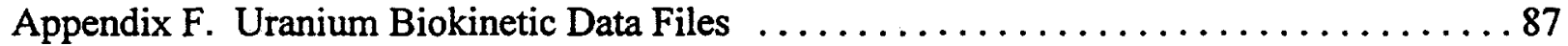

Appendix G. Analysis of Intake Contributions from Type $M$ and $S$ Uranium .......... 91 


\section{EXECUTIVE SUMMARY}

Following the recent restart of operations at the Y-12 Plant, the Radiological Control Organization (RCO) observed that the enriched uranium exposures appeared to involve insoluble rather than soluble uranium that presumably characterized most earlier Y-12 operations. These observations necessitated changes in the bioassay program, particularly the need for routine fecal sampling. In addition, it was not reasonable to interpret the bioassay data using metabolic parameter values established during earlier Y-12 operations. Thus, the recent urinary and fecal bioassay data were interpreted using the default guidance in Publication 54 of the International Commission on Radiological Protection (ICRP); that is, inhalation of Class Y uranium with an activity median aerodynamic diameter $(A M A D)$ of $1 \mu \mathrm{m}$. Faced with apparently new workplace conditions, these actions were appropriate and ensured a cautionary approach to worker protection. As additional bioassay data were accumulated, it became apparent that the data were not consistent with Publication 54. Therefore, this study was undertaken to examine the situation.

This study uses state-of-the-art information on the behavior of uranium in the respiratory tract and in the body to assess the enriched uranium intakes in a small subset of Y-12 workers during late 1998 and early 1999. Specifically, the mathematical models applied are those that form the basis for ICRP Publication 78 which superseded Publication 54 noted above. The study confirmed that the enriched uranium exposures involve insoluble uranium and found that the $\mathrm{Y}-12$ bioassay was consistent with the methods of ICRP Publication 78. The methods of Publication 78 for interpretation of the bioassay data also were found to reduce the estimated Y-12 worker doses from insoluble uranium by a factor of about five. Thus, the following recommendations are made:

- The methods of ICRP Publication 78 should be used in the interpretation of uranium bioassay data. The new models of the respiratory tract and of the behavior of uranium in the body in that publication are broadly consistent with the observed urinary and fecal bioassay data for the Y-12 workers.

- The routine bioassay program must continue to include both fecal and urine sampling to enable clarification of the workplace conditions. Monthly fecal sampling, while desirable from a statistical viewpoint, can probably be reduced to bimonthly or quarterly sampling once more experience is gained in the application of the new models to uranium exposures at the Y-12 Plant.

- Use of the methods of Publication 78 requires that the models underlying these methods be used in assigning the worker's radiation dose. Components of these models have no counterpart in the models upon which 10 CFR 835 is based; thus, efforts should be promptly initiated to obtain the appropriate regulatory exemptions.

- Further assistance should be provided to Y-12 RCO staff in implementing the methods of ICRP Publication 78. Considering the demands on their time by routine tasks, it is unreasonable to expect that the staff can implement and evaluate these methods while performing their other duties. 
Although beyond the scope of this study, it is suggested that the cursory review of the $Y-12$ personal air monitoring program in this study be expanded to include more workers who are currently wearing personal air monitoring devices. While workers' intakes can best be determined by bioassay. methods, air sampling is a primary indicator of the potential exposure of a worker to airborne materials and can provide early information on changes in workplace conditions. 


\section{INTRODUCTION}

Uranium exposures at the Y-12 Plant are currently being interpreted using the methods embodied in various computer codes such as INDOS (Skrable 1987), CINDY (Strenge 1995), and DOSEXPRT (Ward and Eckerman 1992). All of these codes are based on Publication 54, issued in 1988, by the International Commission on Radiological Protection (ICRP). Publication 54 (ICRP 1988b) is a companion volume to Publication 30 (ICRP 1979a,b; 1980; 1981a,b; 1982a,b; 1988a) which gave values for the Annual Limits on Intake $(A L I)$ and Derived Air Concentration $(D A C)$ for radionuclides based on the then current models for the behavior of radionuclides within the respiratory tract and the body following their absorption to blood. Since 1988, there have been major developments in radiation protection which have an impact on the analyses of workers' intakes of uranium. These developments include a comprehensive revision of the respiratory tract model and a revision of the biokinetic model describing uranium's behavior following its absorption into blood. Because of these developments for uranium and other radioelements, the ICRP has replaced Publication 54 by a new Publication 78 (ICRP 1997) which details the application of the newer models in operational radiation protection.

In this study, we used the newer guidance of the ICRP to assess the uranium intakes at Y-12 following the recent restart of enriched uranium operations. The stimulus for the study is the observation that these exposures appear to involve insoluble uranium rather than the soluble uranium exposures characterizing most earlier Y-12 operations and that the observed bioassay data were inconsistent with the Publication 54 models.

The report begins with a discussion of the new ICRP respiratory tract model in Section 2 followed by brief discussions, in Section 3, of the gastrointestinal tract model and, in Section 4, of the physiological-based model for the behavior of uranium in the body. These models are used in Publication 78. A comparison of the uranium excretion rates indicated by the models of Publication 54 and 78 are given in Section 5 and the values of the committed effective dose per unit intake tabulated in Publication 30 and Publication 68 are discussed in Section 6 - the latter publication used the newer models. Following this introductory material, the discussion turns to the application of these methods to the Y-12 uranium exposures. Section 7 discusses some general aspects of the intake and dose calculation practices at Y-12 and Section 8 presents our analysis of the bioassay data for a small subset of the Y-12 workers. Our conclusions are presented in Section 9. In addition, several appendices are included to provide details regarding the analysis. 


\section{RESPIRATORY TRACT MODELS}

The ICRP has recently adopted, in Publication 66 (ICRP 1994a), a new model for the human respiratory tract that involves considerably greater detail and physiological realism than the respiratory tract model used in Publication 30 (ICRP 1979a). The Publication 30 model was initially published in 1966 (ICRP 1966). There are a number of differences between these models which result in changes in the estimates of fractional deposition of inhaled material within the respiratory tract, the subsequent clearance of the deposited material from the lung, and dose to the lung. The newer model (ICRP 1994a) was formulated to:

- facilitate calculations of biologically meaningful dose,

- incorporate current knowledge with respect to morphological, physiological, and radiobiological characteristics of the respiratory tract,

- meet the needs of both prospective (e.g., derivation of secondary quantities) and retrospective (e.g, interpretation of bioassay measurements) radiation protection, and

- enable use of information on the deposition and clearance of specific materials encountered in the workplace.

The old and new models are shown in schematic form in Figs. 1a and 1b, respectively.

2.1 Model Structure. The new model divides the respiratory system into extrathoracic $(E T)$ and thoracic regions. The airways of the $E T$ region are further divided into the anterior nasal passages, in which deposits are removed by extrinsic means such as nose blowing, and the posterior nasal passages including the nasopharynx, oropharynx, and larynx, from which deposits are swallowed. The airways of the thorax include the bronchi (compartments labeled $B B_{i}$ ), bronchioles (compartments labeled $b b_{i}$ ), and alveolar-interstitial region (compartments labeled $A I_{i}$ ). Material deposited in the thoracic airways may be cleared into blood by absorption, to the gastrointestinal (GI) tract by mechanical processes (that is, transported upward and swallowed), and to the regional lymph nodes via lymphatic channels.

The number of compartments in each region was chosen to duplicate the different kinetic phases observed in humans and laboratory animals. In Fig. 1b, the particle transport rates shown beside the arrows are reference values in units of $\mathrm{d}^{-1}$. For example, mechanical transport of particles from $b b$, to $B B_{1}$ is assumed to occur at a fractional rate of $2 \mathrm{~d}^{-1}$ and the mechanical transport from $E T_{2}$ to the $G I$ tract is assumed to occur at a fractional rate of $100 \mathrm{~d}^{-1}$. The mechanical transport rates are assumed to be independent of the physio-chemical nature of the deposited material.

In addition to the mechanical clearance, particles undergo dissolution with subsequent absorption of the dissolved constituents to blood. Unlike mechanical clearance, the rate of absorption (the movement of material to blood regardless of the mechanism) depends on the physio-chemical form of the inhaled material. Clearance is discussed further in Section 2.3. 


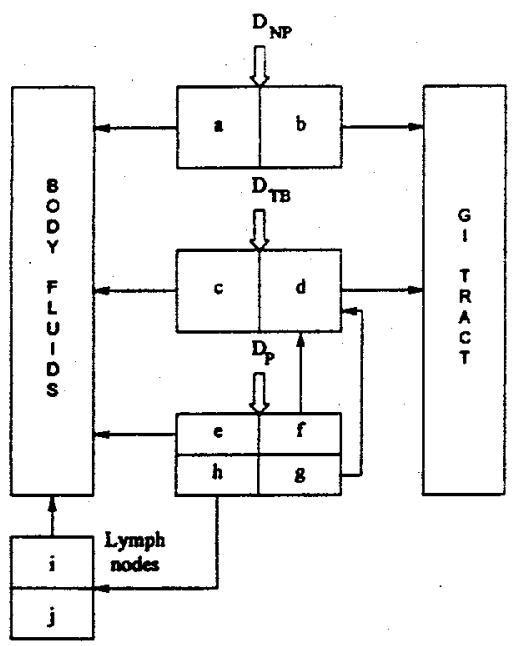

Fig. 1a. Compartment model used to describe the clearance of materials deposited in the lung in ICRP Publication 30.

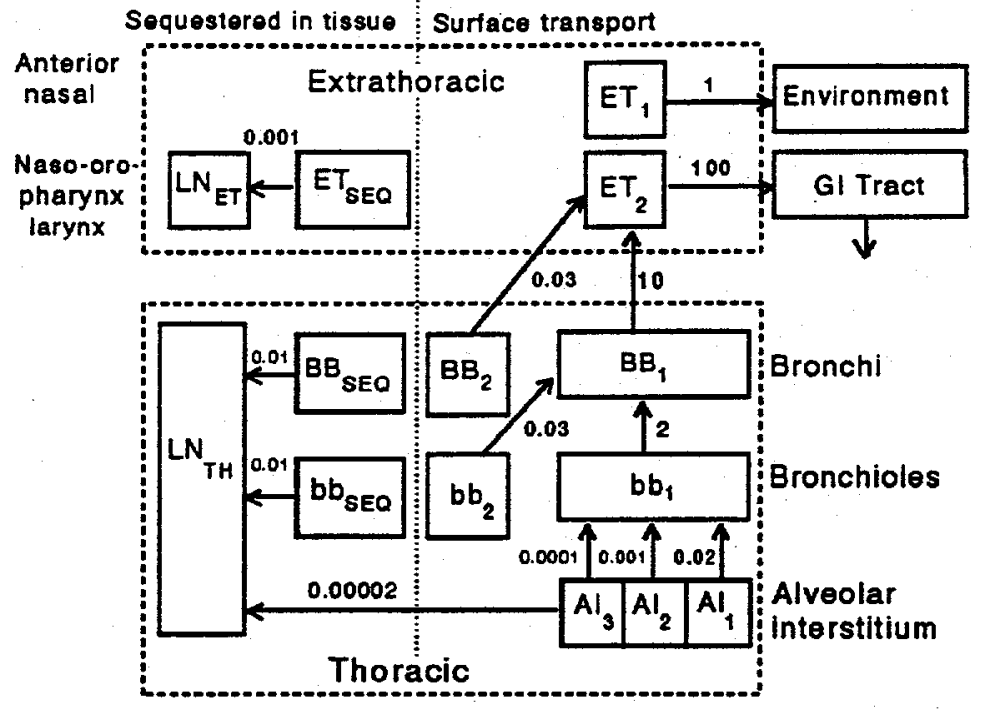

Fig. 1b. Time-dependent particle transport from each respiratory region within the respiratory tract model of ICRP Publication 66. Transfer to blood (not shown) occurs from all components except $E T_{l}$.

2.2 Deposition. The deposition of particles in the respiratory tract and the underlying physical mechanisms that determine the distribution of deposited material in the respiratory tract have been the subject of considerable experimental and theoretical research since the issuance of the earlier ICRP lung model (ICRP 1966). These developments were extensively reviewed during the development of the new lung model (ICRP.1994a).

The deposition model in Publication 66 (ICRP 1994a) provides estimates of the regional deposition for a wide range of particle sizes. This range extends from atomic dimensions (approximately $0.0005 \mu \mathrm{m}$ in diameter) to large aerosols characterized by an activity median aerodynamic diameter $(A M A D)$ on the order of $100 \mu \mathrm{m}$. In addition, the deposition depends upon physiological factors (e.g., nose vs mouth breathing) and the level of physical exertion. In Publication 66, the default value of the $A M A D$ for workplace aerosols is $5 \mu \mathrm{m}$ (ICRP 1994a, Dorrian and Baily 1995). Other information on aerosols at uranium handling and processing facilities, including the Y-12 plant, support the choice of a default value of a least $5 \mu \mathrm{m}$ (Schieferdecker $e$ t al. 1985, Barber and Forrest 1995, Ansoborlo et al. 1998, Chazel et al. 1998, Hoover et al. 1998). The previous default value used by ICRP had been $1 \mu \mathrm{m}$. The fraction of the inhaled activity that is deposited in the respiratory tract is given in Table 1 for the default aerosols. The larger size of the aerosol assumed in the newer model and the consideration of nose breathing (the earlier model was based on mouth breathing) result in increased deposition of inhaled activity in the respiratory tract $(82.2 \%$ vs $63 \%)$. The increased deposition occurs largely in the $E T$ airways and the deposition is reduced in the distal airways of the new model. 
Table 1. Default deposition values for old and new lung models.

\begin{tabular}{||l|c|l|c||}
\hline \multicolumn{2}{||c|}{$\begin{array}{c}\text { ICRP Publication 30 } \\
(\mathrm{AMAD}=1 \mu \mathrm{m})\end{array}$} & \multicolumn{2}{c|}{$\begin{array}{c}\text { ICRP Publication 66 } \\
(\mathrm{AMAD}=5 \mu \mathrm{m})\end{array}$} \\
\hline Region & Deposition (\%) & Region & Deposition (\%) \\
\hline \hline NP & 30 & $\mathrm{ET}_{1}$ & 34 \\
\hline TB & 8 & $\mathrm{ET}_{2}$ & 40 \\
\hline $\mathrm{P}$ & 25 & (Subtotal) & $(74)$ \\
\hline Total & 63 & BB & 1.8 \\
\hline & & bb & 1.1 \\
\hline & & AI & 5.3 \\
\hline & & (Subtotal) & $(8.2)$ \\
\hline & & Total & $\mathbf{8 2 . 2}$ \\
\hline
\end{tabular}

The partitioning of the regional deposition in the new model among the compartments in each region is given in Table 2 for the default aerosol. The partitioning to the slow-clearing compartments $B B_{2}$ and $b b_{2}$ depends on particle size and, at 5- $\mu \mathrm{m} A M A D$, are 0.333 and 0.397 , respectively.

2.3 Clearance. Materials deposited in the respiratory tract are cleared (or translocated) by three main routes:

- to blood by absorption,

- to the GI tract by mechanical clearance, and

- to regional lymph nodes $(L N)$ via lymphatic channels.

These routes of clearance are considered to operate in all regions of the model, with the exception of the $E T$, region in which the deposited material is removed only by extrinsic means (e.g., nose blowing).

Although the model permits consideration of compound-specific absorption rates, aerosols are generally assigned to one of three default absorption types: Type $\mathrm{F}$ (fast dissolution and a high level of absorption to blood), Type $\mathrm{M}$ (an intermediate rate of dissolution and level of absorption to blood), and Type S (slow dissolution rate and low level of absorption to blood). The absorption coefficient for Type $\mathrm{M}$ and $\mathrm{S}$ compounds are time-dependent and can be considered to arise as the deposited particles are transformed from their "initial state" to a "transformed state". Particles in either state are subject to the same mechanical clearance but different absorption rates to blood. It is also possible to envision particles in a "bound state" where they are not subject to mechanical 
Table 2. Partition of deposition $(A M A D=5 \mu \mathrm{m})$ in regions of respiratory tract among compartments in ICRP 66 model.

\begin{tabular}{|l|l|c||}
\hline Region & Compartment & $\begin{array}{c}\text { Fraction of regional deposition } \\
\text { assigned to compartment }\end{array}$ \\
\hline \hline $\mathrm{ET}_{2}$ & $\mathrm{ET}_{2}$ & 0.9995 \\
\hline & $\mathrm{ET}_{\text {seq }}$ & 0.0005 \\
\hline $\mathrm{BB}$ & $\mathrm{BB}_{1}$ & 0.660 \\
\hline & $\mathrm{BB}_{2}$ & 0.333 \\
\hline & $\mathrm{BB}_{\text {seq }}$ & 0.007 \\
\hline $\mathrm{bb}$ & $\mathrm{bb}_{1}$ & 0.596 \\
\hline & $\mathrm{bb}_{2}$ & 0.397 \\
\hline & $\mathrm{bb}_{\text {seq }}$ & 0.007 \\
\hline $\mathrm{AI}$ & $\mathrm{AI}_{1}$ & 0.3 \\
\hline & $\mathrm{Al}_{2}$ & 0.6 \\
\hline & $\mathrm{AI}_{3}$ & 0.1 \\
\hline
\end{tabular}

clearance; however, the "bound state" is not part of the kinetics for Type F, M, and S compounds. The fractional rate of absorption $\left(\mathrm{d}^{-1}\right)$ assigned to the default types are:

Type F: $\quad 100$

Type M: $\quad 10.0 e^{-100.0 t}+5.0 \times 10^{-3} e^{-0.005 t}$

Type S: $\quad 0.1 e^{-100.0 t}+1.0 \times 10^{-4} e^{-0.0001 t}$

where $t$ is the time (days) since the initial deposition. Thus, for example, a Type $M$ compound is transferred at time zero from the compartments of the respiratory tract model (see Fig. 1b) to blood at a fractional rate of $10.005 \mathrm{~d}^{-1}$ which declines with time to about $5.0 \times 10^{-3}$ at 0.1 day and $3.0 \times 10^{-3}$ at 100 days. Type $F$ materials are remove at the constant rate of $100 \mathrm{~d}^{-1}$. The fraction rate at which inhaled Type $\mathrm{M}$ and $\mathrm{S}$ uranium is translocated from the lung to blood (the absorption rate) and to the $G I$ tract is shown graphically in Fig. 2. From that figure, one notes the decreased transfer to blood (absorption) of Type S uranium relative to Type $\mathrm{M}$ and that the transfer rate into the GI tract is largely independent of absorption type. 

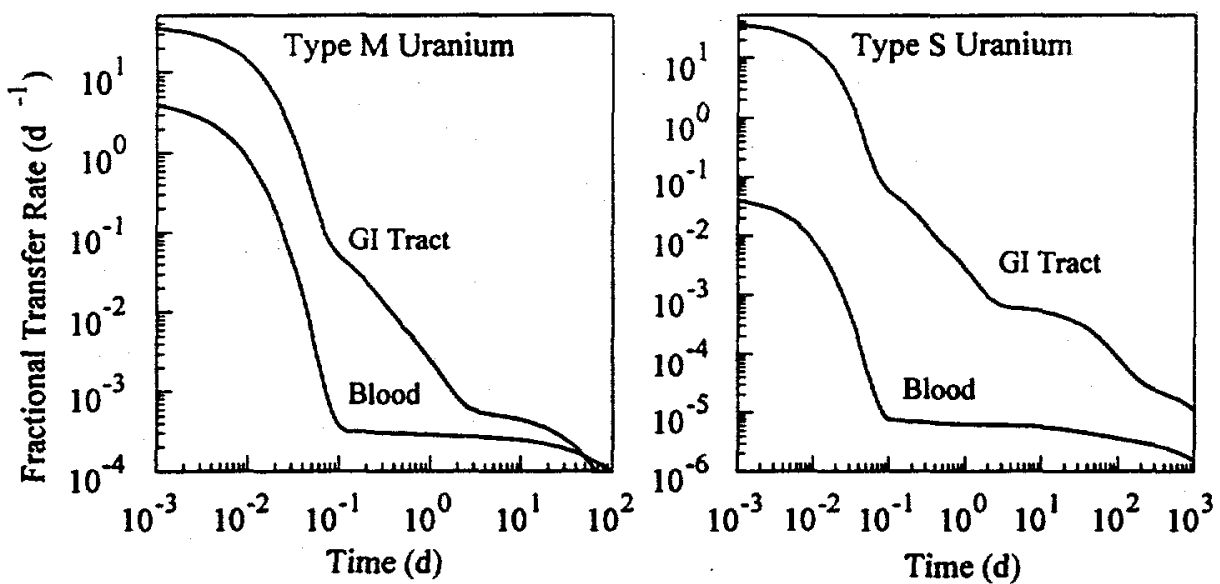

Fig. 2. The instantaneous transfer rate of inhaled uranium from the lung into the blood (the absorption) and into the gastrointestinal (GI) tract as predicted by the Publication 66 lung model for Type $M$ and $S$ compounds. The workplace aerosol was characterized by an $A M A D$ of $5 \mu \mathrm{m}$.

Assignment of compounds of different chemical forms to absorption Type $F, M$, or $S$ is best based on the experimental data for compounds expected to be encountered in the workplace. For uranium compounds, Publication 78 (ICRP 1997) suggests the following classification:

Type F Soluble U compounds including most hexavalent compounds, e.g., $\mathrm{UF}_{6}, \mathrm{UO}_{2} \mathrm{~F}_{2}$ and $\mathrm{UO}_{2}\left(\mathrm{NO}_{3}\right)_{2}$

Type $\mathrm{M} \quad$ Less soluble compounds, e.g., $\mathrm{UO}_{3}, \mathrm{UF}_{4}, \mathrm{UCl}_{4}$, and other hexavalent compounds

Type $\mathrm{S} \quad$ Highly insoluble compounds, e.g., $\mathrm{UO}_{2}$ and $\mathrm{U}_{3} \mathrm{O}_{8}$

The Publication 30 model assigned aerosols to one of three clearance classes $\mathrm{D}, \mathrm{W}$, and $\mathrm{Y}$ that represented clearance half-times in the deep lung on the order of days, weeks, and years. The assignment of uranium compounds to these clearance classes in Publication 30 (ICRP 1979a) and Publication 54 (ICRP 1988b) was as above with absorption Type F, M, and S corresponding to clearance Class $\mathrm{D}, \mathrm{W}$, and $\mathrm{Y}$, respectively.

Table 3 summarizes the fraction of the inhaled activity which is predicted to be translocated to blood (fractional uptake) by absorption from the lung and GI tract for both lung models using the recommended default aerosol sizes for each model. For example, the Publication 30 model indicates that $63 \%$ (see Table 1) of the inhaled activity is deposited in the respiratory tract. For Class Y uranium, $5.4 \%$ of the inhaled activity is absorbed directly from the lung and the remainder, $63 \%$ minus $5.4 \%$ or $57.6 \%$, is translocated to the $G I$ tract where the $0.2 \%$ of the swallowed uranium is absorbed; hence, 0.002 times $57.6 \%$ or $0.12 \%$ is absorbed via the GI tract. The total uptake of Class $\mathrm{Y}$ uranium is $5.5 \%$ of the inhaled activity. 
Table 3. Absorption of inhaled uranium.

\begin{tabular}{|c|c|c|c|c|c|c|c|}
\hline \multicolumn{4}{|c|}{$\begin{array}{l}\text { ICRP Publication } 30 \\
(\mathrm{AMAD}=1 \mu \mathrm{m})\end{array}$} & \multicolumn{4}{|c|}{$\begin{array}{l}\text { ICRP Publication } 66 \\
(\mathrm{AMAD}=5 \mu \mathrm{m})\end{array}$} \\
\hline \multirow{2}{*}{ Class } & \multicolumn{3}{|c|}{ Uptake (\%) } & \multirow{2}{*}{ Type } & \multicolumn{3}{|c|}{ Uptake (\%) } \\
\hline & Blood & GI Tract $^{\mathrm{a}}$ & Total & & Blood & GI Tract ${ }^{b}$ & Total \\
\hline $\mathrm{D}$ & 47.6 & 0.77 & 48.4 & $\mathrm{~F}$ & 28.2 & 0.40 & 28.6 \\
\hline W & 12.0 & 2.6 & 14.6 & $\mathbf{M}$ & 8.2 & 0.80 & 9.0 \\
\hline$Y$ & 5.4 & 0.12 & 5.5 & $\mathrm{~S}$ & 0.6 & 0.095 & 0.70 \\
\hline
\end{tabular}

${ }^{a}$ The fractional absorption, $\mathrm{f}_{1}$ parameter, in $G I$ tract was taken to be 0.05 for Class $\mathrm{D}$ and $\mathrm{W}$ uranium compounds and 0.002 for Class $Y$ uranium compounds (ICRP 1979a).

${ }^{b}$ The fractional absorption, $\mathrm{f}_{1}$ parameter, in $G I$ tract was taken to be 0.02 for Type $F$ and $M$ uranium compounds and 0.002 for Type S uranium compounds (ICRP 1994b).

In the Publication 66 lung model, the deposition of an aerosol characterized by an $A M A D$ of $5 \mu \mathrm{m}$, is $82.2 \%$ (see Table 1). The activity deposited in the anterior portion of the nose (the $E T_{I}$ region), $34 \%$ of the inhaled activity, is not translocated to either blood or the GI tract. Thus, $82.2 \%$ minus $34 \%$ or $48.2 \%$ of the inhaled activity is subject to absorption or translocation to the GI tract. For Type S uranium, $0.6 \%$ of the inhaled activity is absorbed directly from the lung and $47.6 \%$ enters the GI tract where the $0.2 \%$ is absorbed; hence, 0.002 times $47.6 \%$ or $0.1 \%$ of the inhaled activity is absorbed via the $G I$ tract. The total fractional uptake of Type S uranium is $0.7 \%$ of the inhaled activity. Thus, the Publication 66 model predicts a lower absorption of Type $S$ uranium than the Publication 30 model ( $0.7 \%$ vs $5.5 \%)$.

2.4 Dosimetric Considerations. The dosimetric model for the respiratory tract in Publication 66 (ICRP 1994a) takes into account the potential for the inhaled radionuclide to irradiate tissues throughout the respiratory tract and the large range in the radiation sensitivity of these tissues. The model recognizes that the doses received by various tissues of the tract can vary substantially, depending upon the physical properties of the inhaled material. The variation in dose among the tissues called into question the organ average dose concept for the lung used in Publication 30 . In Publication 30 (1979a), the lung dose was computed as the total energy deposition in the $T B, P$, and $L N$ regions ( $N P$ region not reflected in the lung dose) of the model divided by the mass of the blood filled lung (1 kg). The Publication 66 model involves a calculation of the dose to the cells at risk (reflecting their depth into the airways) in each region of the respiratory tract. These doses are then weighted by an apportionment factor to derive the "lung" dose. The apportionment factors for the regions reflect their contributions to the overall risk of lung cancer. The dose to the lung, $H_{\text {lumg, }}$, is computed as

$$
H_{\text {lung }}=A_{B B} H_{B B}+A_{b b} H_{b b}+A_{A I} H_{A I}+A_{L N_{T H}} H_{L N_{T H}}
$$


and the dose to the extrathoracic region, $H_{E T}$, is computed as

$$
H_{E T}=A_{E T_{1}} H_{E T_{1}}+A_{E T_{2}} H_{E T_{2}}+A_{L N_{E T}} H_{L N_{E T}}
$$

where the apportionment factors are:

\begin{tabular}{|l|l|}
\hline Tissue & Apportionment factor (A) \\
\hline Extrathoracic Region & \\
ET $_{1}$ (anterior nose) & 0.001 \\
ET $_{2}$ (posterior nasal passages, larynx, & \\
$\quad$ pharynx, and mouth & 1.0 \\
LN $_{\mathrm{ET}}$ (lymphatics) & 0.001 \\
\hline Thoracic Region & \\
BB (bronchial) & 0.333 \\
bb (bronchiolar) & 0.333 \\
AI (alveolar-interstitial) & 0.333 \\
LN $_{\text {TH (lymphatics) }}$ & 0.001 \\
\hline
\end{tabular}

The dose to tissues other than the lung are computed in the manner of Publication 30 (ICRP 1979a). 


\section{GASTROINTESTINAL TRACT MODEL}

The model used to describe the behavior of radionuclides in the gastrointestinal $(G I)$ tract is that described in ICRP Publication 30 (ICRP 1979a). The model, shown in Fig. 3, divides the GI tract into four segments or compartments: stomach (St), small intestine (SI), upper large intestine (ULI), and lower large intestine (LLD), and depicts first-order transfer of material from one segment to the next. Material is assumed to transfer from $S t$ to $S I$ at the fractional rate of $24 \mathrm{~d}^{-1}$, from $S I$ to $U L I$ at $6 \mathrm{~d}^{-1}$, from $U L I$ to $L L I$ at $1.8 \mathrm{~d}^{-1}$, and from $L L I$ to the compartment $F E C E S$ at $1 \mathrm{~d}^{-1}$.

Absorption of ingested material to blood generally is assumed to occur only in SI. Absorption to blood is described in terms of a fraction $f_{l}$. In the absence of radioactive decay, the fraction $f_{l}$ of ingested material moves from $S I$ to $B L O O D$ and the fraction $1-f_{l}$ moves from $S I$ to $U L I$ and eventually is excreted in feces. The transfer coefficient from $S I$ to $B L O O D$ is $6 f_{1} /\left(1-f_{l}\right) \mathrm{d}^{-1}$.

In the calculation of doses from inhalation of radionuclides, allowance is made for the absorption of material passing through the gastrointestinal tract after clearance from the respiratory tract. Radionuclides cleared from the respiratory tract may typically be present as minor constituents of the inhaled particles and the absorption from the gastrointestinal tract may depend on dissolution of the particle matrix as well as the elemental form of the radionuclide (ICRP 1996). In ICRP Publication 68 (ICRP 1994b) and hence in this report, the element-specific $f_{l}$ values applied to uranium ingestion are applied to inhalation. For inhaled uranium of Type $\mathrm{F}$ and $\mathrm{M}$, a default $f_{l}$ value of 0.02 is applied and for Type $\mathrm{S}$ a default $f_{f}$ value of 0.002 is applied.

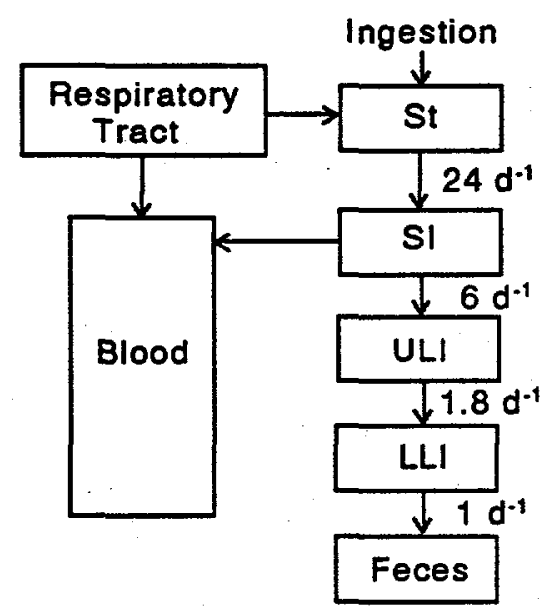

Fig. 3. Model of transit of material through the gastrointestinal tract (ICRP 1979a). 


\section{BIOKINETIC MODELS}

A new physiologically-based model of the behavior of uranium following its uptake to blood was presented in Publication 69 (ICRP 1995). The model describes, in detail, the kinetics of uranium in bone (the main site of systemic retention) and in the liver, kidneys, and other soft tissues. The model takes account of the initial uptake of uranium onto the surfaces of bone, its transfer from the bone surface into bone volume, and recycle from bone and other tissues back to blood. The movement of uranium between these sites and into the routes of excretion are explicitly addressed in the model. The new model is shown in schematic form in Fig. $4 \mathrm{a}$ and its parameter values are given in Appendix F.

The Publication 30 uranium model (ICRP 1979a), typical of a class of biokinetic models called retention models, was designed for calculation of time-integrated activities and characteristically failed to describe the behavior of uranium shortly after its uptake to blood. It is, of course, just these times that are important in bioassay applications. As seen in schematic of Fig. 4b, the old model does not explicitly address the excretion pathways. Instead, it simply indicates, for example, that uranium leaving "bone" appears in urine without being transferred to the kidney and urinary bladder. This is not physiologically correct.

Figure $5 \mathrm{a}$ compares the expected urinary excretion indicated by the biokinetic models of Publications 54 and 78 (ICRP 1988b, 1997) following a hypothetical injection of uranium into blood. Figure 5b shows both the urinary and fecal excretion rate predicted by the model used in Publication 78 . In Publication 54, no fecal excretion of injected uranium was indicated. As seen from Fig. 5a, the urinary excretion rates indicated by the two models are in reasonable agreement with the discrepancy at a day being only a factor of 4 . 


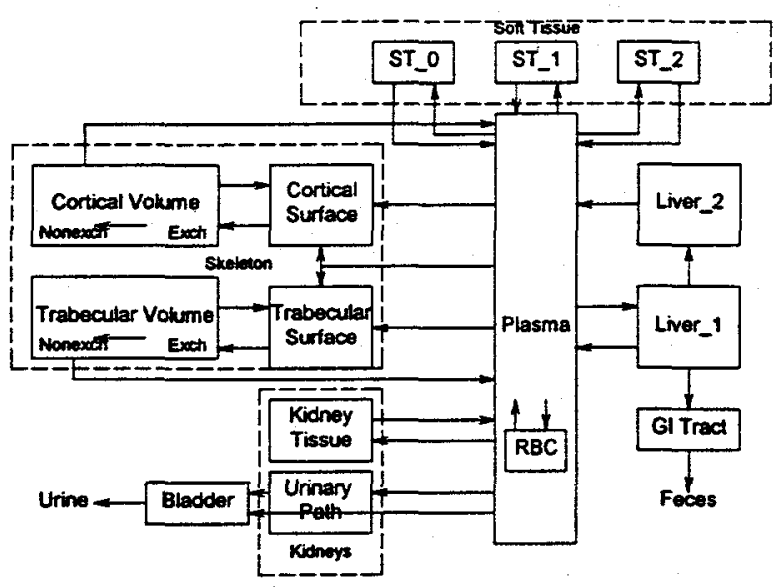

(a)

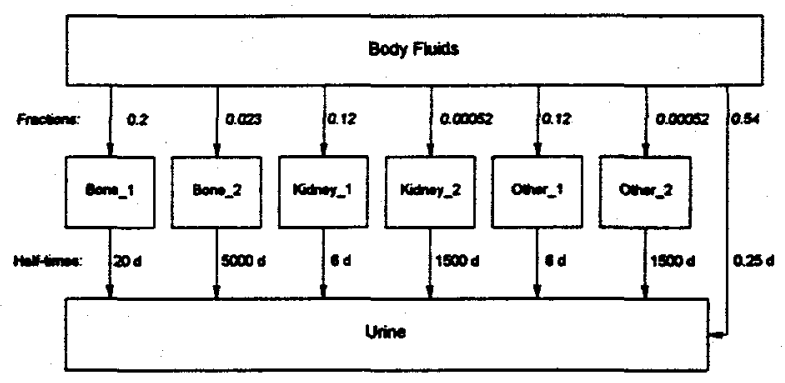

(b)

Fig. 4. Biokinetic models of uranium used in the ICRP Publications. The physiologically-based model of Fig. 4a is the model that was introduced in Publication 69 and later used in Publication 78. Note that this model explicitly details the excretion of systemic uranium, including both urinary and fecal excretion. Fig. 4b illustrates the retention model used in Publications 30 and 54. Note that uranium leaving systemic tissues is simply taken to enter urinary excretion.
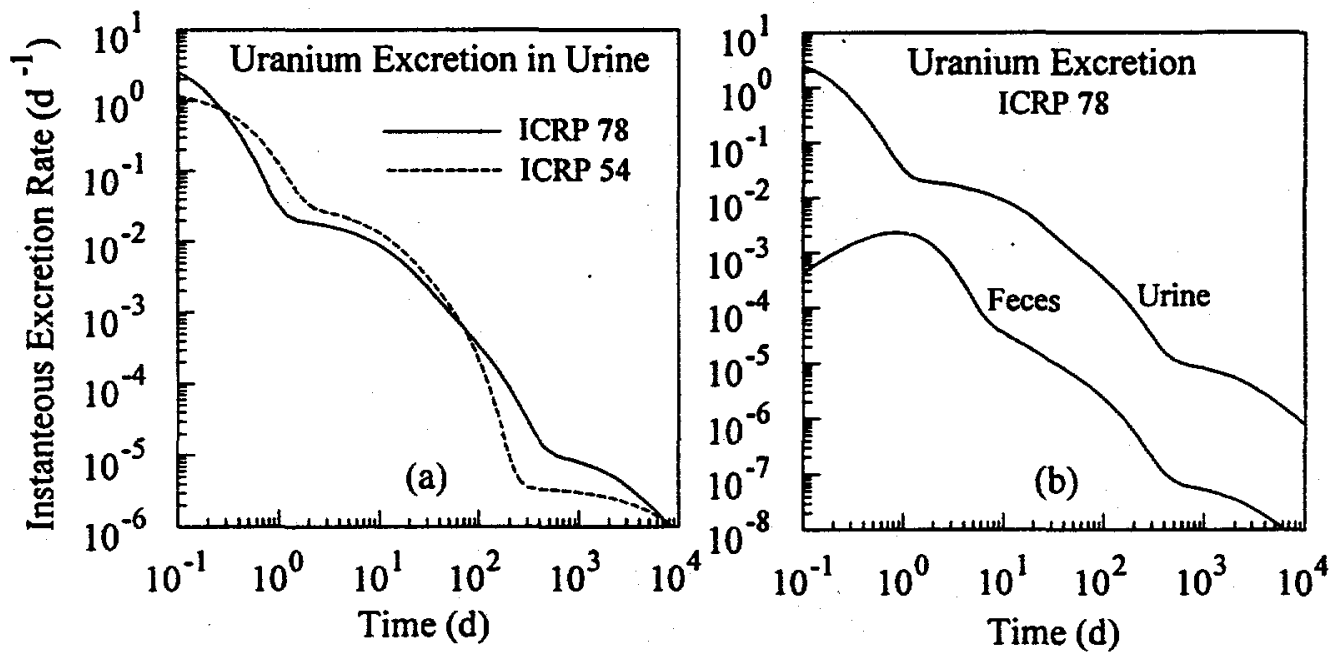

Fig. 5. Excretion of uranium following its introduction into blood. Fig. 5a compares the urinary excretion rate indicated in ICRP Publications 54 and 78, the latter being based on the model of Publication 69. Fig. 5b shows the fecal and urinary excretion rates predicted by the models of Publication 78. 


\section{EXCRETION RATES}

The expected urinary and fecal excretion rates following inhalation of uranium compounds have been calculated assuming acute intakes of various chem cal forms using the old and new models (see Fig. 6). The urinary excretion rates predicted by the two models are quite different, especially those for insoluble uranium (Class $Y$ and Type S); however, little difference is indicated in the fecal excretion rates. For Type $S$ uranium, the ratio of the amount excreted in urine to that in feces is considerably lower than that indicated by Class $Y$ uranium. This is, of course, just the issue evident in the processing of the $\mathrm{Y}-12$ bioassay data.

In interpreting the $\mathrm{Y}-12$ bioassay data, it was observed that urinary and fecal data were not consistent with the predictions of the older model. The older model indicated a feces to urine ratio that was smaller than observed (i.e., it either underestimated fecal excretion or overestimated urinary excretion). The new model was known to increase the amount of material entering the GI tract; thus, it was clear that this model might well be consistent with the $\mathrm{Y}-12$ observations. This is evident in the panel of Fig. 6 that compares Class $Y$ and Type $S$ urinary and fecal excretion.
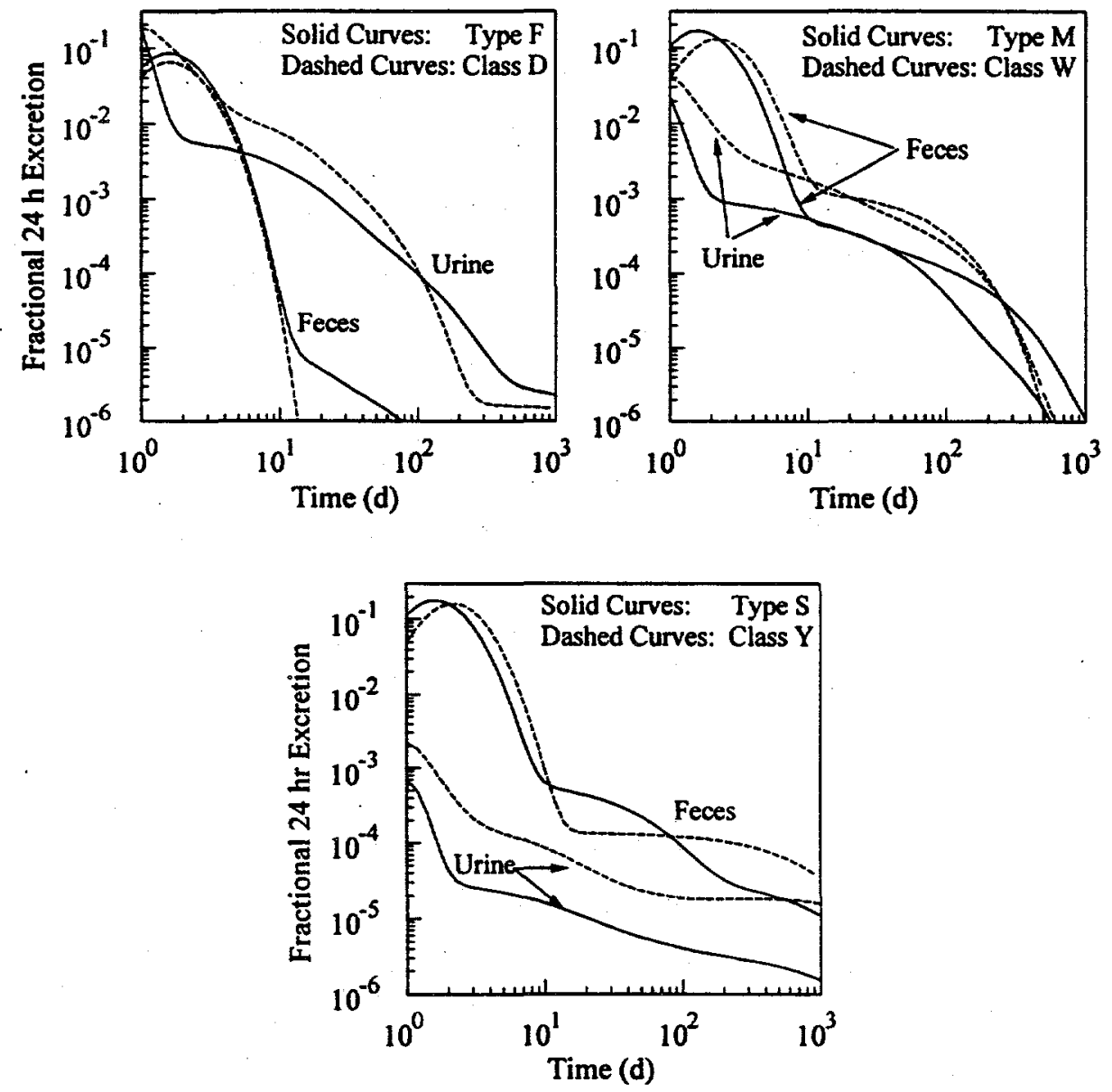

Fig. 6. Expected 24-hour urinary and fecal excretion of uranium following an acute intake using the models of ICRP Publication $54(A M A D=1 \mu \mathrm{m})$ and ICRP Publication $78(A M A D=5 \mu \mathrm{m})$. 


\section{DOSIMETRIC MODELS}

Committed effective doses per unit intake for the various uranium isotopes based on the old (ICRP Publication 30) and new (ICRP Publication 68) models are listed in Table 4. The values of the dose coefficients for soluble forms of uranium (D and W compared to $\mathrm{F}$ and $\mathrm{M}$, respectively) are not sensitive to the changes between the old and new models. However, the dose coefficient for insoluble uranium (Type S) based on the newer model is about one-fifth of the earlier value for Class $\mathrm{Y}$ uranium compounds.

Table 4. Inhalation dose coefficients for uranium.

\begin{tabular}{|c|c|c|c|c||}
\hline \multirow{2}{*}{ Nuclide } & \multicolumn{2}{|c|}{$\begin{array}{c}\text { ICRP Publication } 30 \\
(\mathrm{AMAD}=1 \mu \mathrm{m})\end{array}$} & \multicolumn{2}{c|}{$\begin{array}{c}\text { ICRP Publication 68 } \\
\text { (AMAD }=5 \mu \mathrm{m})\end{array}$} \\
\cline { 2 - 5 } & $\mathrm{Class}$ & $\mathrm{h}_{\mathrm{E}}, \mathrm{Sv} / \mathrm{Bq}$ & $\mathrm{Type}$ & $\mathrm{e}(50), \mathrm{Sv} / \mathrm{Bq}$ \\
\hline \hline${ }^{234} \mathrm{U}$ & $\mathrm{D}$ & $7.4 \mathrm{E}-7$ & $\mathrm{~F}$ & $6.4 \mathrm{E}-7$ \\
& $\mathrm{~W}$ & $2.1 \mathrm{E}-6$ & $\mathrm{M}$ & $2.1 \mathrm{E}-6$ \\
& $\mathrm{Y}$ & $3.6 \mathrm{E}-5$ & $\mathrm{~S}$ & $6.8 \mathrm{E}-6$ \\
\hline${ }^{233} \mathrm{U}$ & $\mathrm{D}$ & $6.8 \mathrm{E}-7$ & $\mathrm{~F}$ & $6.0 \mathrm{E}-7$ \\
& $\mathrm{~W}$ & $2.0 \mathrm{E}-6$ & $\mathrm{M}$ & $1.8 \mathrm{E}-6$ \\
& $\mathrm{Y}$ & $3.3 \mathrm{E}-5$ & $\mathrm{~S}$ & $6.1 \mathrm{E}-6$ \\
\hline${ }^{238} \mathrm{U}$ & $\mathrm{D}$ & $6.6 \mathrm{E}-7$ & $\mathrm{~F}$ & $5.8 \mathrm{E}-7$ \\
& $\mathrm{~W}$ & $1.9 \mathrm{E}-6$ & $\mathrm{M}$ & $1.6 \mathrm{E}-6$ \\
& $\mathrm{Y}$ & $3.2 \mathrm{E}-5$ & $\mathrm{~S}$ & $5.7 \mathrm{E}-6$ \\
\hline
\end{tabular}




\section{Y-12 INTAKE AND DOSE CALCULATION PRACTICES}

For purposes of comparing intake and dose calculations between old and new models, we adopted the standard Y-12 Plant assumption that the majority of the activity observed in uranium bioassay samples is attributable to the ${ }^{234} \mathrm{U}$ isotope and therefore intakes and doses are calculated by assuming all uranium is ${ }^{234} \mathrm{U}$ (Snapp 1999). This assumption was adopted to reduce the length of the computational time required for completion of the dose assessment from the large number of positive results due to the chronic low-level exposures at the Y-12 Plant. Attributing all the uranium activity to ${ }^{234} \mathrm{U}$ in the dose assessment process, instead of assessing separate doses for ${ }^{234} \mathrm{U},{ }^{235} \mathrm{U}$, and ${ }^{238} \mathrm{U}$, reduced the computational time involved in the dose assessments by a factor of $1 / 3$. For dose assessments based on ICRP Publication 30 data for Class $Y$ uranium, this assumption only overestimates the dose by approximately $11 \%$ in the case of depleted uranium and by less than approximately $0.2 \%$ in the case of highly enriched uranium (Snapp 1999).

The effect of this assumption for dose calculations based on ICRP Publication 68 data for Type M and $\mathrm{S}$ uranium is considered in Table 5 . It is further assumed that the isotopic distribution of the depleted uranium is $0.001 \%, 0.119 \%$, and $99.8 \%$ by weight ${ }^{234} \mathrm{U},{ }^{235} \mathrm{U}$, and ${ }^{238} \mathrm{U}$, respectively, and that the isotopic distribution of the enriched uranium is $1 \%, 93 \%$, and $6 \%$ by weight ${ }^{234} \mathrm{U},{ }^{235} \mathrm{U}$, and ${ }^{238} \mathrm{U}$, respectively (see, for example, Rucker and Johnson 1999). For Type $S$ uranium, the assumption that all activity is due to ${ }^{234} \mathrm{U}$ overestimates the inhalation dose by approximately $0.3 \%$ in the case of highly enriched uranium and $16 \%$ in the case of depleted uranium, and for Type $M$ uranium, the assumption that all activity is due to ${ }^{234} \mathrm{U}$ overestimates the inhalation dose by approximately $0.5 \%$ in the case of highly enriched uranium and $20 \%$ in the case of depleted uranium. Because the computational speed of new computers no longer necessitates the practice of assuming all activity is due to ${ }^{234} \mathrm{U}$ and because the dose for depleted uranium exposures could be overestimated with the new model by as much as $20 \%$ with this assumption, it is recommended that the isotopic bioassay results be used for assessment of dose from depleted uranium exposures. However, since the overestimation of doses due to enriched uranium exposures is minimal with the new model $(0.5 \%)$, it remains acceptable to continue using the assumption that all activity comes from ${ }^{234} \mathrm{U}$ for enriched uranium dose calculation purposes.

Table 5. Comparison of committed effective doses for a total inhalation intake of $1000 \mathrm{dpm}$ of various uranium materials with an $A M A D$ of $5 \mu \mathrm{m}$.

\begin{tabular}{||l|c|c|}
\hline \multirow{2}{*}{ Uranium material } & \multicolumn{2}{|c|}{ Committed effective dose $(\mathrm{mrem} / 1000 \mathrm{dpm})^{\mathrm{a}}$} \\
\cline { 2 - 3 } & Type $\mathrm{S}$ & Type $\mathrm{M}$ \\
\hline \hline All ${ }^{234} \mathrm{U}$ material & 11.33 & 3.50 \\
\hline Enriched uranium & 11.30 & 3.48 \\
\hline Depleted uranium & 9.79 & 2.80 \\
\hline
\end{tabular}

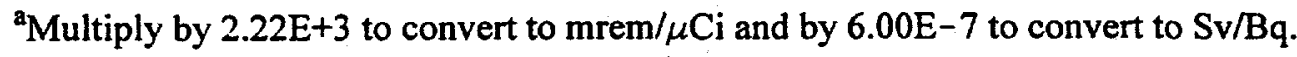


Most bioassay samples at the Y-12 Plant are collected over a twenty-four hour period; thus, the measurement of a sample's activity is a measurement of the daily excretion. However, in some instances, particularly fecal samples, it becomes necessary to normalize samples with a smaller than expected size to the standard 24 hour sample size. This is accomplished by multiplying the observed concentration by the standard or reference sample size for a 24 hour sample. The applicable reference values are a urine volume of 1.4 liters and a fecal mass of $135 \mathrm{~g}$ (ICRP 1975).

The activity of naturally occurring uranium in the diet must be considered in the interpretation of low-level uranium exposures. Two items of information of general interest in this particular study concerned with the assessment of enriched uranium exposures at the $\mathrm{Y}-12$ Plant are the ${ }^{234} \mathrm{U}:{ }^{238} \mathrm{U}$ activity ratio in the diet and the typical daily dietary intake of ${ }^{238} \mathrm{U}$ in the Oak Ridge area. No studies of the daily intake of uranium for the Oak Ridge area could be found (Snapp 1999). However, food samples collected in the New York City area were used recently to determine the uranium isotopic content in 19 different food types in a typical diet (Fisenne et al. 1987) and the Oak Ridge National Laboratory (ORNL) Office of Environmental Compliance routinely samples local resident drinkingwater wells in the Oak Ridge area. By the use of these well-water data for 1992 through 1995 and the data for foodstuffs from Fisenne et al. (1987), the daily intake in the Oak Ridge area was estimated to be $1.7 \mathrm{dpm}$ of ${ }^{234} \mathrm{U}$ and $1.2 \mathrm{dpm}$ of ${ }^{238} \mathrm{U}$, and the ${ }^{234} \mathrm{U}:{ }^{238} \mathrm{U}$ activity ratio was estimated to be about 1.4 (Snapp 1999). The observed uranium activity in the fecal samples of individuals exposed to only enriched uranium provides an independent set of data to assess the dietary intake of ${ }^{238} U$ since the fractional absorption of ingested uranium is small (see Section 3 ). Figure 7a shows a plot of the distribution in the ${ }^{238} \mathrm{U}$ concentration in the feces of a set of unexposed subjects at the Y-12 Plant and Fig. $7 \mathrm{~b}$ shows the data for workers exposed to only enriched uranium at the Y-12 Plant. The log-normal distributions of these data as shown in Figs. $7 \mathrm{a}$ and $7 \mathrm{~b}$ are similar. The geometric mean of $0.0087 \mathrm{dpm} / \mathrm{g}$ and the standard fecal mass of $135 \mathrm{~g}$ indicates a daily excretion of about $1.2 \mathrm{dpm}$ of ${ }^{238} \mathrm{U}$. This value is consistent with the value estimated for the Oak Ridge area population using levels observed in New York City foodstuffs and in Oak Ridge area wells. The scatter plot in Fig. 8 shows the ${ }^{234} \mathrm{U}:{ }^{238} \mathrm{U}$ activity ratio observed in the fecal samples from the unexposed subjects and indicates a mean value of 1.4 which is also in agreement with the value suggested by the estimated Oak Ridge intakes.

In its interpretation of the bioassay data for subjects exposed to enriched uranium, Y-12's RCO subtracts from the observed total uranium activity in fecal samples a value corresponding to twice the observed ${ }^{238} \mathrm{U}$ activity. The factor of two assumes that the ${ }^{234} \mathrm{U}$ activity in the diet is in equilibrium with that of ${ }^{238} \mathrm{U}$. The data of Fig. 8 indicates that the equilibrium ratio is greater than one; hence, the subtraction of only twice the ${ }^{238} \mathrm{U}$ activity is a conservative approach. The data of Fig. 7 clearly demonstrates that the observed ${ }^{238} \mathrm{U}$ activity in feces of a subject exposed to enriched uranium is a valid measure of the subject's dietary intake. Thus, these procedures are valid. 

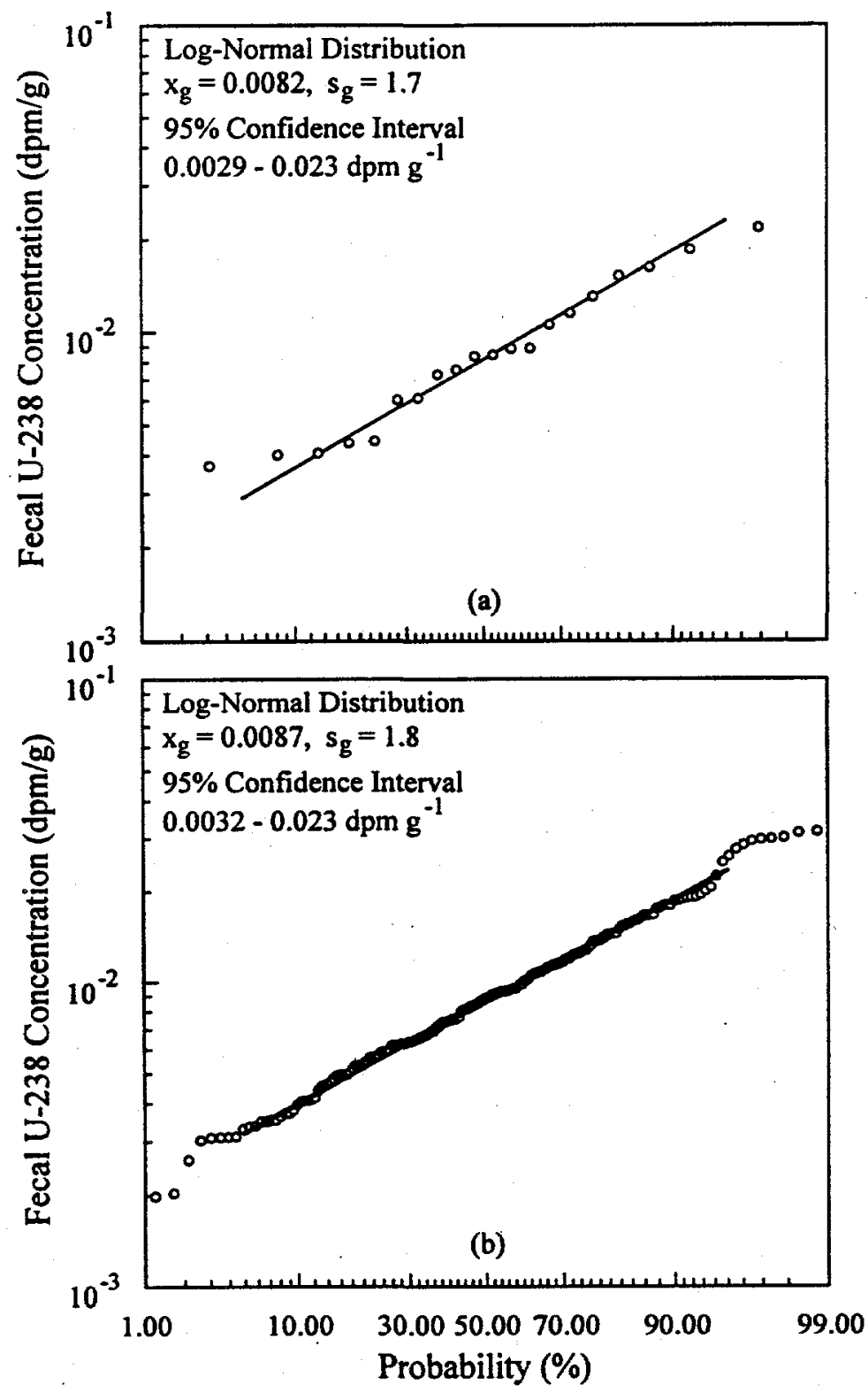

Fig. 7. Log-normal distributions of the concentration of ${ }^{238} U$ in fecal samples. Fig. 7a is the data for unexposed subjects while Fig. $7 b$ is the corresponding data in workers exposed to enriched uranium. These observed distributions are not significantly different. 


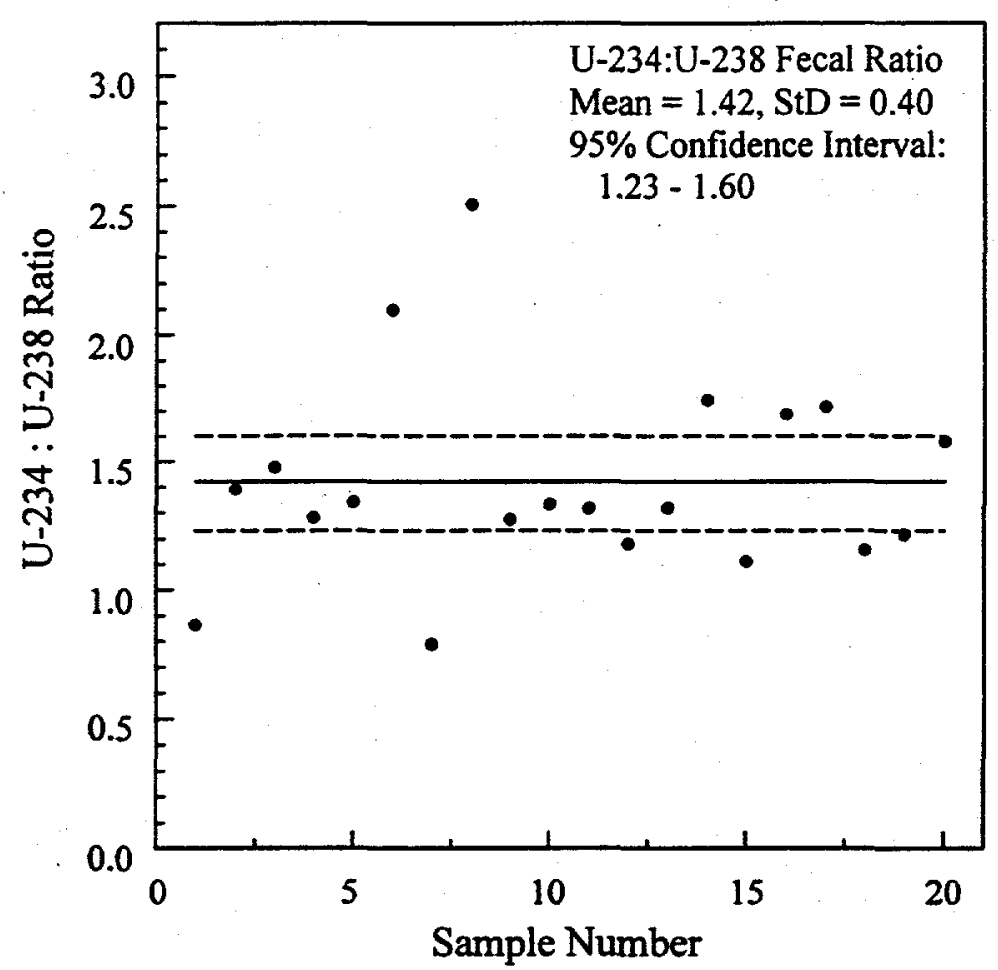

Fig. 8. The ${ }^{234} \mathrm{U}:{ }^{239} \mathrm{U}$ activity ratio observed in the fecal samples of unexposed subject. 


\section{Y-12 CASE STUDIES}

Exposure histories of 15 employees at the Y-12 Plant were selected for use in this study. These 15 employees are designated here simply as Employees "A" through "O" (see Appendix A). All of these employees were exposed to enriched uranium aerosols during the recent restart of enriched uranium casting and machining operations at the Y-12 Plant on June 8, 1998. With the exception of Employee " $\mathrm{H}$ ", the selected employees were restricted from working at their normal jobs and were reassigned to other jobs in non-radiological areas at various dates between September 4, 1998 and December 3, 1998. The restrictions were necessary so that follow-up bioassay samples in response to results that had exceeded Y-12 established trigger levels could be obtained for purposes of dose calculations without interference from additional exposures. The exposures of Employee " $\mathrm{H}$ " were restricted by methods other than job reassignment starting on September 16,1998 and ending around November 1, 1998.

Three types of bioassay measurements are made routinely at the Y-12 Plant: lung counting, urinalysis, and fecal analysis. Depending on the situation, any combination of the three methods may be used to determine an employee's dose. In addition, air sampling measurements are made using both area and personal monitoring devices. The 1998 data selected for evaluation were the lung counts and the bioassay data that were collected between the start up of the enriched uranium operations (June 8, 1998) and the date the employee was released from restriction (September 4 through December 3, 1998). Five of the 15 employees also were restricted from their normal jobs for brief periods of time during the first four months of 1999. Therefore, to make an assessment of intakes and doses under normal conditions without the interruption caused by restriction, the other 10 employees were selected for evaluation of their 1999 data. The 1999 data are of interest because the monthly collection of bioassay samples was initiated and the collection of air samples using personal air monitor $(P A M)$ devices was expanded. The $P A M$ devices are used to sample air in the breathing zones of the individual employees.

8.1 Studies Using 1998 Bioassay Data. The estimated intakes derived in this study using the new model (Type $\mathrm{M} \& \mathrm{~S}$ uranium, $A M A D=5 \mu \mathrm{m}$ ) and in previous $\mathrm{Y}-12$ studies using the old model (Class Y uranium, $A M A D=1 \mu \mathrm{m}$ ) are compared in Table 6. The old model calculations are based in some instances on the fecal data (all cases used in this study except Employees " $C$ " and " $M$ "), in some instances on the urine data (Employees " $\mathrm{C}$ " and " $\mathrm{M}$ "), and in some instances on both (other cases where individuals were monitored for insoluble exposure but were not included in this study) (Snapp 1999). The new model calculations are based on the fecal data, unless the estimated intake based on fecal data is larger than that based on urine data assuming exposure to pure Type $S$ uranium. In these cases, an average value based on both the fecal and urine data is used, along with the assumption of exposure to only Type $\mathrm{S}$ uranium. For example, the estimated intake for Employee " $\mathrm{K}$ " is the average of the estimated intake rates of $286 \mathrm{dpm} / \mathrm{d}$ based on the fecal data and $120 \mathrm{dpm} / \mathrm{d}$ based on the urine data (see Fig. B-11 of Appendix B) or $203 \mathrm{dpm} / \mathrm{d}$ multiplied by his exposure period of 60 days (see Table A-11 of Appendix A) or $1.22 \times 10^{4} \mathrm{dpm}\left(5.49 \times 10^{-3} \mu \mathrm{Ci}\right)$. In other cases, the intake was based on an average of the intake rates derived from the fecal data assuming either Type M or Type S uranium (see Eg. G-3 of Appendix G). For Employee "B", the 
Table 6. Estimates of intakes from 1998 uranium exposures based on old (ICRP-30) and new (ICRP-66) models.

\begin{tabular}{|c|c|c|}
\hline \multirow{2}{*}{ Employee } & \multicolumn{2}{|c|}{ Uranium intake $(\mu \mathrm{Ci})^{\mathrm{a}}$} \\
\hline & Old model ${ }^{b}$ & New model ${ }^{c}$ \\
\hline A & $6.42 \mathrm{E}-3$ & $5.89 \mathrm{E}-3$ \\
\hline B & $6.14 \mathrm{E}-3$ & $6.64 E-3$ \\
\hline $\mathrm{C}$ & $8.49 E-3$ & $1.66 \mathrm{E}-2$ \\
\hline $\mathrm{D}$ & $3.43 E-3$ & $1.19 E-3$ \\
\hline$E$ & $2.91 \mathrm{E}-3$ & $5.19 E-3$ \\
\hline $\mathrm{F}$ & $4.62 \mathrm{E}-3$ & $1.57 \mathrm{E}-2$ \\
\hline $\mathrm{G}$ & $5.23 E-3$ & $9.79 E-3$ \\
\hline $\mathrm{H}$ & $5.02 \mathrm{E}-3$ & $7.42 \mathrm{E}-3$ \\
\hline I & $5.05 \mathrm{E}-3$ & $9.04 \mathrm{E}-3$ \\
\hline $\mathrm{J}$ & $6.61 E-3$ & $9.39 E-3$ \\
\hline $\mathrm{K}$ & $6.15 E-3$ & $5.49 E-3$ \\
\hline $\mathbf{L}$ & $4.03 E-3$ & $2.18 E-3$ \\
\hline $\mathbf{M}$ & $7.91 \mathrm{E}-3$ & $8.51 E-3$ \\
\hline$N$ & $2.03 E-3$ & $2.43 E-3$ \\
\hline 0 & $4.35 \mathrm{E}-3$ & $3.97 E-3$ \\
\hline
\end{tabular}

${ }^{\mathrm{a}}$ Multiply by $3.7 \mathrm{E}+4$ to convert to $\mathrm{Bq}$.

b Intakes are based on fecal data predictions assuming exposure to Class $\mathrm{Y}$ uranium with an $A M A D$ of $1 \mu \mathrm{m}$, except for Cases " $C$ " and " $M$ " where an intake based on the urine data prediction assuming exposure to Class $Y$ uranium with an $A M A D$ of $1 \mu \mathrm{m}$ is used.

${ }^{c}$ Intakes are based on fecal data assuming exposure to a mixture of Type $\mathrm{M}$ and $\mathrm{S}$ uranium with an $A M A D$ of $5 \mu \mathrm{m}$, except for Cases "K" and "O" where an average intake rate based on both the urine and fecal data predictions assuming exposure to only Type $\mathrm{S}$ uranium with an $A M A D$ of $5 \mu \mathrm{m}$ is used.

estimated intake is average of the estimated intake rates of $98 \mathrm{dpm} / \mathrm{d}$ assuming Type $S$ uranium and $108 \mathrm{dpm} / \mathrm{d}$ assuming Type M uranium (see Fig. B-2 of Appendix B) or $103 \mathrm{dpm} / \mathrm{d}$ multiplied by his exposure period of 143 days (see Table A-2 of Appendix A) or $1.47 \times 10^{4} \mathrm{dpm}\left(6.64 \times 10^{-3} \mu \mathrm{Ci}\right)$. It should be noted that the intakes based on the new model are typically larger than those based on the older model.

The estimated doses derived in this study using the new model and in the previous $\mathrm{Y}-12$ studies using the old model are compared in Table 7. To illustrate the calculation of the newer doses, the examples in the above paragraph are used. For Employee "K", it was assumed that his exposure was due to Type $S$ uranium (see Appendix $G$ ) and the Type $M$ fraction, $f^{M}$, for his exposure was zero (see Table 7). The dose coefficient for pure Type $S$ uranium is $11.33 \mathrm{mrem} / 1000 \mathrm{dpm}$ or $1.133 \times$ $10^{-2} \mathrm{mrem} / \mathrm{dpm}$ (see Table 5), and the estimated dose for Employee " $\mathrm{K}$ " is this dose coefficient multiplied by his estimated intake of $1.22 \times 10^{4} \mathrm{dpm}$ (see above paragraph) or $138 \mathrm{mrem}(1.38 \mathrm{mSv}$ ). For Employee "B", the Type $\mathrm{M}$ fraction, $f^{\mathrm{M}}$, is 0.134 (see Table 7), and his dose coefficient is 0.134 multiplied by the dose coefficient of $3.50 \mathrm{mrem} / 1000 \mathrm{dpm}$ for Type $\mathrm{M}$ uranium (see Table 5) plus 
Table 7. Estimates of committed effective dose from 1998 uranium exposures based on old (ICRP-30) and new (ICRP-60) models.

\begin{tabular}{|c|c|c|c|}
\hline \multirow{2}{*}{ Employee } & \multicolumn{2}{|c|}{ Committed effective dose (mrem) ${ }^{a}$} & \multirow{2}{*}{$\begin{array}{c}\text { Type } M \\
\text { fraction, } \\
f^{\mathrm{M}}\end{array}$} \\
\hline & Old model ${ }^{\mathrm{b}}$ & New model ${ }^{\mathfrak{c}}$ & \\
\hline A & 850 & 148 & $0.4 \%^{d}$ \\
\hline B & 813 & 151 & $13.4 \%$ \\
\hline $\mathrm{C}$ & 1,124 & 399 & $6.1 \%$ \\
\hline D & 454 & 25 & $23.6 \%$ \\
\hline $\mathrm{E}$ & 386 & 128 & $3.1 \%$ \\
\hline F & 612 & 388 & $2.4 \%$ \\
\hline $\mathrm{G}$ & 693 & 246 & 0 \\
\hline $\mathrm{H}$ & 665 & 187 & $0.1 \%$ \\
\hline I & 669 & 227 & $0.2 \%$ \\
\hline $\mathbf{J}$ & 875 & 235 & $0.9 \%$ \\
\hline $\mathrm{K}$ & 814 & 138 & 0 \\
\hline L & 533 & 47 & $19.3 \%$ \\
\hline $\mathbf{M}$ & 1,048 & 201 & $8.8 \%$ \\
\hline $\mathbf{N}$ & 244 & 59 & $4.7 \%$ \\
\hline 0 & 576 & 100 & 0 \\
\hline
\end{tabular}

${ }^{a}$ Multiply by $1 E-5$ to convert to Sv.

${ }^{b}$ Assumes an exposure to Class $\mathrm{Y}$ uranium with an $A M A D$ of $1 \mu \mathrm{m}$.

${ }^{c}$ Assumes an exposure to a mixture of Type $\mathrm{M}$ and $\mathrm{S}$ uranium with an $A M A D$ of $5 \mu \mathrm{m}$.

${ }^{d}$ Fraction of intake due to Type $M$ uranium in new model (see Appendix $G$ ).

0.866 (i.e., $f^{\mathrm{s}}$ )(see Appendix $\mathrm{G}$ ) multiplied by the dose coefficient of $11.33 \mathrm{mrem} / 1000 \mathrm{dpm}$ for Type $S$ uranium or $10.28 \mathrm{mrem} / 1000 \mathrm{dpm}\left(1.028 \times 10^{-2} \mathrm{mrem} / \mathrm{dpm}\right)$. The estimated dose for Employee " $\mathrm{B}$ " is this dose coefficient multiplied by his estimated intake of $1.47 \times 10^{4} \mathrm{dpm}$ (see above paragraph) or $151 \mathrm{mrem}(1.51 \mathrm{mSv})$. The new dose estimates in Table 7 are smaller in spite of the fact that the new model calculations typically predicted larger intake values than the old model calculations (see Table 6). Aside from differences in estimated intakes in Table 6, the new dose estimates are smaller on the average by a factor of about 5 because the dose coefficients for insoluble uranium (Type $S$ ) used in the new dose calculations are one-fifth the earlier values for Class Y uranium compounds used in the older model calculations (see Table 4). The new model calculations allow adjustments for the mixture of soluble (Type $M$ ) and insoluble (Type $S$ ) uranium involved in the $\mathrm{Y}-12$ exposures, but the adjustments result in small reductions of less than $15 \%$ in the dose estimates because the 1998 exposures considered in this study were dominated by Type $S$ uranium (see Table 7).

8.2 Studies Using 1998 Lung Counts. A comparison of measured and calculated values for ${ }^{235} \mathrm{U}$ activity in the lungs is provided in Table 8. The measured values are specified as less than some minimum detectable level of ${ }^{235} U$ activity for the various employees. The calculated values for each employee are based on the new model assuming a continuous exposure to Type $S$ uranium with an 
Table 8. Comparison of measured and calculated values for ${ }^{235} \mathbf{U}$ activity in the lungs.

\begin{tabular}{|c|c|c|c||}
\hline \multirow{2}{*}{ Employee } & \multirow{2}{*}{ Date } & \multicolumn{2}{|c|}{${ }^{235} \mathrm{U}_{\text {lung activity }(\mathrm{nCi})^{\mathrm{a}}}$} \\
\cline { 3 - 4 } & & Measured & Calculated $^{*}$ \\
\hline \hline \multirow{2}{*}{$\mathrm{A}$} & $09 / 22 / 98$ & $<1.62 \mathrm{E}-1$ & $7.91 \mathrm{E}-3$ \\
$\mathrm{~B}$ & $10 / 29 / 98$ & $<1.99 \mathrm{E}-1$ & $8.44 \mathrm{E}-3$ \\
$\mathrm{C}$ & $09 / 23 / 98$ & $<2.28 \mathrm{E}-1$ & $2.18 \mathrm{E}-2$ \\
$\mathrm{D}$ & $09 / 28 / 98$ & $<2.20 \mathrm{E}-1$ & $1.41 \mathrm{E}-3$ \\
$\mathrm{E}$ & $11 / 09 / 98$ & $<4.75 \mathrm{E}-1$ & $6.34 \mathrm{E}-3$ \\
$\mathrm{~F}$ & $12 / 04 / 98$ & $<3.24 \mathrm{E}-1$ & $1.92 \mathrm{E}-2$ \\
$\mathrm{G}$ & $09 / 28 / 98$ & $<2.23 \mathrm{E}-1$ & $1.32 \mathrm{E}-2$ \\
$\mathrm{H}$ & $10 / 12 / 98$ & $<2.22 \mathrm{E}-1$ & $8.27 \mathrm{E}-3$ \\
$\mathrm{I}$ & $09 / 24 / 98$ & $<2.48 \mathrm{E}-1$ & $1.21 \mathrm{E}-2$ \\
$\mathrm{~J}$ & $09 / 08 / 98$ & $<2.28 \mathrm{E}-1$ & $1.29 \mathrm{E}-2$ \\
$\mathrm{~K}$ & $09 / 22 / 98$ & $<1.58 \mathrm{E}-1$ & $1.58 \mathrm{E}-2$ \\
$\mathrm{~L}$ & $10 / 30 / 98$ & $<2.79 \mathrm{E}-1$ & $2.75 \mathrm{E}-3$ \\
$\mathrm{M}$ & $10 / 06 / 98$ & $<1.57 \mathrm{E}-1$ & $1.11 \mathrm{E}-2$ \\
$\mathrm{~N}$ & $09 / 23 / 98$ & $<1.58 \mathrm{E}-1$ & $3.25 \mathrm{E}-3$ \\
$\mathrm{O}$ & $09 / 22 / 98$ & $<1.69 \mathrm{E}-1$ & $7.69 \mathrm{E}-3$ \\
\hline
\end{tabular}

${ }^{a}$ Multiply by $3.7 \mathrm{E}+1$ to convert to $\mathrm{Bq}$.

$A M A D$ of $5 \mu \mathrm{m}$ starting on June 8,1998 and ending on the lung counting date for the employee (see Table 8). The calculated values also assume the inhaled uranium was highly enriched uranium containing $93 \%$ by weight ${ }^{235} \mathrm{U}$ (see Section 7). These calculated values are conservative because the Y-12 exposures involved primarily Type S uranium, and Type S uranium has a slower dissolution rate and lower level of absorption to blood than Type $M$ uranium in the lung (see Section 2.3). The calculated and measured values are considered to be consistent because the calculated ${ }^{235} \mathrm{U}$ lung activities are at least an order of magnitude smaller than the minimum detectable limits of the lung counting measurements. Even though lung counting lacks the necessary analytical sensitivity to serve as the basis for assessing chronic low-level intakes, it can provide information that is useful (e.g., the "less than" result serves to cap an intake amount by predicting the amount that could be observed in the lungs).

8.3 Studies Using 1999 Bioassay Data. Intakes based on the new model were calculated for 10 employees who were exposed continuously to enriched uranium aerosols at the Y-12 Plant during the first four months of 1999 (see Tables C-1 through C-10 of Appendix C). The 10 employees were selected from the group of 15 who were included in the $Y-12$ case studies using 1998 bioassay data (see Section 8.1 and Appendix A). Five of these 15 employees were restricted from their normal jobs for brief periods of time during the first four months of 1999. Therefore, in an effort to make an assessment of intakes and doses under normal conditions without the interruption caused by restriction, the other 10 employees were selected for evaluation of their 1999 data. The exposures during this period of time were modeled as a continuous exposure starting on the date the employee was released from restriction in 1998, except for employee " $\mathrm{H}$ " (see Appendix A). Because Employee " $\mathrm{H}$ " was not restricted from his normal job in the latter part of 1998, his exposure was 
modeled, based on other considerations, as a continuous exposure starting on November 1, 1998. The ending date for all exposures was taken to be April 30, 1999, and the intakes and doses were calculated for the 120 days between January 1 and April 30, 1999.

The estimated intakes and doses derived in this study using the newer model and 1999 bioassay data are summarized in Table 9. These new model calculations for the 1999 exposures are more complex than those for the 1998 exposures (see Fig. C-1 of Appendix C). For example, the excretion from the earlier 1998 exposures must be taken into account in the derivation of intakes and doses from the 1999 exposures. The excretion contributions from the 1998 exposures are significant in the case of Employee " $\mathrm{H}$ " whose estimated intake rate in 1999 was only $27.3 \mathrm{dpm} / \mathrm{d}$ compared to his earlier 1998 intake rate of $165 \mathrm{dpm} / \mathrm{d}$ (see Fig. C-1 of Appendix C). The excretion contributions from earlier 1998 exposures are less important in the case of Employee " $\mathrm{A}$ " whose intake rates were quite similar in both 1998 and 1999. The most interesting aspect of the 1999 exposures is that they are still dominated by Type S uranium like the earlier 1998 exposures at the Y-12 Plant (see Table 10). The only exception is Employee " $\mathrm{C}$ ", whose 1999 exposures appear to be about 50\% Type M uranium and 50\% Type $\mathrm{S}$ uranium. To better characterize the current inhalation exposures at the Y-12 Plant, it is necessary to expand the current cohort to include more employees and to follow this expanded group of employees through the end of 1999. Of course, the expanded cohort should be carefully selected to include employees working in as many different crafts and job types as possible. The current cohort of 15 employees includes 1 radiation control technician, 2 supervisors, 2 material handlers, 3 machinists, 3 pack and ship operators, and 4 casting operators. Thus, the number of employees in any one craft or job type is too small and the 1999 bioassay data for these employees are too limited to draw any generalized conclusions regarding their exposures to soluble (Type $M$ ) and insoluble (Type S) uranium in the workplace.

Table 9. Estimated intakes, doses, and Type $M$ fractions based on 1999 bioassy data and new model for exposure to a mixture of Type $M$ and $S$ uranium with an $A M A D$ of $5 \mu \mathrm{m}$.

\begin{tabular}{|c|c|c|c|}
\hline Employee & $\begin{array}{c}\text { Intake } \\
(\mu \mathrm{Ci})^{\mathrm{a}}\end{array}$ & $\begin{array}{c}\text { Dose } \\
(\mathrm{mrem})^{\mathrm{b}}\end{array}$ & $\begin{array}{c}\text { Type M } \\
\text { fraction, } f^{\mathrm{M}}\end{array}$ \\
\hline \hline A & $6.46 \mathrm{E}-3$ & 113 & 0 \\
B & $1.57 \mathrm{E}-3$ & 32 & $29.3 \%$ \\
C & $1.33 \mathrm{E}-3$ & 22 & $50.3 \%$ \\
D & $1.11 \mathrm{E}-3$ & 23 & $24.3 \%$ \\
G & $5.44 \mathrm{E}-4$ & 13 & $5.9 \%$ \\
H & $1.46 \mathrm{E}-3$ & 36 & $1.2 \%$ \\
I & $1.69 \mathrm{E}-3$ & 38 & $16.3 \%$ \\
J & $1.91 \mathrm{E}-3$ & 47 & $3.1 \%$ \\
K & $6.31 \mathrm{E}-4$ & 16 & $5.6 \%$ \\
$\mathrm{~N}$ & $4.29 \mathrm{E}-3$ & 107 & $0.6 \%$ \\
\hline
\end{tabular}

${ }^{a}$ Multiply by $3.7 \mathrm{E}+4$ to convert to $\mathrm{Bq}$.

bultiply by $1 \mathrm{E}-5$ to convert to Sv. 
Table 10. Comparison of the Type $M$ fraction, $f^{M}$, for enriched uranium exposures of Y-12 employees during 1998 and 1999.

\begin{tabular}{|c|c|c|}
\hline \multirow{2}{*}{ Employee } & \multicolumn{2}{|c|}{ Type $\mathrm{M}$ fraction, $f^{\mathrm{M}}$} \\
\cline { 2 - 3 } & 1998 exposures & 1999 exposures \\
\hline \hline A & $0.4 \%$ & 0 \\
$\mathrm{~B}$ & $13.4 \%$ & $29.3 \%$ \\
$\mathrm{C}$ & $6.1 \%$ & $50.3 \%$ \\
$\mathrm{D}$ & $24.7 \%$ & $24.3 \%$ \\
$\mathrm{G}$ & 0 & $5.9 \%$ \\
$\mathrm{H}$ & $0.1 \%$ & $1.2 \%$ \\
I & $0.3 \%$ & $16.3 \%$ \\
$\mathrm{~J}$ & $0.9 \%$ & $3.1 \%$ \\
$\mathrm{~K}$ & 0 & $5.6 \%$ \\
$\mathrm{~N}$ & $4.7 \%$ & $0.6 \%$ \\
\hline
\end{tabular}

8.4 Studies Using 1999 Personal Air Monitoring Data. The commercially available personal air monitoring (PAM) devices used at the Y-12 Plant consist of a pump that attaches to a workers belt with a flexible hose between the pump and air sampling head (Thomas 1999). The pump contains a laminar flow element and a differential pressure sensor to measure and maintain a flow rate of 3 liters per minute. The air sampling head, containing a membrane filter, is typically attached to the worker's lapel or as close to the worker's breathing zone as possible. The uranium aerosols are collected on the membrane filter (mixed cellulose ester, supported membrane filter) with a diameter of $47 \mathrm{~mm}$ (1.85 inches). The counts of uranium activity on the air filter are used to estimate a worker's exposure in terms of the Derived Air Concentration $(D A C)$ as required in 10 CFR 835.209. The PAM data are not used for dose estimation purposes, because 10 CFR 835.209 requires that the estimation of internal dose shall be based on bioassay data rather than air concentrations values unless bioassay data are: (1) unavailable; (2) inadequate; or (3) internal dose estimates based on representative air concentrations are demonstrated to be as accurate or more accurate. The PAM data are important, however, for planning purposes and for obtaining early information on air concentration changes in the work place.

Poor correlations between intakes based on $P A M$ data and bioassay data have been noted in other studies by Alvarez et al. 1994, Birchall et al. 1991, and Johnson and Kalos 1989. The poor correlations have been attributed in some instances to particle size distributions and in other instances to high ventilation rates in the immediate work areas of the employees. Thus, a comparison of intakes calculated for Y-12 employees based on the new models and bioassay date and on their PAM data for the first four months of 1999 are provided in Table 11. The PAM data for Employee "A" are provided as an example in Table D-1 of Appendix D, the cumulative $D A C$ hours of exposure for each worker during the first four months of 1999 are provided in Table D-2 of Appendix D, and the conversion of the cumulative $D A C$-hours for an employee to an intake is discussed in the text of Appendix D. The intake estimates based on PAM data are $49 \%$ on the average of the values derived using the bioassay data (see Table 11). The estimated intakes based 
Table 11. Comparison of intakes calculated using the new ICRP model and 1999 bioassay and those calculated using the older ICRP-30 model and portable air monitoring (PAM) data.

\begin{tabular}{|c|c|c|c|}
\hline \hline \multirow{2}{*}{ Employee } & \multicolumn{2}{|c|}{ Intake $(\mu \mathrm{Ci})^{\mathrm{a}}$} & $\begin{array}{c}\text { Ratio of PAM } \\
\text { to bioassay } \\
\text { values }\end{array}$ \\
\cline { 2 - 4 } & Bioassay & PAM & 0.11 \\
A & $6.64 \mathrm{E}-3$ & $6.98 \mathrm{E}-4$ & 1.11 \\
$\mathrm{~B}$ & $1.57 \mathrm{E}-3$ & $1.74 \mathrm{E}-3$ & 0.66 \\
$\mathrm{C}$ & $1.33 \mathrm{E}-3$ & $8.81 \mathrm{E}-4$ & 0.17 \\
$\mathrm{D}$ & $1.11 \mathrm{E}-3$ & $1.90 \mathrm{E}-4$ & 0.30 \\
$\mathrm{G}$ & $5.44 \mathrm{E}-4$ & $1.82 \mathrm{E}-4$ & 0.29 \\
$\mathrm{H}$ & $1.46 \mathrm{E}-3$ & $4.34 \mathrm{E}-4$ & 0.31 \\
I & $1.69 \mathrm{E}-3$ & $5.38 \mathrm{E}-4$ & 0.43 \\
$\mathrm{~J}$ & $1.91 \mathrm{E}-3$ & $8.33 \mathrm{E}-4$ & 1.38 \\
$\mathrm{~K}$ & $6.31 \mathrm{E}-4$ & $8.71 \mathrm{E}-4$ & 0.11 \\
$\mathrm{~N}$ & $4.29 \mathrm{E}-3$ & $4.70 \mathrm{E}-4$ & 0.49 \\
\hline \hline
\end{tabular}

Multiply by $3.7 \mathrm{E}+4$ to convert to $\mathrm{Bq}$.

on the $P A M$ data range from a low of $11 \%$ to a high of $138 \%$ of the intakes based on the bioassay data. In the current study, the poor correlations may also be due in part to the use of the conservative low values of 25 and 50 to account for the respiratory protection provided by the use of a powered air purifying respirator and a full-face air purifying respirator, respectively (see Table D-1 of Appendix D). To better understand the overall uncertainties in the $P A M$ data, it seems necessary to expand the current sample population to include more employees and to follow these employees through the end of 1999. As discussed previously, the expanded sample should be carefully selected to include employees working in as many different crafts and job types as possible (see Section 8.3).

Derived air concentration ( $D A C$ ) values provided in Appendix A to 10 CFR 835 and specified for use in controlling workers' exposures to airborne radioactive materials at DOE facilities are based on the older Class Y data for uranium from ICRP Publication 30 and Federal Guidance Report No. 11 (Eckerman et al. 1988). The continued use of these old $D A C$ values in controlling exposures of $Y-12$ workers is also of interest here. Thus, the doses for each employee based on their bioassay data (and the new ICRP model) and on their PAM data (and the older ICRP Publication 30 model) for the first four months of this year are compared in Table12. The doses based on the 1999 bioassay data are from new model calculations assuming exposure to a mixture of Type $\mathrm{M}$ and $\mathrm{S}$ uranium with an $A M A D$ of $5 \mu \mathrm{m}$ (see Section 8.3) and the doses based on the 1999 PAM data assume exposure to the older ICRP-30 model and Class Y uranium with an $A M A D$ of $1 \mu \mathrm{m}$ (see Appendix D). The intakes based on the PAM data are, on the average, half those derived from bioassay data using the newer models (see Table 11) and the effective dose coefficient used in the derivation of the $D A C$ (Class Y, $A M A D=1 \mu \mathrm{m}$ ) of 10 CFR 835 is about five times that indicated by the newer models (see Table 4). Thus, dose estimates derived from the $P A M$ data using the old 
Table 12. Committed equivalent doses calculated using the new ICRP model and 1999 bioassay and those calculated using the older ICRP-30 model and portable air monitoring (PAM) data.

\begin{tabular}{|c|c|c|c|}
\hline \multirow{2}{*}{ Employee } & \multicolumn{2}{|c|}{ Committed equivalent dose (mrem) $^{\mathrm{a}}$} & \multirow{2}{*}{$\begin{array}{c}\text { Ratio of PAM } \\
\text { to bioassay } \\
\text { values }\end{array}$} \\
\cline { 2 - 4 } & Bioassay $^{\mathrm{b}}$ & PAM $^{\mathrm{c}}$ & 0.65 \\
$\mathrm{~A}$ & 113 & 73 & 5.66 \\
B & 32 & 181 & 4.18 \\
$\mathrm{C}$ & 22 & 92 & 0.87 \\
$\mathrm{D}$ & 23 & 20 & 1.46 \\
G & 13 & 19 & 1.25 \\
H & 36 & 45 & 1.47 \\
I & 38 & 56 & 1.85 \\
J & 47 & 87 & 5.69 \\
K & 16 & 91 & 0.46 \\
N & 107 & 49 & 2.35 \\
\hline \hline
\end{tabular}

${ }^{a}$ Multiply by $1 \mathrm{E}-5$ to convert to Sv.

based on new model and assumption of an exposure to a mixture of Type $M$ and $S$ uranium with an $A M A D$ of $5 \mu \mathrm{m}$. See Table 9 for a listing of the Type $\mathrm{M}$ fraction used in the assumed mixture.

${ }^{c}$ Based on exposure to Class $Y$ uranium with an $A M A D$ of $1 \mu \mathrm{m}$ and assumption that $2.5 \mathrm{mrem}$ is equal to $1 D A C$-hour.

$D A C$ value are about 2.5 times higher than those derived by interpreting bioassay data with the new models (see Table 12). The use of the older $D A C$ values for uranium in Appendix A of 10 CFR 835 may still be operationally appropriate, since these older $D A C$ values are still adequate for controlling a worker's exposure to airborne uranium materials even though there is a poor correlation between intakes based on the PAM and bioassay data (see Table 11). 


\section{SUMMARY AND CONCLUSIONS}

Following the restart of enriched uranium operations at the Y-12 Plant it became apparent that the exposures involved insoluble uranium rather than soluble uranium which had characterized earlier plant operations. Furthermore, the fecal and urine bioassay samples appeared to be inconsistent with the standard regulatory models used to interpret the bioassay data. This study was undertaken to review the procedures followed to assess intakes and to apply state-of-the-art methods to the Y-12 Plant situation. The following is a summary of our findings.

Faced with workplace conditions that apparently differ from that characteristic of earlier plant operations, the RCO set forth appropriate measures to assess the situation. These included an increased frequency of fecal sampling which is the preferred bioassay technique for assessing intakes of insoluble uranium. We find that RCO staff took appropriate actions in addressing the situation. Furthermore their approach to normalization of the fecal samples, correction for dietary uranium, and analysis of the plant situation was found to be technically valid.

Our application of the newer models and methods for assessing intakes from bioassay measurement data did indeed confirm that the current enriched uranium exposures involve an insoluble component. Furthermore, the newer methods yielded results which were broadly consistent with the bioassay data. This is apparently because the newer methods were formulated with the objective of serving the needs for assessing both intake and dose. For the Y-12 Plant to be able to perform stateof-the-art assessments of workers' exposure it is necessary to use these newer models. It always has been the practice that the best available information be used in assessing intakes by workers and thus one need not be limited to use of a regulatory model. Major differences exist in the structure of the old and new models which necessitate that the same model be used in both the interpretation of the bioassay measurements and the assignment of doses. Thus, DOE approval should be sought on the application of these newer models within the existing regulatory framework.

We have outlined an approach by which one can estimate the fraction of the uranium intake that might best be characterized as soluble uranium (absorption Type $M$ in terms of the new respiratory tract model). This procedure involves development of independent estimates of the intake rate (assuming chronic intakes) based on the fecal and urine samples. The procedure does not require that the bioassay samples be obtained on the same date but only that the samples be representative of the period of interest. The procedure was illustrated in our assessment of the intakes and doses among the set of Y-12 workers considered in this study. Derivation of the fraction of the uranium intake indicated to be soluble should provide a more stable index of the exposures than examination of the ratio of fecal to urine excretion indicated by samples collected on the same date.

The Y-12 bioassay program should continue to involve both urinary and fecal sampling. Further information on the soluble and insoluble nature of uranium exposures may eventually enable characterizing the workplace environment and eventually suggest a default mixture for the stabilized workplace. 
Although beyond the scope of this study, it is suggested that the cursory review of the $Y-12$ personal air monitoring program in this study be expanded to include more workers who are currently wearing $P A M$ devices. While workers' intakes can best be determined by bioassay methods, air sampling is a primary indicator of the potential exposure of a worker to airborne materials and can provide early information on changes in workplace conditions. 


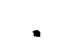

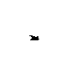




\section{ACKNOWLEDGMENTS}

We wish to thank and to acknowledge the help of Lisa Snapp, Johnafred Thomas, and Rhonda Bogard during this brief study of about one month. In this short period of time, they quickly provided numerous electronic and hard copies of data files and technical reports necessary to complete the study. They also provided advice and other guidance by telephone and at numerous meetings during the study and the subsequent preparation of this report. 
$+$ 


\section{REFERENCES}

Alvarez, J.L.; Bennett, W.S.; Davidson, T.L. 1994. Design of an airborne plutonium survey program for personnel protection. Health Phys. 66: 634-642.

Ansoborlo, E.; Hodson, A.; Stradling, G.N.; Hodgson, S.; Metivier, H.; Henge-Napoli, M.H.; Jarvis, N.S.; Birchall, A. 1998. Exposure implications for uranium aerosols formed at a new laser enrichment facility: Application of the ICRP respiratory tract and systemic model. Radiat. Prot. Dosim. 79: 23-27

Barber, J.M.; Forrest, R.D. 1995. A study of uranium lung clearance at a uranium processing plant. Health Phys. 68: 661-669.

Birchall, A.; James, A.C.; Muirhead, C.R. 1991. Adequacy of personal air samples for monitoring plutonium intakes. Radiat. Prot. Dosim. 37: 179-188.

Chazel, V.; Houpert, P.; Ansoborlo, E. 1998. Effect of $\mathrm{U}_{3} \mathrm{O}_{8}$ specific area on in vitro dissolution, biokinetics, and dose coefficients. Radiat. Prot. Dosim. 79: 39-42.

Dorrian, M.D.; Bailey, M.R. 1995. Particle size distributions of radioactive aerosols measured in workplaces. Radiat. Prot. Dosim. 60: 119-133.

Eckerman, K.F.; Wolbarst, A.B.; Richardson, A.C.B. 1988. Limiting Values of Radionuclide Intake and Air Concentration and Dose Conversion Factors for Inhalation, Submersion, and Ingestion. U.S. Environmental Protection Agency, Federal Guidance Report No. 11, EPA-520/1-88-020, Washington, D.C.

Fisenne, I.M.; Perry, P.M.; Decker, K.M.; Keller, H.W. 1987. The daily intake of ${ }^{234,235,238} \mathrm{U}$, ${ }^{228,230,232} \mathrm{Th}$ and ${ }^{226,228} \mathrm{Ra}$ by New York City residents. Health Phys. 53: 357-363.

Hoover, M.D.; Newton, G.J.; Guilmette, R.A.; Howard, R.J.; Ortiz, R.N.; Thomas, J.M.; Trotter, S.M.; Ansoborlo, E. 1998. Characterization of enriched uranium dioxide particles from a uranium handling facility. Radiat. Prot. Dosim. 79: 57-62.

International Commission on Radiological Protection (ICRP). 1966. Deposition and retention models for internal dosimetry of the human respiratory tract. Health Phys. 12: 173-207; 1966.

International Commission on Radiological Protection (ICRP). 1975. Report of the Task Group on Reference Man. ICRP Publication 23. Pergamon Press, Oxford, England.

International Commission on Radiological Protection (ICRP). 1979a. Limits for intakes of radionuclides by workers. ICRP Publication 30, Part 1. Annals of the ICRP 2(3/4). 
International Commission on Radiological Protection (ICRP). 1979b. Limits for intakes of radionuclides by workers. ICRP Publication 30, Supplement to Part 1. Annals of the ICRP 3(1-4).

International Commission on Radiological Protection (ICRP). 1980. Limits for intakes of radionuclides by workers. ICRP Publication 30, Part 2. Annals of the ICRP 4(3/4).

International Commission on Radiological Protection (ICRP). 1981a. Limits for intakes of radionuclides by workers. ICRP Publication 30, Supplement to Part 2. Annals of the ICRP 5(1-6).

International Commission on Radiological Protection (ICRP). 1981b. Limits for intakes of radionuclides by workers. ICRP Publication 30, Part 3 (including addendum to Parts 1 and 2). Annals of the ICRP 6(2/3).

International Commission on Radiological Protection (ICRP). 1982a. Limits for intakes of radionuclides by workers. ICRP Publication 30, Supplement A to Part 3. Annals of the ICRP 7(1-3).

International Commission on Radiological Protection (ICRP). 1982b. Limits for intakes of radionuclides by workers. ICRP Publication 30, Supplement B to Part 3. Annals of the ICRP 8(1-3).

International Commission on Radiological Protection (ICRP). 1988a. Limits for intakes of radionuclides by workers. ICRP Publication 30, Part 4. Annals of the ICRP 19(4).

International Commission on Radiological Protection (ICRP). 1988b. Individual monitoring for intakes of radionuclides by workers: Design and implementation. ICRP Publication 54. Annals of the ICRP 19(1-3).

International Commission on Radiological Protection (ICRP). 1994a. Human respiratory tract model for radiological protection. ICRP Publication 66. Annals of the ICRP 24(1-4).

International Commission on Radiological Protection (ICRP). 1994b. Dose coefficients for intakes of radionuclides by workers. ICRP Publication 68. Annals of the ICRP 24(4).

International Commission on Radiological Protection (ICRP). 1995. Age-dependent dose to members of the public from intake of radionuclides: Part 3. Ingestion dose coefficients. ICRP Publication 69. Annals of the ICRP 25(1).

International Commission on Radiological Protection (ICRP). 1997. Individual monitoring for internal exposure of workers: Replacement of ICRP Publication 54. ICRP Publication 78. Annals of the ICRP 27(3/4).

Johnson, J.R.; Kalos, F. 1989. A review of CRL's use of personnel air samplers for exposure in a recycle fuel fabrication laboratory. Radiat. Prot. Dosim. 26: 97-100. 
Rucker, T.L.; Johnson, C.M. Jr. 1998. Relationship between isotopic uranium activities and total uranium at various uranium enrichments. J. Radioanal. Nucl. Chem. 235: 47-52.

Schieferdecker, H.; Dilger, H.; Doerfel, H.; Rudolph, W.; Anton, R. 1985. Inhalation of U aerosols from $\mathrm{UO}_{2}$ fuel element fabrication. Health Phys. 48: 29-48.

Skrable, K.W. 1987. INDOS-Technical Reference Manual. Skrable Enterprises, Chelmsford, Massachusetts.

Skrable, K.W.; Chabot, G.E.; French, C.S.; La Bone, T.R. 1994. Estimation of intakes from repetitive bioassay measurements, pp. 431-460. In: Internal Radiation Dosimetry (Rabbe, O.G., ed.). Medical Physics Publishing, Madison, Wisconsin.

Snapp, L.M. 1999. Personal communication.

Strenge, D. 1995. Code for INternal DosimetrY (CINDY Version 1.4). Pacific Northwest Laboratories, PNL-7493, Richland, Washington.

Thomas, J.M. 1999. Personal communication.

Ward, R.C.; Eckerman, K.F. 1992. DOSEXPRT-A Bioassay Dosimetry Code for Martin Marietta Energy Systems, Inc. Oak Ridge National Laboratory, ORNL/TM-11857, Oak Ridge, Tennessee. 


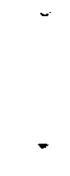




\section{APPENDIX A}

\section{SUMMARY OF 1998 BIOASSAY DATA FOR SELECTED EMPLOYEES}

This appendix provides summaries of bioassay data for 15 selected employees who were exposed to enriched uranium following the restart of enriched uranium operations at the Y-12 Plant on June 8, 1998. The 15 employees are designated here as Employee " $A$ " through Employee "O" (see Tables A-1 through A-15). With the exception of Employee " $\mathrm{H}$ ", the selected employees were restricted from working at their normal jobs and were reassigned to other jobs in non-radiological areas at various dates between September 4, 1998 and December 3, 1998. The bioassay data summarized here starts on June 8, 1998 and ends when the employee was released from restriction. The restrictions were necessary so that follow-up samples in response to results that had exceed Y-12 established trigger levels could be obtained for purposes of dose calculations without interference from additional on-going exposures. The exposures of Employee " $\mathrm{H}$ " were restricted by methods other than job reassignment starting on September 16, 1998 and ending around November 1, 1998. It needs to be noted, however, that these employees' total inhalation doses of record for 1998 are based on their entire exposure history for 1998 rather than the partial bioassay data set provided in Tables A-1 through A-15. 
Table A-1. Summary of bioassay data from 1998 for Employee "A"

\begin{tabular}{||l|c|c|c|c||}
\hline Date & $\begin{array}{c}\text { Period of } \\
\text { intake }\end{array}$ & $\begin{array}{c}\text { Num iner of } \\
\text { days }\end{array}$ & $\begin{array}{c}\text { Fecal sample } \\
(\mathrm{dpm} / \mathrm{d})\end{array}$ & $\begin{array}{c}\text { Urine sample } \\
(\mathrm{dpm} / \mathrm{d})^{\mathrm{a}}\end{array}$ \\
\hline \hline $06 / 08 / 98$ & Start & 0 & & \\
\hline $07 / 19 / 98$ & $*$ & 41 & & $8.77 \mathrm{E}-2(2.71 \mathrm{E}-2)$ \\
\hline $09 / 13 / 98$ & $*$ & 97 & $7.25 \mathrm{E}+1(6.40 \mathrm{E}+0)$ & $2.54 \mathrm{E}-1(4.36 \mathrm{E}-2)$ \\
\hline $09 / 18 / 98$ & End & 102 & & \\
\hline $09 / 20 / 98$ & & 104 & $4.90 \mathrm{E}+0(3.35 \mathrm{E}-1)$ & $1.92 \mathrm{E}-1(4.11 \mathrm{E}-2)$ \\
\hline $09 / 27 / 98$ & & 111 & $4.68 \mathrm{E}-1(8.80 \mathrm{E}-2)$ & \\
\hline $09 / 28 / 98$ & & 112 & & $4.63 \mathrm{E}-2(2.63 \mathrm{E}-2)$ \\
\hline
\end{tabular}

aNormalized result minus background contribution with uncertainty for each result in parenthesis.

Table A-2. Summary of bioassay data from 1998 for Employee "B"

\begin{tabular}{||l|c|c|c|c||}
\hline Date & $\begin{array}{c}\text { Period of } \\
\text { intake }\end{array}$ & $\begin{array}{c}\text { Number of } \\
\text { days }\end{array}$ & $\begin{array}{c}\text { Fecal sample } \\
(\mathrm{dpm} / \mathrm{d})\end{array}$ & $\begin{array}{c}\text { Urine sample } \\
(\mathrm{dpm} / \mathrm{d})\end{array}$ \\
\hline \hline $06 / 08 / 98$ & Start & 0 & & \\
\hline $06 / 28 / 98$ & $*$ & 20 & & $9.29 \mathrm{E}-2(3.83 \mathrm{E}-2)$ \\
\hline $09 / 26 / 98$ & $*$ & 110 & & $1.16 \mathrm{E}+0(1.01 \mathrm{E}-1)$ \\
\hline $10 / 11 / 98$ & $*$ & 125 & & $6.38 \mathrm{E}-1(6.99 \mathrm{E}-2)$ \\
\hline $10 / 21 / 98$ & $*$ & 135 & $5.05 \mathrm{E}+1(3.64 \mathrm{E}+0)$ & \\
\hline $10 / 29 / 98$ & End & 143 & & $1.34 \mathrm{E}+0(2.61 \mathrm{E}-1)$ \\
\hline $11 / 02 / 98$ & & 147 & & $7.79 \mathrm{E}-1(7.85 \mathrm{E}-2)$ \\
\hline $11 / 08 / 98$ & & 153 & $9.46 \mathrm{E}-1(9.76 \mathrm{E}-2)$ & \\
\hline $11 / 09 / 98$ & & 154 & $2.90 \mathrm{E}-1(1.02 \mathrm{E}-1)$ & \\
\hline $11 / 16 / 98$ & & 161 & & $1.08 \mathrm{E}-1(3.59 \mathrm{E}-2)$ \\
\hline $11 / 17 / 98$ & & 162 & & \\
\hline
\end{tabular}

a Normalized result minus background contribution with uncertainty for each result in parenthesis. 
Table A-3. Summary of bioassay data from 1998 for Employee "C"

\begin{tabular}{|c|c|c|c|c|}
\hline Date & $\begin{array}{l}\text { Period of } \\
\text { intake }\end{array}$ & $\begin{array}{c}\text { Number of } \\
\text { days }\end{array}$ & $\begin{array}{c}\text { Fecal sample } \\
(\mathrm{dpm} / \mathrm{d})^{\mathrm{a}}\end{array}$ & $\begin{array}{l}\text { Urine sample } \\
(\mathrm{dpm} / \mathrm{d})^{\mathrm{a}}\end{array}$ \\
\hline $06 / 08 / 98$ & Start & 0 & & \\
\hline $07 / 25 / 98$ & * & 47 & & $1.19 \mathrm{E}+0(1.08 \mathrm{E}-1)$ \\
\hline $09 / 12 / 98$ & $*$ & 96 & $8.47 \mathrm{E}+1(8.10 \mathrm{E}+0)$ & $1.72 \mathrm{E}+0(1.48 \mathrm{E}-1)$ \\
\hline $09 / 14 / 98$ & End & 98 & & \\
\hline $09 / 19 / 98$ & & 103 & & $6.90 \mathrm{E}-1(7.67 \mathrm{E}-2)$ \\
\hline $09 / 20 / 98$ & & 105 & $8.90 \mathrm{E}+1(9.60 \mathrm{E}+0)$ & \\
\hline 09/24/98 & & 109 & $2.18 \mathrm{E}+0(2.22 \mathrm{E}-1)$ & \\
\hline $09 / 26 / 98$ & & 110 & & $4.59 \mathrm{E}-1(5.96 \mathrm{E}-2)$ \\
\hline 09/29/98 & & 114 & $9.93 E+0(6.13 E-1)$ & \\
\hline $10 / 10 / 98$ & & 124 & & $4.51 \mathrm{E}-1(6.11 \mathrm{E}-2)$ \\
\hline $10 / 20 / 98$ & & 135 & $1.64 \mathrm{E}+0(2.21 \mathrm{E}-1)$ & \\
\hline
\end{tabular}

a Normalized result minus background contribution with uncertainty for each result in parenthesis.

Table A-4. Summary of bioassay data from 1998 for Employee "D"

\begin{tabular}{||l|c|c|c|c|}
\hline Date & $\begin{array}{c}\text { Period of } \\
\text { intake }\end{array}$ & $\begin{array}{c}\text { Number of } \\
\text { days }\end{array}$ & $\begin{array}{c}\text { Fecal sample } \\
(\mathrm{dpm} / \mathrm{d})\end{array}$ & $\begin{array}{c}\text { Urine sample } \\
(\mathrm{dpm} / \mathrm{d})\end{array}$ \\
\hline \hline $06 / 08 / 98$ & Start & 0 & & \\
\hline $06 / 28 / 98$ & $*$ & 20 & & $1.97 \mathrm{E}-1(4.94 \mathrm{E}-2)$ \\
\hline $09 / 17 / 98$ & $*$ & 101 & $3.73 \mathrm{E}+0(5.60 \mathrm{E}-1)$ & $1.16 \mathrm{E}-1(3.56 \mathrm{E}-2)$ \\
\hline $09 / 21 / 98$ & $*$ & 105 & $4.15 \mathrm{E}+0(1.20 \mathrm{E}+0)$ & $2.69 \mathrm{E}-1(4.97 \mathrm{E}-2)$ \\
\hline $09 / 28 / 98$ & End & 112 & & \\
\hline $10 / 05 / 98$ & & 119 & $9.76 \mathrm{E}+0(9.50 \mathrm{E}-1)$ & \\
\hline $10 / 13 / 98$ & & 127 & $1.12 \mathrm{E}+0(2.24 \mathrm{E}-1)$ & $1.45 \mathrm{E}-1(3.45 \mathrm{E}-2)$ \\
\hline $10 / 18 / 98$ & & 132 & & $2.13 \mathrm{E}-1(4.31 \mathrm{E}-2)$ \\
\hline $10 / 22 / 98$ & & 136 & $2.82 \mathrm{E}+0(5.56 \mathrm{E}-1)$ & \\
\hline
\end{tabular}

a Normalized result minus background contribution with uncertainty for each result in parenthesis. 
Table A-5. Summary of bioassay data from 1998 for Employee "E"

\begin{tabular}{||l|c|c|c|c||}
\hline Date & $\begin{array}{c}\text { Period of } \\
\text { intake }\end{array}$ & $\begin{array}{c}\text { Number of } \\
\text { days }\end{array}$ & $\begin{array}{c}\text { Fecal sample } \\
(\mathrm{dpm} / \mathrm{d})\end{array}$ & $\begin{array}{c}\text { Urine sample } \\
(\mathrm{dpm} / \mathrm{d})^{\mathrm{a}}\end{array}$ \\
\hline \hline $06 / 08 / 98$ & Start & 0 & & \\
\hline $07 / 20 / 98$ & $*$ & 42 & & $2.35 \mathrm{E}-1(3.52 \mathrm{E}-2)$ \\
\hline $10 / 04 / 98$ & $*$ & 118 & & $1.57 \mathrm{E}-1(3.31 \mathrm{E}-2)$ \\
\hline $10 / 11 / 98$ & $*$ & 125 & & $9.00 \mathrm{E}-2(3.32 \mathrm{E}-2)$ \\
\hline $10 / 21 / 98$ & $*$ & 135 & $2.06 \mathrm{E}+1(1.85 \mathrm{E}+0)$ & \\
\hline $10 / 30 / 98$ & End & 144 & $4.56 \mathrm{E}+1(2.77 \mathrm{E}+0)$ & \\
\hline $11 / 02 / 98$ & & 147 & & $2.98 \mathrm{E}-1(5.10 \mathrm{E}-2)$ \\
\hline $11 / 06 / 98$ & & 151 & $2.75 \mathrm{E}+0(3.95 \mathrm{E}-1)$ & \\
\hline $11 / 08 / 98$ & & 153 & & $6.36 \mathrm{E}-2(3.37 \mathrm{E}-2)$ \\
\hline $11 / 18 / 98$ & & 163 & $3.16 \mathrm{E}+0(7.98 \mathrm{E}-1)$ & \\
\hline $11 / 22 / 98$ & & 167 & & $1.39 \mathrm{E}-1(3.74 \mathrm{E}-2)$ \\
\hline
\end{tabular}

Aormalized result minus background contribution with uncertainty for each result in parenthesis.

Table A-6. Summary of bioassay data from 1998 for Employee "F"

\begin{tabular}{||l|c|c|c|c||}
\hline Date & $\begin{array}{c}\text { Period of } \\
\text { intake }\end{array}$ & $\begin{array}{c}\text { Number of } \\
\text { days }\end{array}$ & $\begin{array}{c}\text { Fecal sample } \\
(\mathrm{dpm} / \mathrm{d})\end{array}$ & $\begin{array}{c}\text { Urine sample } \\
(\mathrm{dpm} / \mathrm{d})\end{array}$ \\
\hline $06 / 08 / 98$ & Start & 0 & & \\
\hline $07 / 19 / 98$ & $*$ & 41 & & $1.29 \mathrm{E}-1(3.12 \mathrm{E}-2)$ \\
\hline $10 / 12 / 98$ & $*$ & 126 & & $1.89 \mathrm{E}-2(2.91 \mathrm{E}-2)$ \\
\hline $11 / 06 / 98$ & $*$ & 151 & $1.07 \mathrm{E}+1(2.51 \mathrm{E}-1)$ & \\
\hline $11 / 08 / 98$ & $*$ & 153 & & $2.50 \mathrm{E}-2(2.61 \mathrm{E}-2)$ \\
\hline $11 / 20 / 98$ & $*$ & 165 & $1.35 \mathrm{E}+2(1.02 \mathrm{E}+1)$ & \\
\hline $11 / 23 / 98$ & $*$ & 168 & & $7.49 \mathrm{E}-1(7.95 \mathrm{E}-2)$ \\
\hline $12 / 03 / 98$ & End & 178 & & \\
\hline $12 / 04 / 98$ & & 179 & $8.62 \mathrm{E}+1(3.73 \mathrm{E}+0)$ & \\
\hline $12 / 06 / 98$ & & 180 & & $1.40 \mathrm{E}+0(1.18 \mathrm{E}-1)$ \\
\hline
\end{tabular}

a Normalized result minus background contribution with uncertainty for each result in parenthesis. 
Table A-7. Summary of bioassay data from 1998 for Employee "G"

\begin{tabular}{|l|c|c|c|c|}
\hline Date & $\begin{array}{c}\text { Period of } \\
\text { intake }\end{array}$ & $\begin{array}{c}\text { Number of } \\
\text { days }\end{array}$ & $\begin{array}{c}\text { Fecal sample } \\
(\mathrm{dpm} / \mathrm{d})\end{array}$ & $\begin{array}{c}\text { Urine sample } \\
(\mathrm{dpm} / \mathrm{d})\end{array}$ \\
\hline \hline $06 / 08 / 98$ & Start & 0 & & \\
\hline $07 / 20 / 98$ & $*$ & 42 & & $1.28 \mathrm{E}-1(3.20 \mathrm{E}-2)$ \\
\hline $09 / 18 / 98$ & End & 102 & & \\
\hline $09 / 20 / 98$ & & 104 & $4.21 \mathrm{E}+1(2.35 \mathrm{E}+0)$ & \\
\hline $09 / 21 / 98$ & & 105 & & $1.96 \mathrm{E}-1(4.03 \mathrm{E}-2)$ \\
\hline $09 / 26 / 98$ & & 110 & $1.03 \mathrm{E}+0(1.53 \mathrm{E}-1)$ & \\
\hline $09 / 27 / 98$ & & 111 & & $2.32 \mathrm{E}-1(4.26 \mathrm{E}-2)$ \\
\hline $10 / 04 / 98$ & & 118 & $1.52 \mathrm{E}+0(3.32 \mathrm{E}-1)$ & $1.16 \mathrm{E}-1(3.25 \mathrm{E}-2)$ \\
\hline
\end{tabular}

ANormalized result minus background contribution with uncertainty for each result in parenthesis.

Table A-8. Summary of bioassay data from 1998 for Employee "H"

\begin{tabular}{|l|c|c|c|c|}
\hline Date & $\begin{array}{c}\text { Period of } \\
\text { intake }\end{array}$ & $\begin{array}{c}\text { Number of } \\
\text { days }\end{array}$ & $\begin{array}{c}\text { Fecal sample } \\
(\mathrm{dpm} / \mathrm{d})\end{array}$ & $\begin{array}{c}\text { Urine sample } \\
(\mathrm{dpm} / \mathrm{d})\end{array}$ \\
\hline $06 / 08 / 98$ & Start & 0 & & \\
\hline $08 / 30 / 98$ & $*$ & 83 & & $2.04 \mathrm{E}-1(4.03 \mathrm{E}-2)$ \\
\hline $09 / 16 / 98$ & End & 100 & & \\
\hline $09 / 20 / 98$ & & 104 & $9.11 \mathrm{E}+0(5.64 \mathrm{E}-1)$ & $1.39 \mathrm{E}-1(3.54 \mathrm{E}-2)$ \\
\hline $09 / 27 / 98$ & & 111 & & $1.61 \mathrm{E}-1(4.09 \mathrm{E}-2)$ \\
\hline $09 / 29 / 98$ & & 113 & $1.67 \mathrm{E}+0(8.20 \mathrm{E}-2)$ & \\
\hline $10 / 18 / 98$ & & 132 & $1.20 \mathrm{E}+0(5.90 \mathrm{E}-2)$ & $4.40 \mathrm{E}-2(2.74 \mathrm{E}-2)$ \\
\hline
\end{tabular}

Normalized result minus background contribution with uncertainty for each result in parenthesis. 
Table A-9. Summary of bioassay data from 1998 for Employee "I"

\begin{tabular}{|c|c|c|c|c|}
\hline Date & $\begin{array}{c}\text { Period of } \\
\text { intake }\end{array}$ & $\begin{array}{c}\text { Number of } \\
\text { days }\end{array}$ & $\begin{array}{c}\text { Fecal sample } \\
(\mathrm{dpm} / \mathrm{d})^{\mathrm{a}}\end{array}$ & $\begin{array}{c}\text { Urine sample } \\
(\mathrm{dpm} / \mathrm{d})^{\mathrm{a}}\end{array}$ \\
\hline $06 / 08 / 98$ & Start & 0 & & \\
\hline $08 / 29 / 98$ & $*$ & 82 & & $1.59 \mathrm{E}-1(3.82 \mathrm{E}-2)$ \\
\hline $09 / 11 / 98$ & * & 95 & & $2.96 \mathrm{E}-1(4.79 \mathrm{E}-2)$ \\
\hline $09 / 12 / 98$ & * & 96 & $1.08 \mathrm{E}+2(2.98 \mathrm{E}+0)$ & \\
\hline $09 / 18 / 98$ & End & 102 & $5.83 \mathrm{E}+1(8.40 \mathrm{E}-1)$ & \\
\hline $09 / 19 / 98$ & & 103 & & $2.14 E-1(4.15 E-2)$ \\
\hline 09/27/98 & & 111 & $6.11 \mathrm{E}+0(1.93 \mathrm{E}-1)$ & \\
\hline $09 / 28 / 98$ & & 112 & & $8.82 \mathrm{E}-2(3.06 \mathrm{E}-2)$ \\
\hline $11 / 25 / 98$ & & 170 & & $2.29 \mathrm{E}-1(4.04 \mathrm{E}-2)$ \\
\hline
\end{tabular}

a Normalized result minus background contribution with uncertainty for each result in parenthesis.

Table A-10. Summary of bioassay data from 1998 for Employee "J"

\begin{tabular}{|c|c|c|c|c|}
\hline Date & $\begin{array}{c}\text { Period of } \\
\text { intake }\end{array}$ & $\begin{array}{c}\begin{array}{c}\text { Number of } \\
\text { days }\end{array} \\
\end{array}$ & $\begin{array}{c}\text { Fecal sample } \\
(\mathrm{dpm} / \mathrm{d})^{\mathrm{a}}\end{array}$ & $\begin{array}{l}\text { Urine sample } \\
(\mathrm{dpm} / \mathrm{d})^{\mathrm{a}}\end{array}$ \\
\hline $06 / 08 / 98$ & Start & 0 & & \\
\hline 08/19/98 & $*$ & 72 & $1.23 \mathrm{E}+2(2.50 \mathrm{E}-1)$ & \\
\hline $08 / 22 / 98$ & * & 75 & & $5.27 \mathrm{E}-1(6.57 \mathrm{E}-2)$ \\
\hline 09/04/98 & End & 88 & & \\
\hline 09/06/98 & & 90 & & $2.44 \mathrm{E}-1(5.43 \mathrm{E}-2)$ \\
\hline 09/07/98 & & 91 & $2.36 \mathrm{E}+0(3.00 \mathrm{E}-1)$ & \\
\hline 09/12/98 & & 96 & $1.10 \mathrm{E}+0(1.98 \mathrm{E}-1)$ & $1.32 \mathrm{E}-1(3.75 \mathrm{E}-2)$ \\
\hline $09 / 26 / 98$ & & 110 & $6.32 \mathrm{E}-1(2.81 \mathrm{E}-1)$ & \\
\hline 09/27/98 & & 111 & & $3.40 \mathrm{E}-2(2.91 \mathrm{E}-2)$ \\
\hline
\end{tabular}

a Normalized result minus background contribution with uncertainty for each result in parenthesis. 
Table A-11. Summary of bioassay data from 1998 for Employee "K"

\begin{tabular}{||l|c|c|c|c||}
\hline \hline Date & $\begin{array}{c}\text { Period of } \\
\text { intake }\end{array}$ & $\begin{array}{c}\text { Number of } \\
\text { days }\end{array}$ & $\begin{array}{c}\text { Fecal sample } \\
(\mathrm{dpm} / \mathrm{d})^{\mathrm{a}}\end{array}$ & $\begin{array}{c}\text { Urine sample } \\
(\mathrm{dpm} / \mathrm{d})^{\mathrm{a}}\end{array}$ \\
\hline \hline $07 / 20 / 98$ & Start & 0 & & \\
\hline $07 / 25 / 98$ & $*$ & 5 & & $1.94 \mathrm{E}-1(3.86 \mathrm{E}-2)$ \\
\hline $09 / 13 / 98$ & $*$ & 55 & $1.15 \mathrm{E}+2(9.79 \mathrm{E}+0)$ & $8.14 \mathrm{E}-2(2.87 \mathrm{E}-2)$ \\
\hline $09 / 18 / 98$ & End & 60 & & \\
\hline $09 / 20 / 98$ & & 62 & $6.01 \mathrm{E}+1(1.41 \mathrm{E}+0)$ & $4.33 \mathrm{E}-2(2.75 \mathrm{E}-2)$ \\
\hline $09 / 26 / 98$ & & 68 & $1.73 \mathrm{E}+0(8.26 \mathrm{E}-2)$ & \\
\hline $09 / 28 / 98$ & $*$ & 70 & & $-1.73 \mathrm{E}-2(1.99 \mathrm{E}-2)$ \\
\hline
\end{tabular}

ANormalized result minus background contribution with uncertainty for each result in parenthesis.

Table A-12. Summary of bioassay data from 1998 for Employee "L"

\begin{tabular}{||l|c|c|c|c||}
\hline Date & $\begin{array}{c}\text { Period of } \\
\text { intake }\end{array}$ & $\begin{array}{c}\text { Number of } \\
\text { days }\end{array}$ & $\begin{array}{c}\text { Fecal sample } \\
(\mathrm{dpm} / \mathrm{d})\end{array}$ & $\begin{array}{c}\text { Urine sample } \\
(\mathrm{dpm} / \mathrm{d})\end{array}$ \\
\hline \hline $06 / 08 / 98$ & Start & 0 & & \\
\hline $06 / 14 / 98$ & $*$ & 6 & & $1.68 \mathrm{E}-2(2.54 \mathrm{E}-2)$ \\
\hline $09 / 13 / 98$ & $*$ & 97 & & $4.29 \mathrm{E}-1(6.04 \mathrm{E}-2)$ \\
\hline $10 / 11 / 98$ & $*$ & 125 & & $3.39 \mathrm{E}-1(5.18 \mathrm{E}-2)$ \\
\hline $10 / 21 / 98$ & $*$ & 135 & $1.51 \mathrm{E}+1(1.93 \mathrm{E}+0)$ & \\
\hline $10 / 29 / 98$ & End & 143 & & $2.71 \mathrm{E}-1(4.44 \mathrm{E}-2)$ \\
\hline $11 / 01 / 98$ & & 146 & & $1.16 \mathrm{E}+0(1.81 \mathrm{E}-1)$ \\
\hline $11 / 02 / 98$ & & 147 & & $1.74 \mathrm{E}-1(4.64 \mathrm{E}-2)$ \\
\hline $11 / 08 / 98$ & & 153 & $6.02 \mathrm{E}-1(1.52 \mathrm{E}-1)$ & \\
\hline $11 / 09 / 98$ & & 154 & & $9.12 \mathrm{E}-2(3.15 \mathrm{E}-2)$ \\
\hline $11 / 15 / 98$ & & 160 & $5.17 \mathrm{E}-1(1.45 \mathrm{E}-1)$ & \\
\hline $11 / 16 / 98$ & & 161 & & \\
\hline
\end{tabular}

Wormalized result minus background contribution with uncertainty for each result in parenthesis. 
Table A-13. Summary of bioassay data from 1998 for Employee "M"

\begin{tabular}{|l|c|c|c|c||}
\hline Date & $\begin{array}{c}\text { Period of } \\
\text { intake }\end{array}$ & $\begin{array}{c}\text { Number of } \\
\text { days }\end{array}$ & $\begin{array}{c}\text { Fecal sample } \\
(\mathrm{dpm} / \mathrm{d})^{\mathrm{a}}\end{array}$ & $\begin{array}{c}\text { Urine sample } \\
(\mathrm{dpm} / \mathrm{d})^{\mathrm{a}}\end{array}$ \\
\hline \hline $06 / 08 / 98$ & Start & 0 & & \\
\hline $06 / 21 / 98$ & $*$ & 13 & & $4.27 \mathrm{E}-1(6.06 \mathrm{E}-2)$ \\
\hline $09 / 20 / 98$ & $*$ & 104 & & $8.48 \mathrm{E}-1(8.28 \mathrm{E}-2)$ \\
\hline $09 / 27 / 98$ & $*$ & 111 & $6.07 \mathrm{E}+1(4.59 \mathrm{E}+0)$ & $6.37 \mathrm{E}-1(7.19 \mathrm{E}-2)$ \\
\hline $10 / 05 / 98$ & End & 119 & & \\
\hline $10 / 11 / 98$ & & 125 & $6.82 \mathrm{E}+0(4.71 \mathrm{E}-1)$ & $3.03 \mathrm{E}-1(5.20 \mathrm{E}-2)$ \\
\hline $10 / 17 / 98$ & & 131 & $4.05 \mathrm{E}+0(2.02 \mathrm{E}-1)$ & \\
\hline $10 / 18 / 98$ & & 132 & & $5.02 \mathrm{E}-1(6.10 \mathrm{E}-2)$ \\
\hline $10 / 26 / 98$ & & 140 & $2.49 \mathrm{E}+0(3.63 \mathrm{E}-1)$ & \\
\hline $10 / 28 / 98$ & & 141 & & $3.82 \mathrm{E}-1(4.82 \mathrm{E}-2)$ \\
\hline $11 / 05 / 98$ & & 150 & $5.66 \mathrm{E}+0(3.27 \mathrm{E}-1)$ & \\
\hline $11 / 06 / 98$ & & 151 & & $4.36 \mathrm{E}-1(6.32 \mathrm{E}-2)$ \\
\hline
\end{tabular}

aNormalized result minus background contribution with uncertainty for each result in parenthesis.

Table A-14. Summary of bioassay data from 1998 for Employee "N"

\begin{tabular}{|l|c|c|c|c||}
\hline Date & $\begin{array}{c}\text { Period of } \\
\text { intake }\end{array}$ & $\begin{array}{c}\text { Number of } \\
\text { days }\end{array}$ & $\begin{array}{c}\text { Fecal sample } \\
(\mathrm{dpm} / \mathrm{d})\end{array}$ & $\begin{array}{c}\text { Urine sample } \\
(\mathrm{dpm} / \mathrm{d})^{\mathrm{a}}\end{array}$ \\
\hline $06 / 08 / 98$ & Start & 0 & & \\
\hline $06 / 23 / 98$ & $*$ & 15 & & $2.15 \mathrm{E}-1(4.75 \mathrm{E}-2)$ \\
\hline $09 / 12 / 98$ & $*$ & 96 & $2.10 \mathrm{E}+1(1.41 \mathrm{E}+0)$ & \\
\hline $09 / 13 / 98$ & $*$ & 97 & & $1.87 \mathrm{E}-1(3.57 \mathrm{E}-2)$ \\
\hline $09 / 18 / 98$ & End & 102 & & \\
\hline $09 / 20 / 98$ & & 104 & $9.85 \mathrm{E}+0(6.03 \mathrm{E}-1)$ & \\
\hline $09 / 21 / 98$ & & 105 & & $4.49 \mathrm{E}-2(2.99 \mathrm{E}-2)$ \\
\hline $09 / 26 / 98$ & & 110 & & $8.66 \mathrm{E}-2(3.69 \mathrm{E}-2)$ \\
\hline $09 / 29 / 98$ & & 113 & $1.24 \mathrm{E}+0(3.35 \mathrm{E}-1)$ & $9.72 \mathrm{E}-3(2.66 \mathrm{E}-2)$ \\
\hline
\end{tabular}

a Normalized result minus background contribution with uncertainty for each result in parenthesis. 
Table A-15. Summary of bioassay data from 1998 for Employee "O"

\begin{tabular}{||l|c|c|c|c||}
\hline Date & $\begin{array}{c}\text { Period of } \\
\text { intake }\end{array}$ & $\begin{array}{c}\text { Number of } \\
\text { days }\end{array}$ & $\begin{array}{c}\text { Fecal sample } \\
(\mathrm{dpm} / \mathrm{d})^{\mathrm{a}}\end{array}$ & $\begin{array}{c}\text { Urine sample } \\
(\mathrm{dpm} / \mathrm{d})^{\mathrm{a}}\end{array}$ \\
\hline \hline $06 / 08 / 98$ & Start & 0 & & \\
\hline $06 / 09 / 98$ & $*$ & 1 & & $4.63 \mathrm{E}-2(2.89 \mathrm{E}-2)$ \\
\hline $09 / 07 / 98$ & $*$ & 91 & $5.19 \mathrm{E}+1(2.56 \mathrm{E}+0)$ & \\
\hline $09 / 09 / 98$ & End & 93 & & \\
\hline $09 / 12 / 98$ & & 96 & $1.98 \mathrm{E}+1(1.08 \mathrm{E}+0)$ & \\
\hline $09 / 15 / 98$ & & 99 & & $2.13 \mathrm{E}-2(2.65 \mathrm{E}-2)$ \\
\hline $09 / 22 / 98$ & & 106 & $1.97 \mathrm{E}+0(2.20 \mathrm{E}-1)$ & \\
\hline $10 / 02 / 98$ & & 116 & & $3.16 \mathrm{E}-2(2.64 \mathrm{E}-2)$ \\
\hline
\end{tabular}

àNormalized result minus background contribution with uncertainty for each result in parenthesis. 


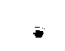




\section{APPENDIX B}

\section{PLOTS OF 1998 BIOASSAY DATA AND ESTIMATED INTAKE RATES}

The figures of this appendix illustrate the bioassay data and estimated intakes rates for 15 selected employees who were exposed to enriched uranium following the restart of enriched uranium casting and machining operations on June 8, 1998 (see Figs. B-1 through B-15). Each of the figures shows the intakes rates derived from the fecal and urine data assuming exposure to Type $\mathrm{S}$ uranium with an $A M A D$ of $5 \mu \mathrm{m}$. The fecal sample data and estimated intake rate based on the fecal samples are shown by solid dots and upper curves in the figures, and the urine sample data and estimated intake rates based on the urine samples are shown by open dots and lower curves in the figures. The fecal sample data, the urine sample data, and the exposure times can be found in Tables A-1 through A-15 of Appendix A. The only data point not used is the negative urine-sample value in Table A-11. Intake rates also were derived for a few employees assuming exposure to Type $M$ uranium with an $A M A D$ of $5 \mu \mathrm{m}$ (see, for example, Fig. B-2b) because of the poor agreement in the intake rates predicted by their fecal and urine data and the assumption of exposure to Type $S$ uranium. The results for these employees clearly suggest that some Y-12 Plant exposures probably involved both Type $\mathrm{M}$ and $\mathrm{S}$ uranium.

The intakes based on the new model were calculated assuming a continuous exposure to enriched uranium aerosols at the Y-12 Plant starting on June 8,1998 and ending on the dates given in the tables of Appendix A. The ending dates correspond to the date that the employee was restricted from their normal jobs and reassigned to other jobs in non-radiological areas of the Y-12 Plant. For purposes of comparing the new model calculations with the old model calculations, the same intake model parameters were used. In other words, whatever was assumed in the old model calculations was also assumed in the new model calculations. There were no attempts to adjust the starting or ending dates of the intake periods in an effort to obtain the best fit to the bioassay data using the new model. The intake rates and $\chi^{2}$ variables for fits of the bioassay data to the new model were calculated using the ACTLITE code and equations discussed in Appendix E.

The intake rates derived from the urine and fecal measurements assuming exposure to Type $S$ uranium with an $A M A D$ of $5 \mu \mathrm{m}$ and the $\chi^{2}$ statistic for the estimated intake rates are summarized in Table C-1. We note that Y-12's RCO makes use of the " $\chi^{2}$ test" in Microsoft's EXCEL.TM The $\chi^{2}$ test and the $\chi^{2}$ statistic used here are not the same quantities. The $\chi^{2}$ statistic is useful as a test to decide whether the measured and expected excretion rates are close enough so that we can conclude they come from the same distribution function. For this reason, the test is called a "goodness-of-fit" test. When the fit is good, the " $\chi^{2}$ test" is small and approaches zero (see Appendix E). While $\chi^{2}$ statistic can be used to obtain the best fit to an expected excretion distribution, it is of limited utility in deciding whether to base the recorded estimated intake on the urine data or on the fecal data. For example, the estimated intakes based on the new model and the fecal data provide relatively stable intake values even if one has no knowledge of the solubility of the uranium involved in the Y-12 exposures (see Figs. B-2, B-3, B-4, B-12, and B-13). 
Table B-1. Summary of estimated intake rates using available 1998 bioassay data and the new ICRP-66 model for exposure to Type $S$ uranium with an $A M A D$ of $5 \mu \mathrm{m}$.

\begin{tabular}{|c|c|c|c|c|}
\hline Employee & $\begin{array}{l}\text { Type of } \\
\text { samples }\end{array}$ & $\begin{array}{c}\text { Number of } \\
\text { samples }\end{array}$ & $\begin{array}{c}\text { Intake rate } \\
(\mathrm{dpm} / \mathrm{d})\end{array}$ & $\chi^{2}$ \\
\hline \multirow[t]{2}{*}{ A } & Urine & 4 & $1.43 E+2$ & $1.36 \mathrm{E}-1$ \\
\hline & Feces & 3 & $1.23 E+2$ & $1.99 \mathrm{E}+1$ \\
\hline \multirow[t]{2}{*}{ B } & Urine & 6 & $4.78 \mathrm{E}+2$ & $1.08 \mathrm{E}+0$ \\
\hline & Feces & 4 & $9.82 \mathrm{E}+1$ & $6.08 \mathrm{E}+0$ \\
\hline \multirow[t]{2}{*}{$\mathrm{C}$} & Urine & 5 & $1.01 E+3$ & $7.38 \mathrm{E}-2$ \\
\hline & Feces & 5 & $3.57 \mathrm{E}+2$ & $6.88 \mathrm{E}+2$ \\
\hline \multirow[t]{2}{*}{ D } & Urine & 5 & $1.80 \mathrm{E}+2$ & $2.14 \mathrm{E}-1$ \\
\hline & Feces & 5 & $2.27 \mathrm{E}+1$ & $1.66 \mathrm{E}+2$ \\
\hline \multirow[t]{2}{*}{$\mathrm{E}$} & Urine & 6 & $1.47 \mathrm{E}+2$ & $3.84 E-1$ \\
\hline & Feces & 4 & $7.68 \mathrm{E}+1$ & $1.09 \mathrm{E}+1$ \\
\hline \multirow[t]{2}{*}{ F } & Urine & 5 & 3.22E+2 & $4.78 \mathrm{E}+0$ \\
\hline & Feces & 3 & $1.89 \mathrm{E}+2$ & $1.03 E+2$ \\
\hline \multirow[t]{2}{*}{ G } & Urine & 4 & $2.14 \mathrm{E}+2$ & $1.43 \mathrm{E}-1$ \\
\hline & Feces & 3 & $2.12 E+2$ & $6.26 \mathrm{E}+0$ \\
\hline \multirow[t]{2}{*}{$\mathrm{H}$} & Urine & 4 & $1.71 \mathrm{E}+2$ & $5.75 E-2$ \\
\hline & Feces & 3 & $1.45 \mathrm{E}+2$ & $1.78 \mathrm{E}+0$ \\
\hline \multirow[t]{2}{*}{ I } & Urine & 5 & $2.10 \mathrm{E}+2$ & $3.45 E-1$ \\
\hline & Feces & 3 & $1.90 \mathrm{E}+2$ & $1.54 \mathrm{E}+1$ \\
\hline \multirow[t]{2}{*}{$\mathbf{J}$} & Urine & 4 & $2.99 \mathrm{E}+2$ & $1.30 \mathrm{E}-1$ \\
\hline & Feces & 4 & $2.27 \mathrm{E}+2$ & $2.53 E+1$ \\
\hline \multirow[t]{2}{*}{ K } & Urine & 3 & $1.20 \mathrm{E}+2$ & $1.36 \mathrm{E}-1$ \\
\hline & Feces & 3 & $2.86 \mathrm{E}+2$ & $7.32 \mathrm{E}+0$ \\
\hline \multirow[t]{2}{*}{ L } & Urine & 6 & $2.11 E+2$ & $2.51 \mathrm{E}-1$ \\
\hline & Feces & 4 & $3.22 \mathrm{E}+1$ & $2.51 \mathrm{E}-\mathrm{I}$ \\
\hline \multirow[t]{2}{*}{$\mathbf{M}$} & Urine & 7 & $5.43 E+2$ & $2.29 \mathrm{E}-1$ \\
\hline & Feces & 5 & $1.51 \mathrm{E}+2$ & $6.72 \mathrm{E}+0$ \\
\hline \multirow[t]{2}{*}{$\mathrm{N}$} & Urine & 5 & $1.22 \mathrm{E}+2$ & $1.56 \mathrm{E}-1$ \\
\hline & Feces & 3 & $5.09 \mathrm{E}+1$ & $3.32 \mathrm{E}-1$ \\
\hline \multirow{2}{*}{0} & Urine & 3 & $5.41 \mathrm{E}+1$ & $8.03 E-3$ \\
\hline & Feces & 3 & $1.36 \mathrm{E}+2$ & $8.17 \mathrm{E}+0$ \\
\hline
\end{tabular}




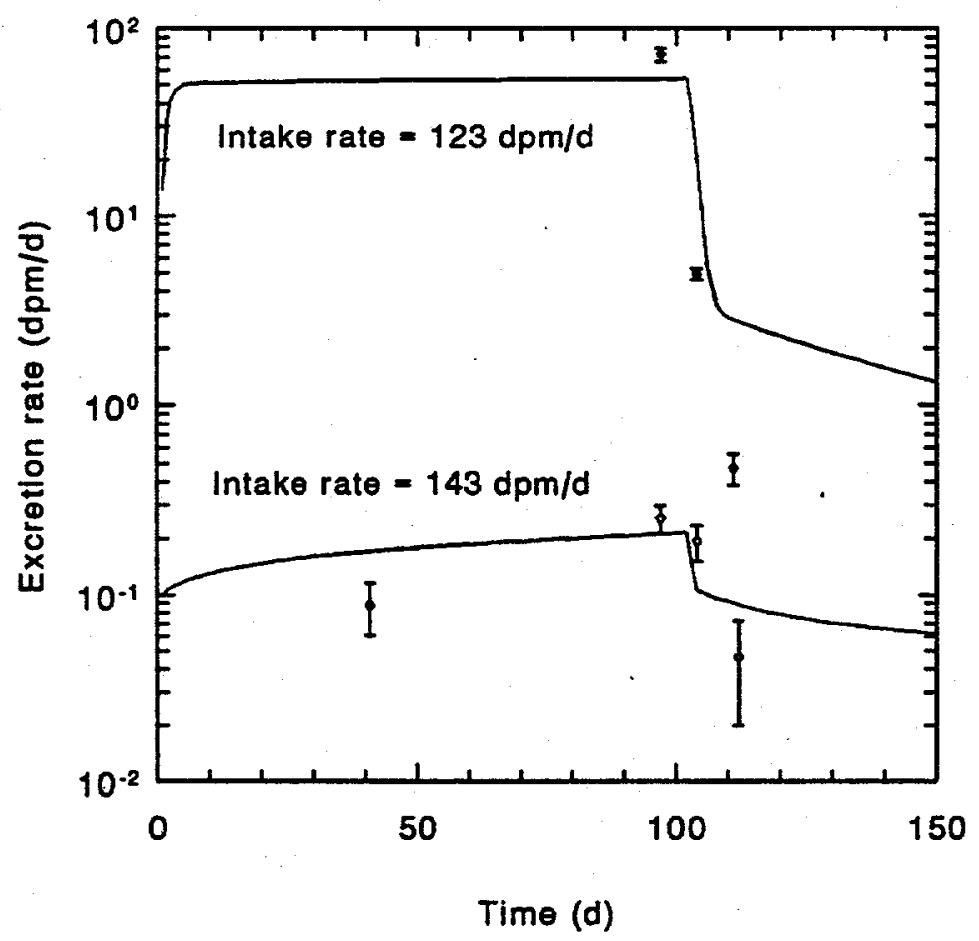

Fig. B-1. Plot of 1998 bioassay data and estimated intake rate for Employee "A" assuming exposure to Type $S$ uranium. 


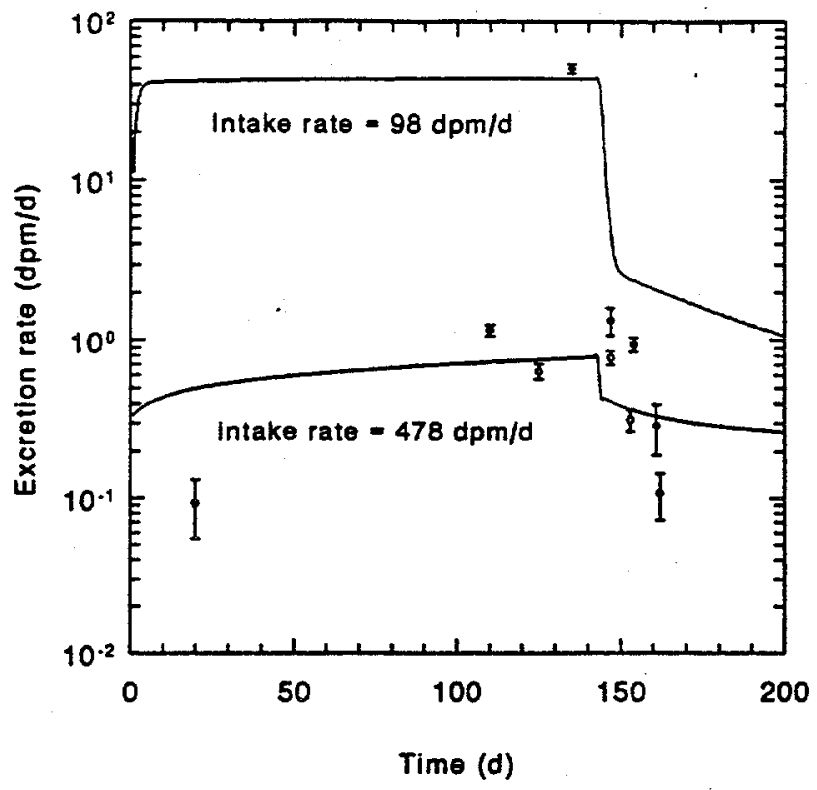

Fig. B-2a. Plot of 1998 bioassay data and estimated intake rate for Employee "B" assuming Type $S$ uranium.

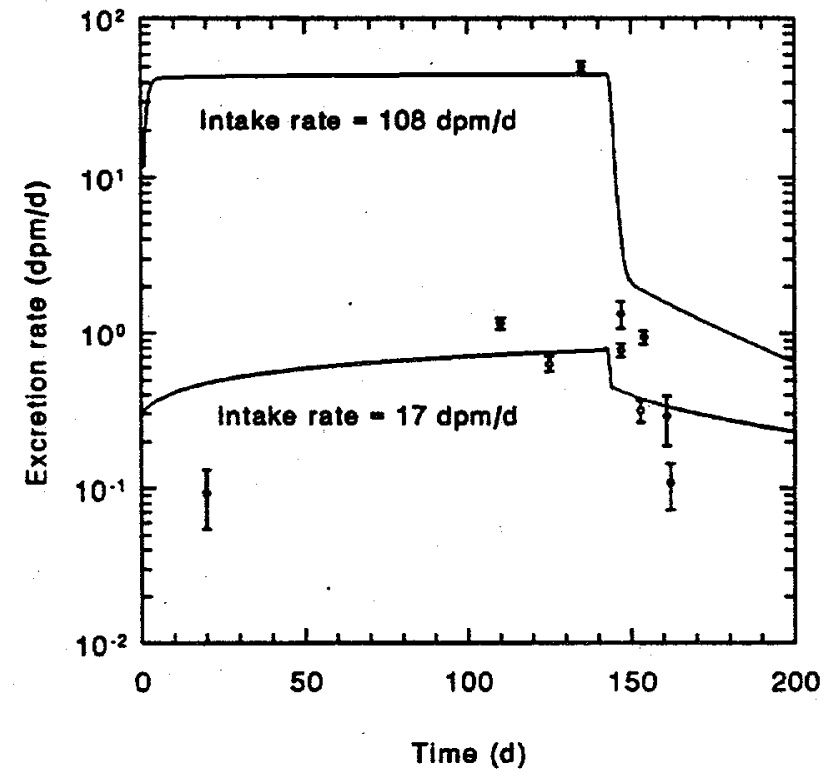

Fig. B-2b. Plot of 1998 bioassay data and estimated intake rate for Employee "B" assuming Type $M$ uranium. 


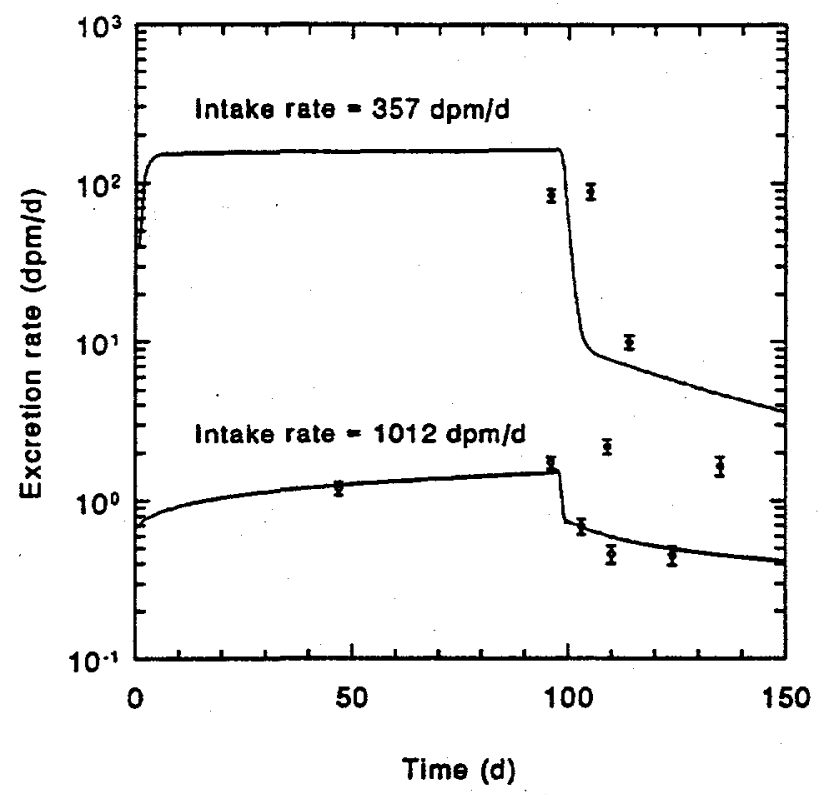

Fig. B-3a. Plot of 1998 bioassay data and estimated intake rate for Employee "C" assuming Type $S$ uranium.

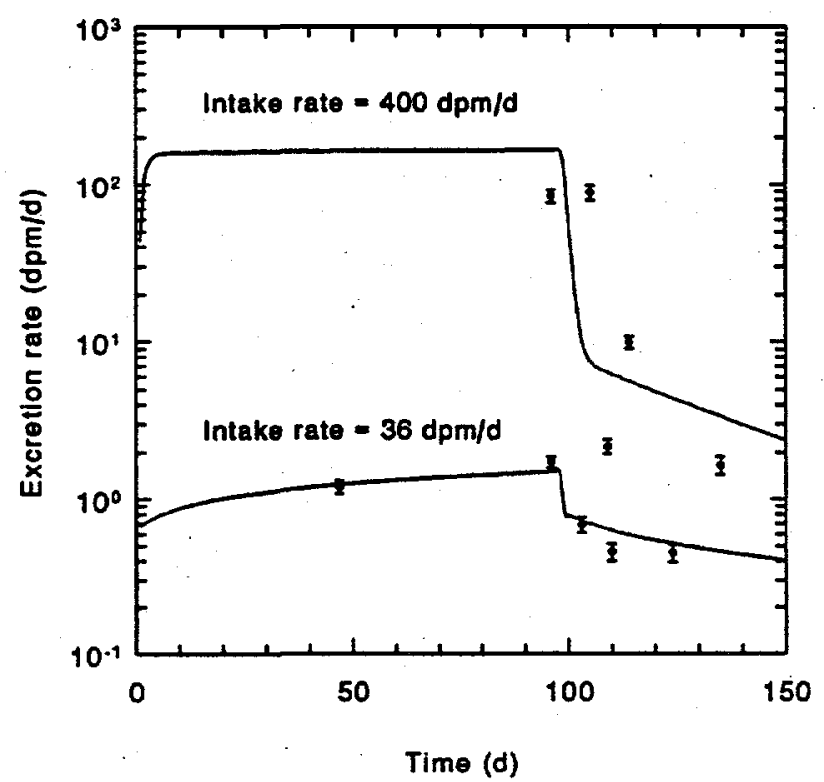

Fig. B-3b. Plot of 1998 bioassay data and estimated intake rate for Employee "C" assuming Type $M$ uranium. 


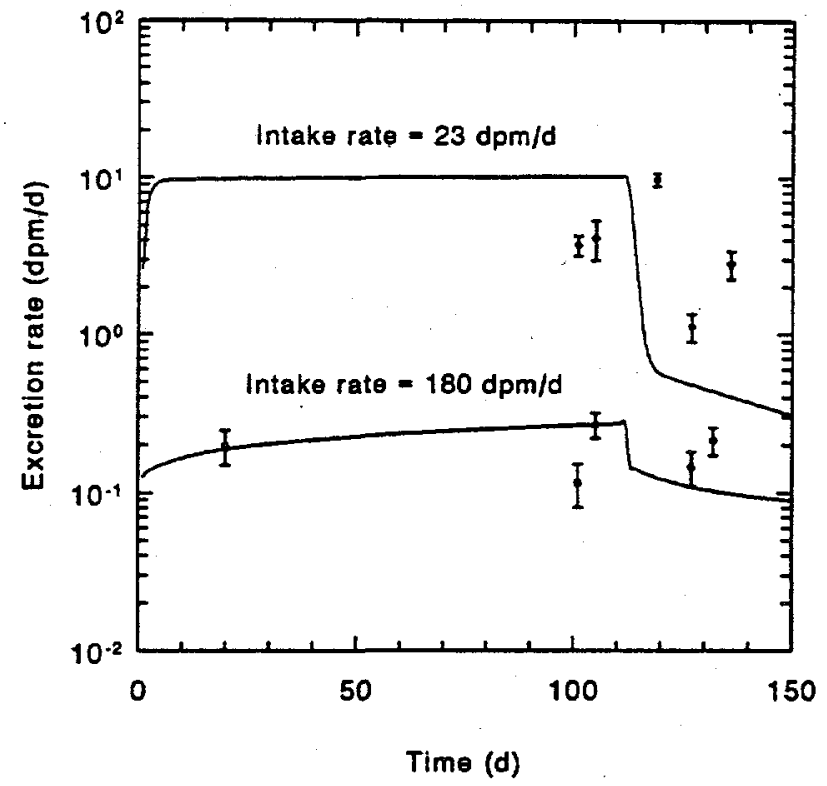

Fig. B-4a. Plot of 1998 bioassay data and estimated intake rate for Employee "D" assuming exposure to Type $S$ uranium.

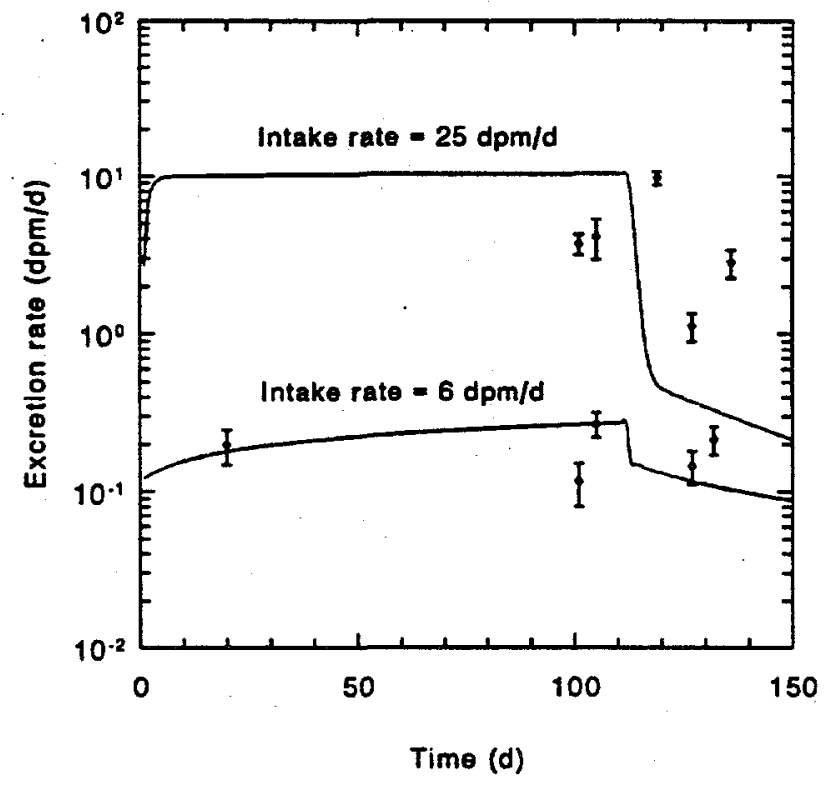

Fig. B-4b. Plot of 1998 bioassay data and estimated intake rate for Employee "D" assuming exposure to Type $M$ uranium. 


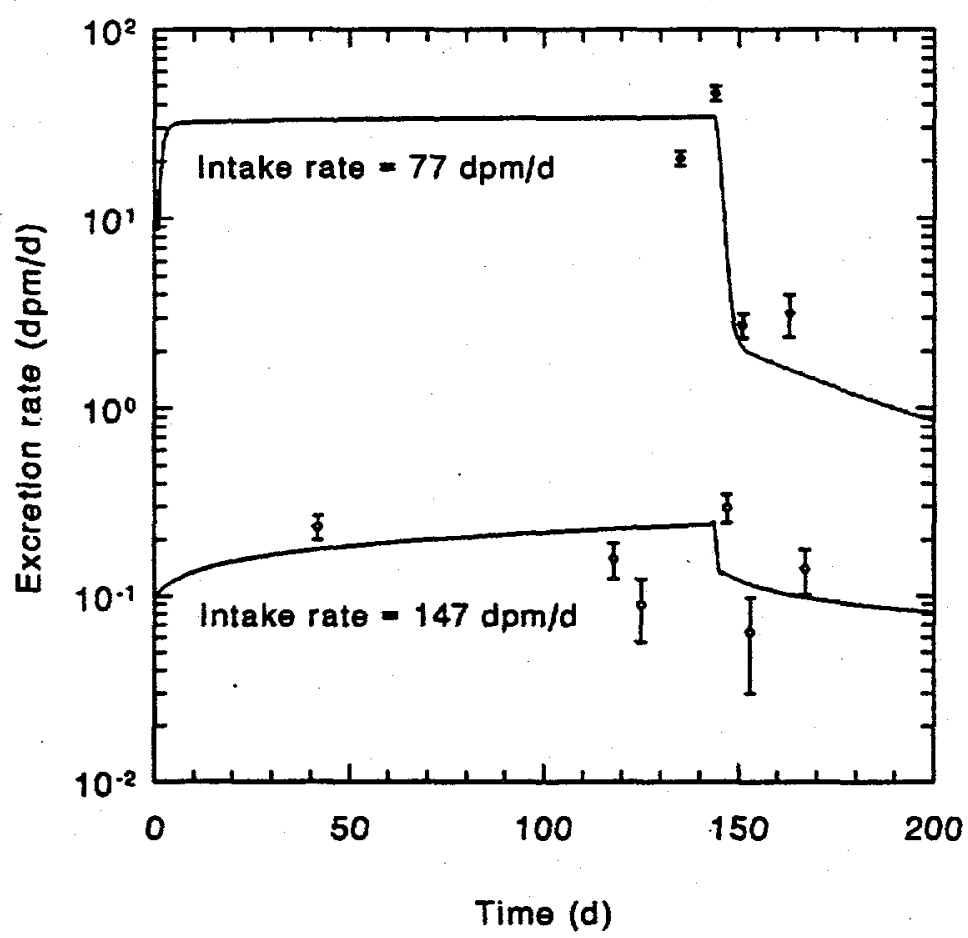

Fig. B-5. Plot of 1998 bioassay data and estimated intake rates for Employee "E" assuming exposure to Type $S$ uranium. 


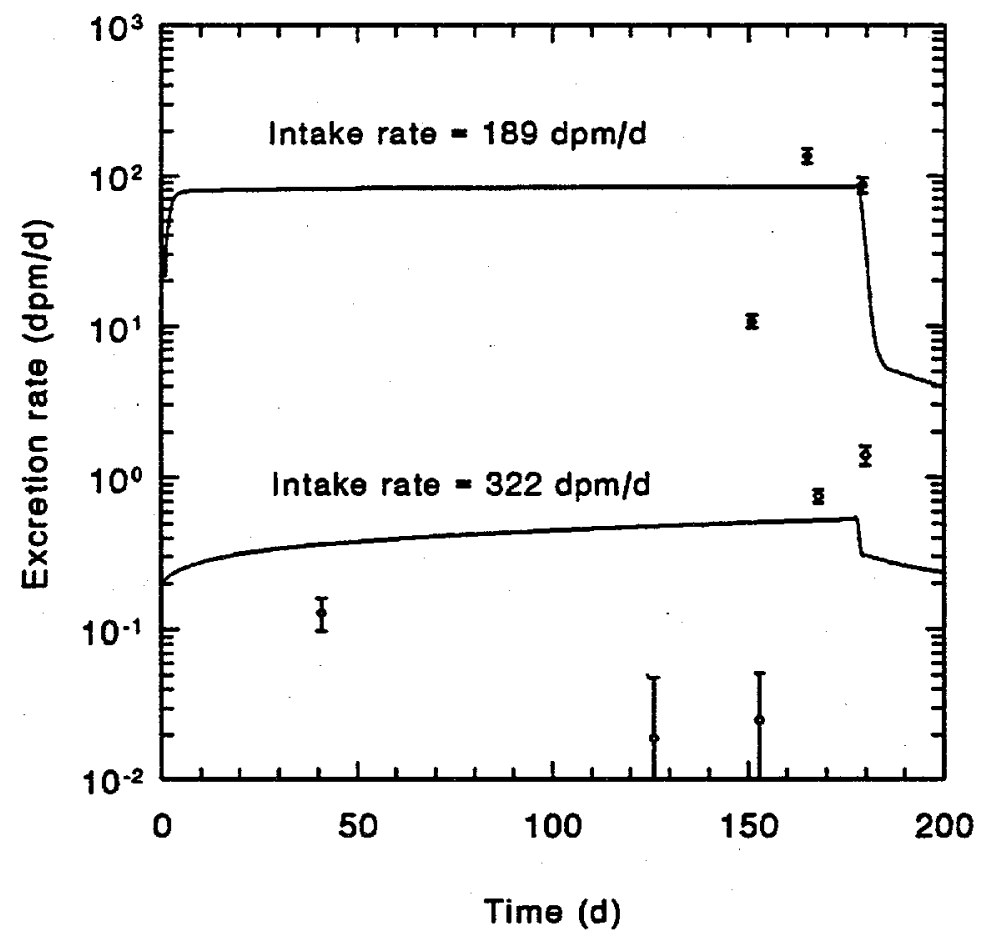

Fig. B-6. Plot of 1998 bioassay data and estimated intake rate for Employee "F" assuming exposure to Type $S$ uranium. 


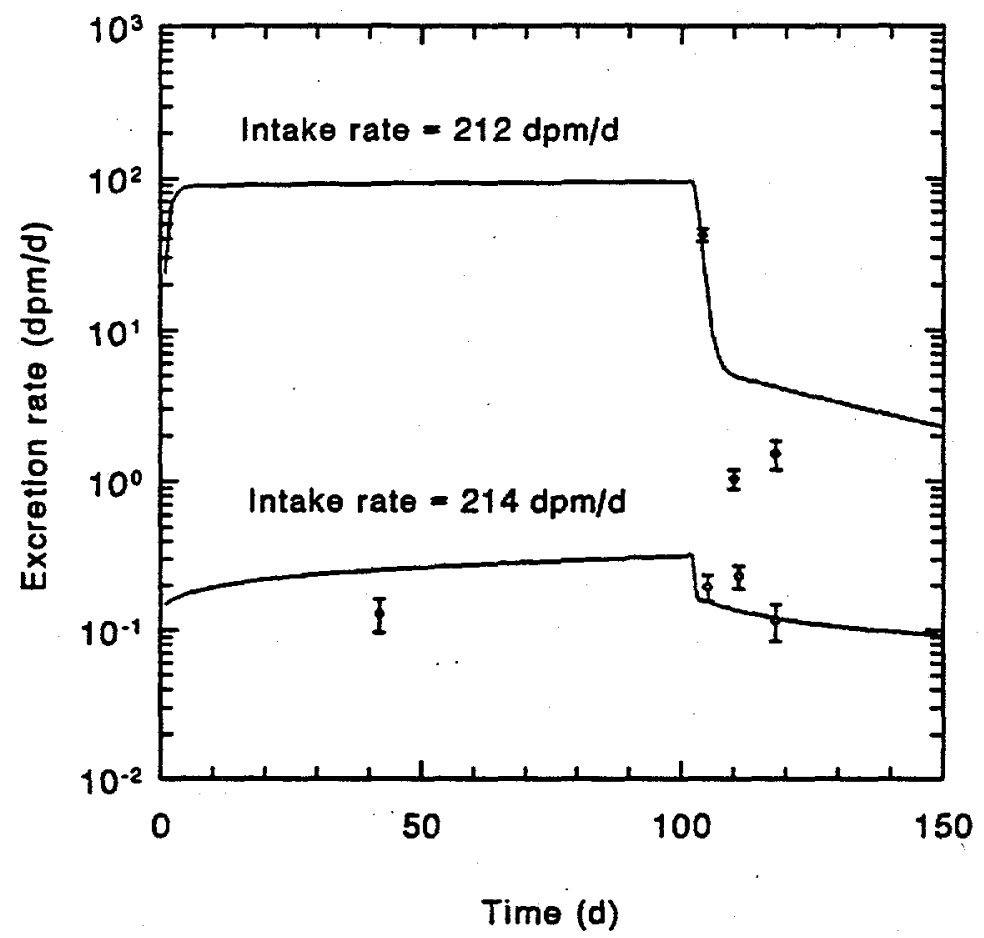

Fig. B-7. Plot of 1998 bioassay data and estimated intake rate for Employee "G" assuming exposure to Type $S$ uranium. 


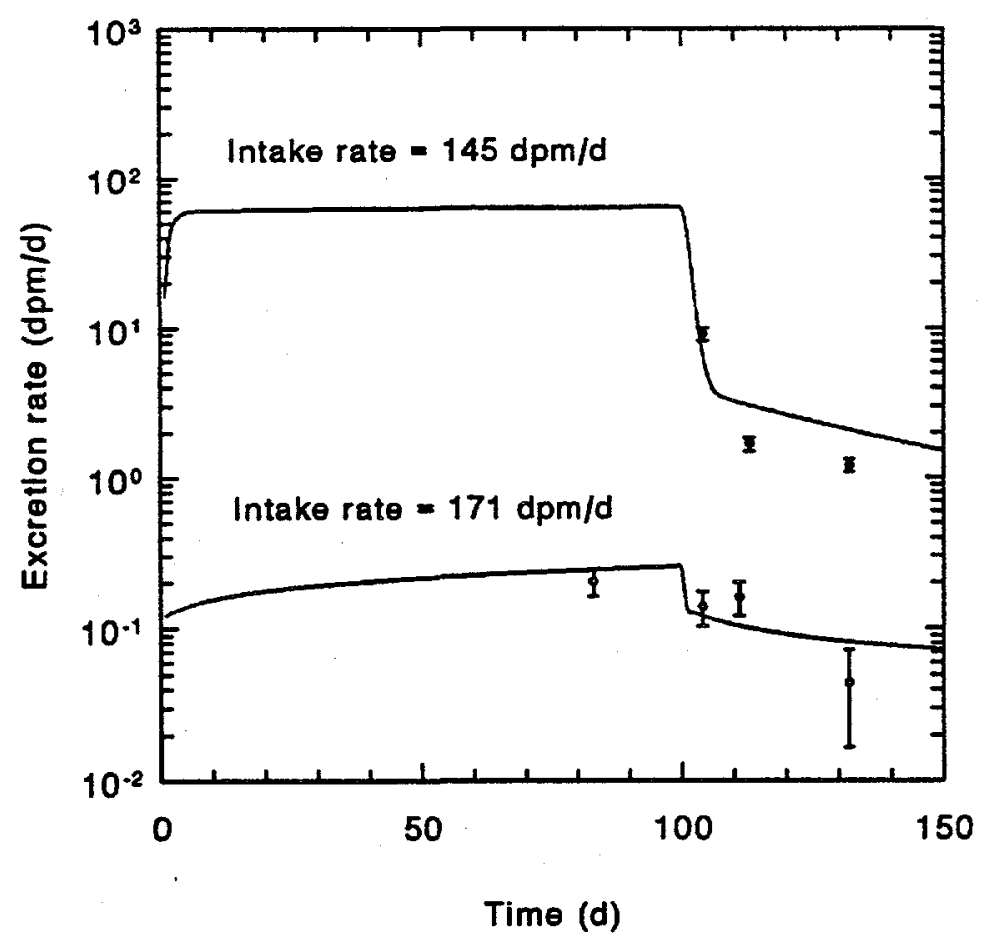

Fig. B-8. Plot of 1998 bioassay data and estimated intake rate for Employee "H" assuming exposure to Type $S$ uranium. 


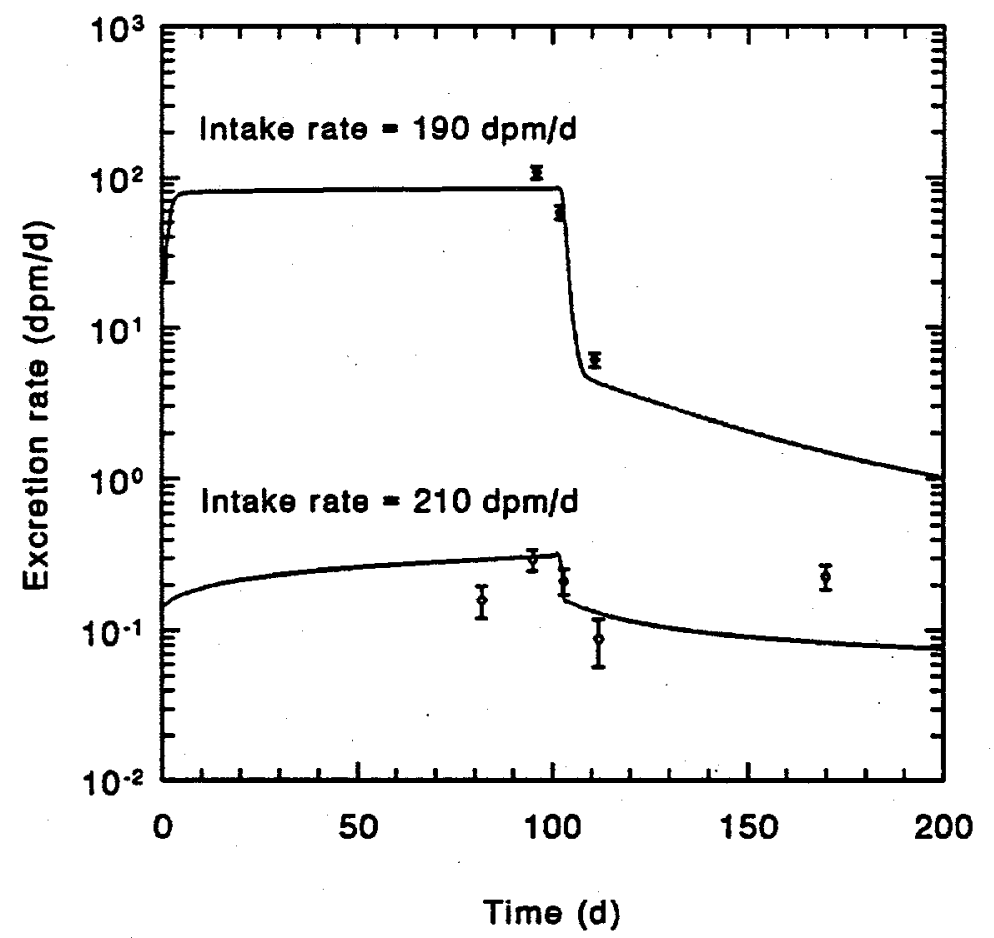

Fig. B-9. Plot of 1998 bioassay data and estimated intake rate for Employee "I" assuming exposure to Type $S$ uranium. 


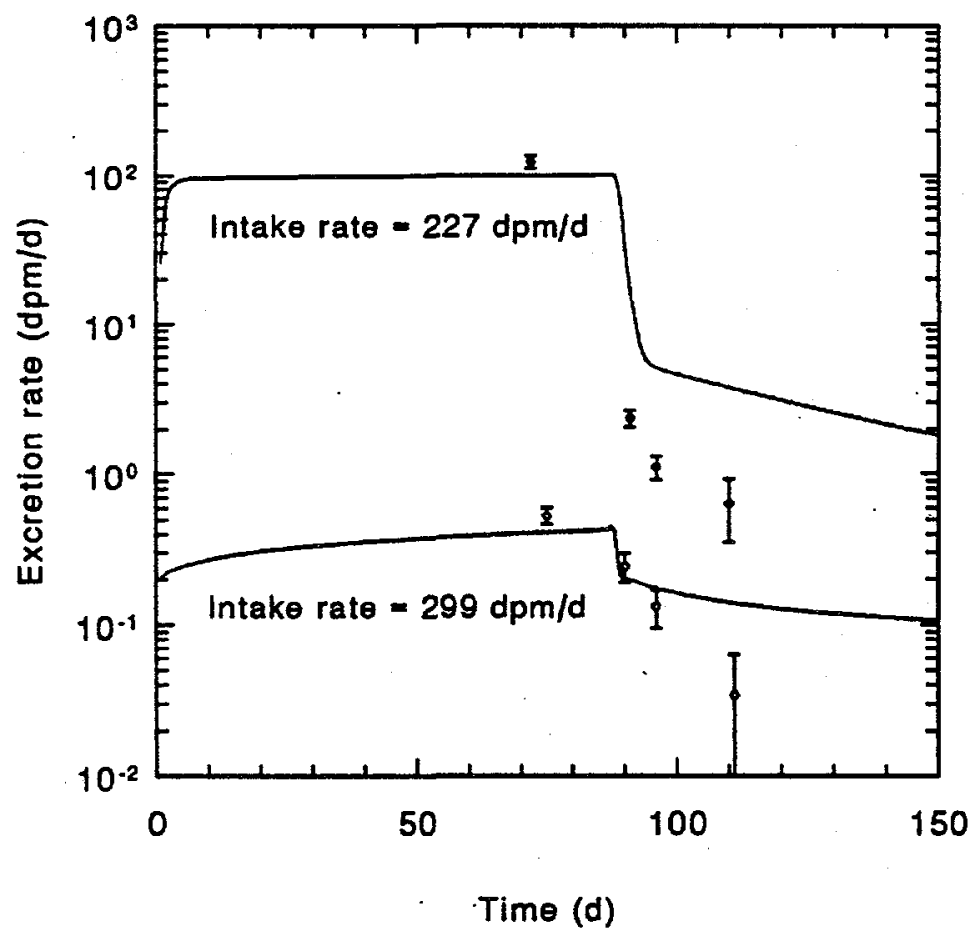

Fig. B-10. Plot of 1998 bioassay data and estimated intake rate for Employee "J" assuming exposure to Type $S$ uranium. 


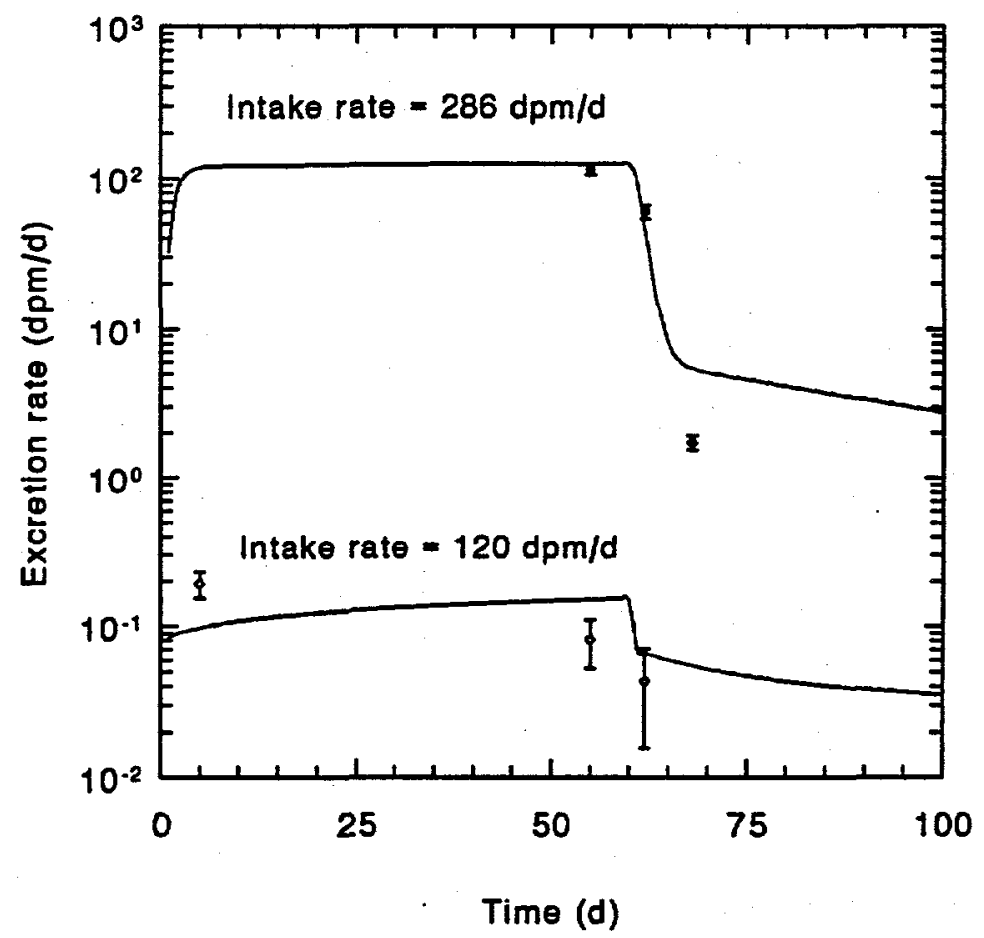

Fig. B-11. Plot of 1998 bioassay data and estimated intake rate for Employee "K" assuming exposure to Type $S$ uranium. 


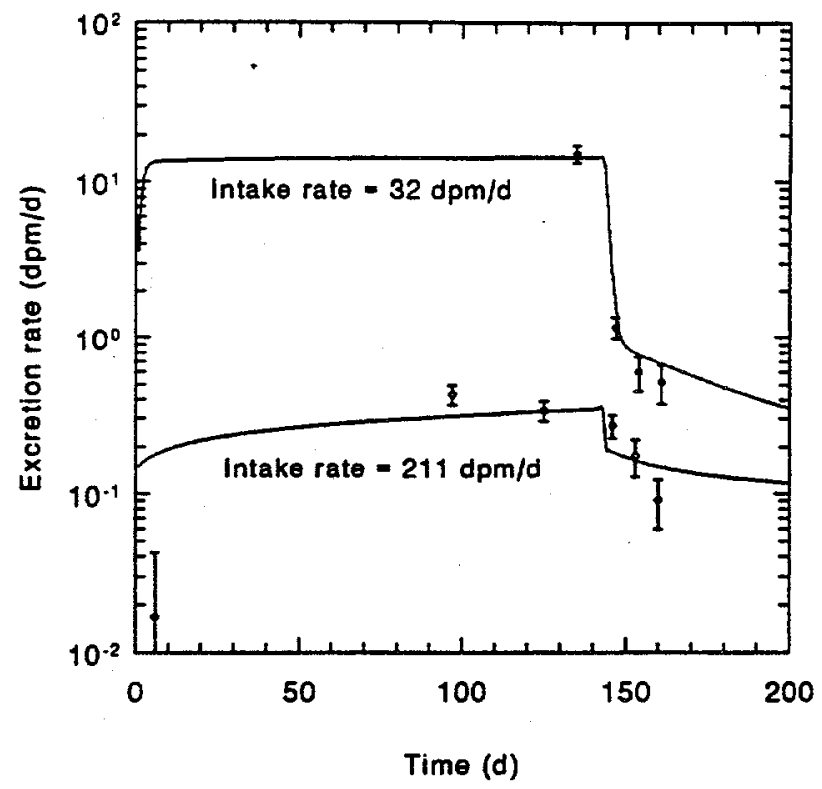

Fig. B-12a. Plot of 1998 bioassay data and estimated intake rate for Employee " $L "$ assuming exposure to Type $S$ uranium.

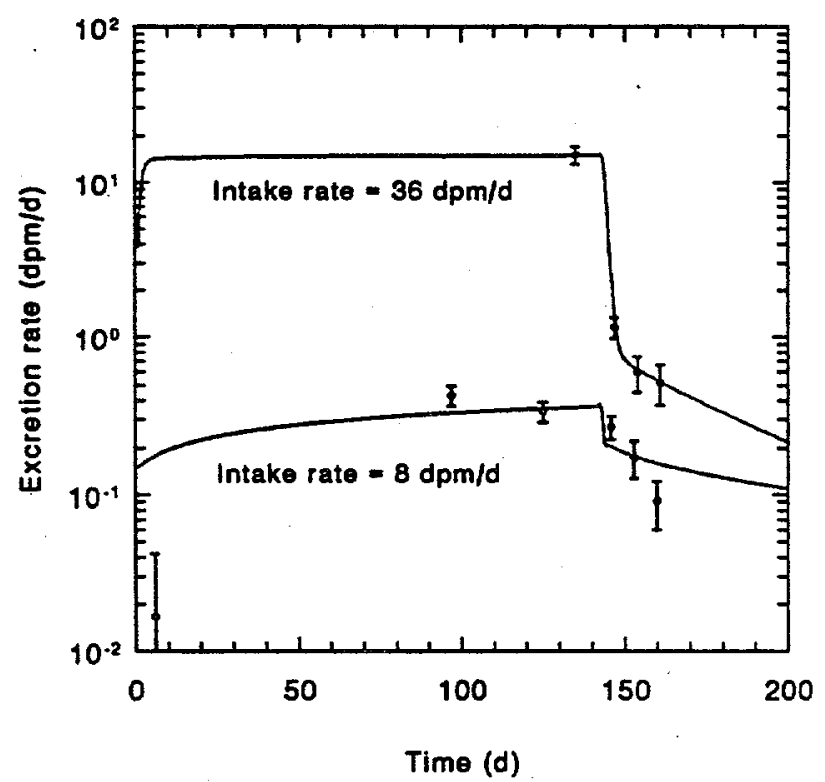

Fig. B-12b. Plot of 1998 bioassay data and estimated intake rate for Employee "L" assuming exposure to Type $M$ uranium. 


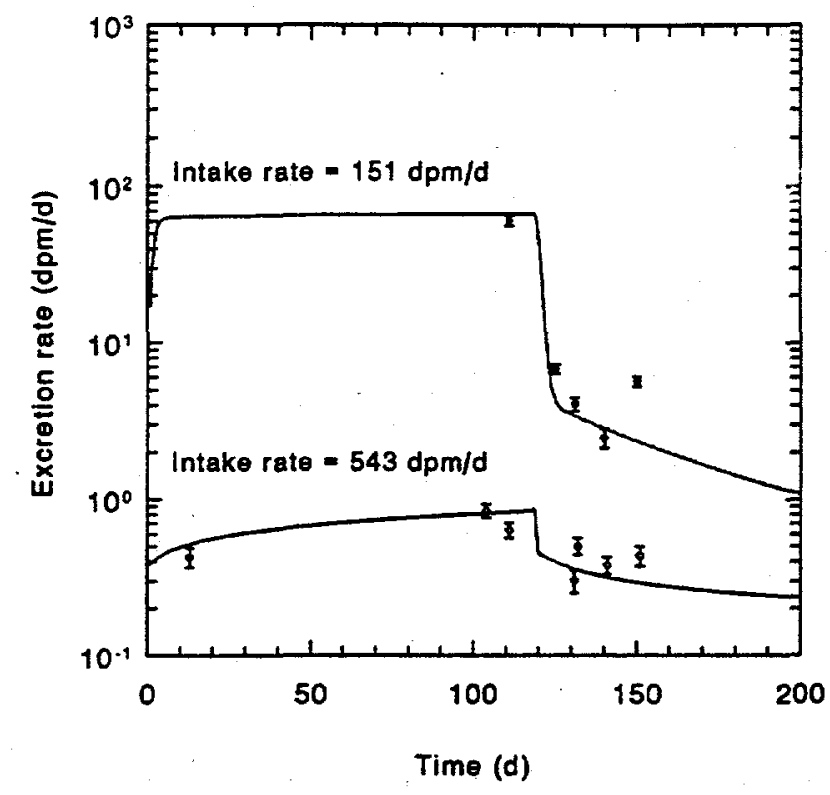

Fig. B-13a. Plot of 1998 bioassay data and estimated intake rate for Employee "M" assuming exposure to Type $S$ uranium.

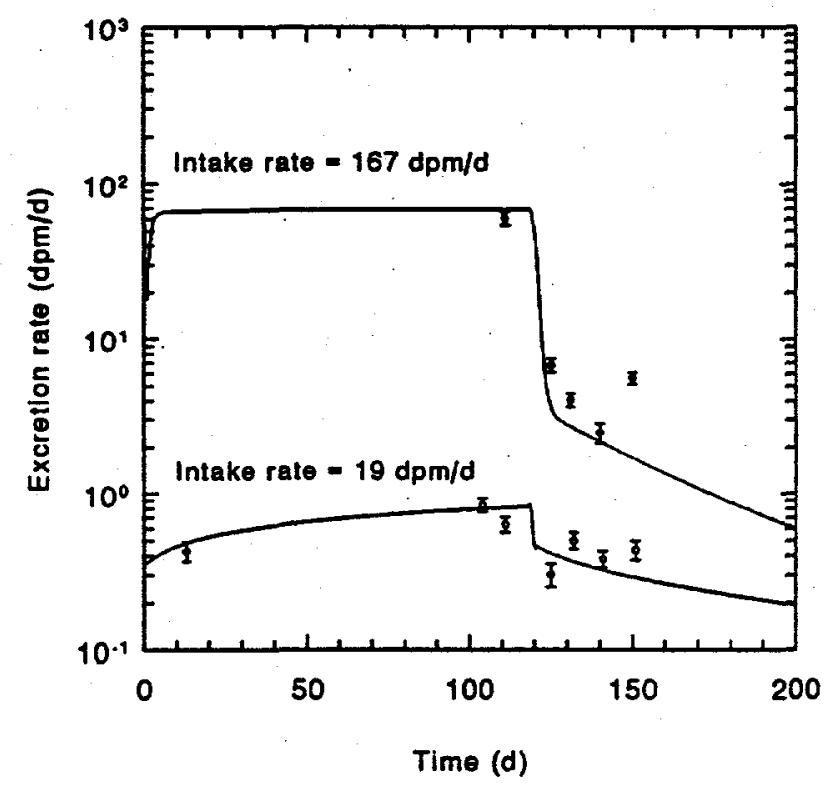

Fig. B-13b. Plot of 1998 bioassay data and estimated intake rate for Employee " $M$ " assuming exposure to Type $M$ uranium. 


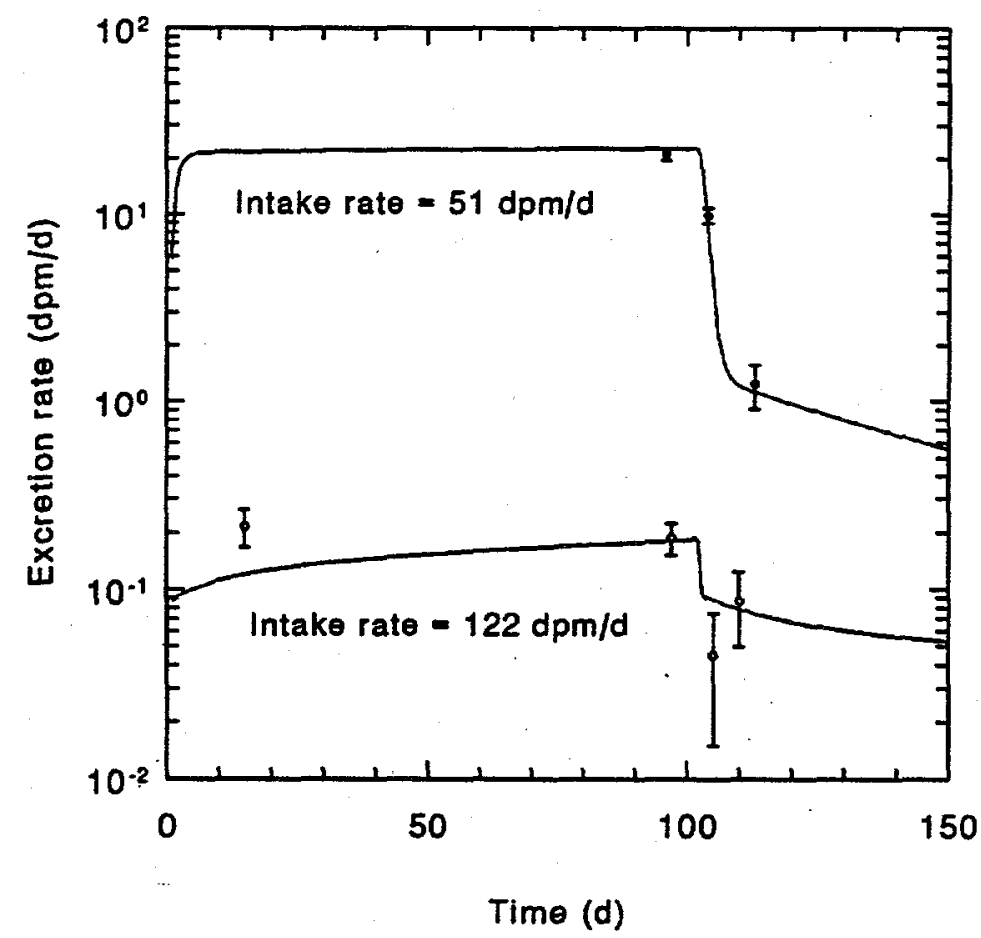

Fig. B-14. Plot of 1998 bioassay data and estimated intake rate for Employee "N" assuming exposure to Type $S$ uranium. 


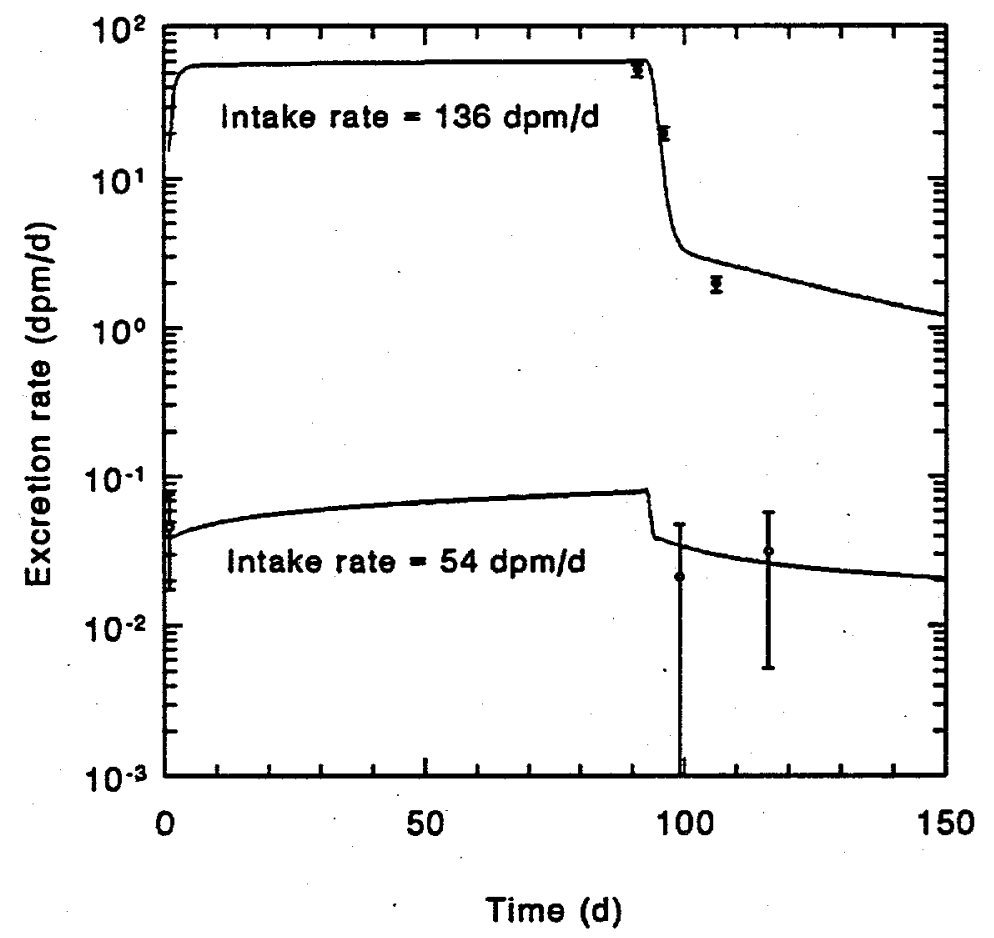

Fig. B-15. Plot of 1998 bioassay data and estimated intake rate for Employee "O" assuming exposure to Type $S$ uranium. 



\section{APPENDIX C}

\section{SUMMARY OF 1999 BIOASSAY DATA FOR SELECTED EMPLOYEES}

This appendix provides summaries of bioassay data for 10 employees who were exposed continuously to enriched uranium aerosols at the Y-12 Plant during the first four months of 1999 (see Tables $\mathrm{C}$-1 through $\mathrm{C}-10$ ). The 10 employees were selected from the group of 15 who were included in the Y-12 case studies using 1998 bioassay data (see Section 8.1 and Appendix A). Five of these 15 employees were restricted from their normal jobs for brief periods of time during the first four months of 1999, and the other 10 employees were used here to make an assessment of intakes and doses under more normal working conditions. The bioassay data summarized here starts on January 1,1999 and ends on April 30,1999. The exposures during this period of time were modeled as two periods of continuous exposure; one starting in 1998 and ending with the work restriction and the second starting on the date the employee was released from restriction in 1998 and extending to April 30, 1999. Intake rates were derived for these two periods. The dose estimates for 1999 reflect only the intake from the start of the year to April 30,1999. Figure C-1 graphically illustrates the nature of these calculations for Employees " $\mathrm{A}$ " and " $\mathrm{H}$ ".
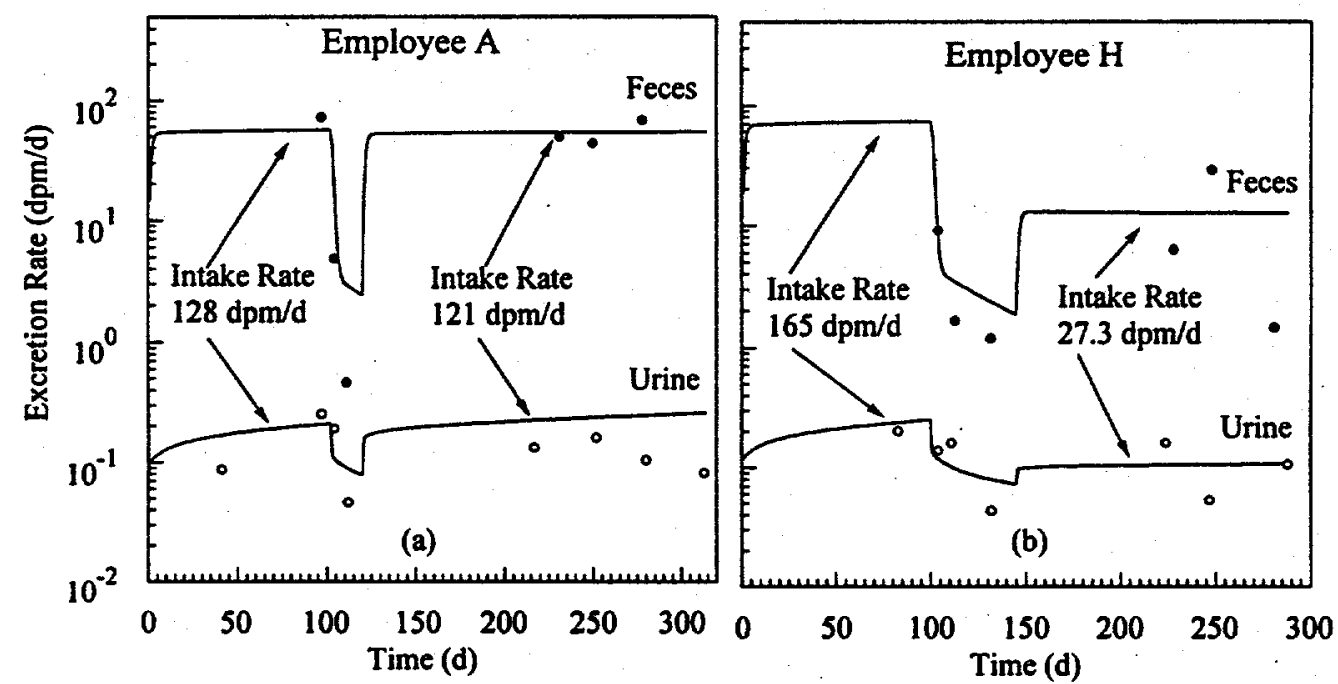

Fig. C-1. Plot of the 1998 and 1999 (to April 30, 1999) bioassay data and estimated intake rates for Employees " $A$ " and "H" assuming chronic exposures during 1998 and 1999. Employee " $A$ " was placed on work restriction on day 102 and released for work on day 121. During the first 102 days the analysis indicated the intake was a mixture of Type $M$ and $S(0.4 \% M)$ while intakes after day 121 were pure Type $S$. The exposures of Employee "H" were restricted between day 100 and day 146. During the first 100 days the analysis indicated the intakes were a mixture of Type $M$ and $S(0.1 \%$ Type $M)$ and those after day 146 also involved a mixture $(1.1 \%$ Type M). 
Table C-1. Summary of bioassay data from 1999 for Employee "A"

\begin{tabular}{||l|c|c|c|c||}
\hline Date & $\begin{array}{c}\text { Period of } \\
\text { intake }\end{array}$ & $\begin{array}{c}\text { Number of } \\
\text { days }\end{array}$ & $\begin{array}{c}\text { Fecal sample } \\
(\mathrm{dpm} / \mathrm{d})\end{array}$ & $\begin{array}{c}\text { Urine sample } \\
(\mathrm{dpm} / \mathrm{d})\end{array}$ \\
\hline \hline $10 / 07 / 98$ & Start & 0 & & $1.33 \mathrm{E}-1$ \\
\hline $01 / 11 / 99$ & $*$ & 96 & & \\
\hline $01 / 25 / 99$ & $*$ & 110 & $4.92 \mathrm{E}+1$ & $1.62 \mathrm{E}-1$ \\
\hline $02 / 13 / 99$ & $*$ & 129 & $4.42 \mathrm{E}+1$ & \\
\hline $02 / 15 / 99$ & $*$ & 131 & & $1.06 \mathrm{E}-1$ \\
\hline $03 / 13 / 99$ & $*$ & 157 & $6.88 \mathrm{E}+1$ & $8.21 \mathrm{E}-2$ \\
\hline $03 / 15 / 99$ & $*$ & 159 & & \\
\hline $04 / 17 / 99$ & $*$ & 192 & & \\
\hline $04 / 30 / 99$ & End & 205 & & \\
\hline
\end{tabular}

Normalized result minus background contribution.

Table C-2. Summary of bioassay data from 1999 for Employee "B"

\begin{tabular}{||l|c|c|c|c||}
\hline Date & $\begin{array}{c}\text { Period of } \\
\text { intake }\end{array}$ & $\begin{array}{c}\text { Number of } \\
\text { days }\end{array}$ & $\begin{array}{c}\text { Fecal sample } \\
(\mathrm{dpm} / \mathrm{d})\end{array}$ & $\begin{array}{c}\text { Urine sample } \\
(\mathrm{dpm} / \mathrm{d})\end{array}$ \\
\hline \hline $11 / 18 / 98$ & Start & 0 & & $3.51 \mathrm{E}-1$ \\
\hline $01 / 04 / 99$ & $*$ & 47 & & \\
\hline $01 / 20 / 99$ & $*$ & 63 & $1.14 \mathrm{E}+1$ & $7.67 \mathrm{E}-1$ \\
\hline $02 / 02 / 99$ & $*$ & 76 & & \\
\hline $02 / 03 / 99$ & $*$ & 77 & $1.97 \mathrm{E}+1$ & \\
\hline $03 / 07 / 99$ & $*$ & 109 & $6.34 \mathrm{E}+0$ & $5.13 \mathrm{E}-1$ \\
\hline $03 / 08 / 99$ & $*$ & 110 & & \\
\hline $03 / 29 / 99$ & $*$ & 131 & $1.49 \mathrm{E}+1$ & \\
\hline $04 / 30 / 99$ & End & 163 & & \\
\hline
\end{tabular}

a Normalized result minus background contribution. 
Table C-3. Summary of bioassay data from 1999 for Employee "C"

\begin{tabular}{||l|c|c|c|c||}
\hline Date & $\begin{array}{c}\text { Period of } \\
\text { intake }\end{array}$ & $\begin{array}{c}\text { Number of } \\
\text { days }\end{array}$ & $\begin{array}{c}\text { Fecal sample } \\
(\mathrm{dpm} / \mathrm{d})\end{array}$ & $\begin{array}{c}\text { Urine sample } \\
(\mathrm{dpm} / \mathrm{d})^{\mathrm{a}}\end{array}$ \\
\hline \hline $10 / 23 / 98$ & Start & 0 & & $4.40 \mathrm{E}-1$ \\
\hline $01 / 03 / 99$ & $*$ & 72 & & \\
\hline $01 / 04 / 99$ & $*$ & 73 & $8.60 \mathrm{E}-1$ & $5.66 \mathrm{E}-1$ \\
\hline $02 / 13 / 99$ & $*$ & 113 & & $1.73 \mathrm{E}+0$ \\
\hline $02 / 15 / 99$ & $*$ & 115 & $4.31 \mathrm{E}+0$ & \\
\hline $03 / 20 / 99$ & $*$ & 148 & & $4.63 \mathrm{E}-1$ \\
\hline $03 / 22 / 99$ & $*$ & 150 & $3.55 \mathrm{E}+1$ & \\
\hline $04 / 17 / 99$ & $*$ & 176 & & \\
\hline $04 / 19 / 99$ & $*$ & 178 & $5.83 \mathrm{E}+0$ & \\
\hline $04 / 30 / 99$ & End & 189 & & \\
\hline
\end{tabular}

aNormalized result minus background contribution.

Table C-4: Summary of bioassay data from 1999 for Employee "D"

\begin{tabular}{||l|c|c|c|c||}
\hline Date & $\begin{array}{c}\text { Period of } \\
\text { intake }\end{array}$ & $\begin{array}{c}\text { Number of } \\
\text { days }\end{array}$ & $\begin{array}{c}\text { Fecal sample } \\
(\mathrm{dpm} / \mathrm{d})\end{array}$ & $\begin{array}{c}\text { Urine sample } \\
(\mathrm{dpm} / \mathrm{d})\end{array}$ \\
\hline \hline $10 / 26 / 98$ & Start & 0 & & \\
\hline $01 / 14 / 99$ & $*$ & 80 & & $1.28 \mathrm{E}-1$ \\
\hline $01 / 18 / 99$ & $*$ & 84 & $1.91 \mathrm{E}+1$ & \\
\hline $01 / 30 / 99$ & $*$ & 96 & $1.03 \mathrm{E}+1$ & $1.32 \mathrm{E}-1$ \\
\hline $02 / 14 / 99$ & $*$ & 111 & & $4.94 \mathrm{E}-1$ \\
\hline $03 / 14 / 99$ & $*$ & 139 & & $5.97 \mathrm{E}-1$ \\
\hline $03 / 15 / 99$ & $*$ & 140 & & \\
\hline $04 / 03 / 99$ & $*$ & 159 & $4.91 \mathrm{E}-1$ & \\
\hline $04 / 12 / 99$ & $*$ & 168 & & \\
\hline $04 / 30 / 99$ & End & 186 & & \\
\hline
\end{tabular}

Aormalized result minus background contribution. 
Table C-5. Summary of bioassay data from 1999 for Employee "G"

\begin{tabular}{|c|c|c|c|c|}
\hline Date & $\begin{array}{c}\text { Period of } \\
\text { intake }\end{array}$ & $\begin{array}{c}\text { Number of } \\
\text { days }\end{array}$ & $\begin{array}{c}\text { Fecal sample } \\
(\mathrm{dpm} / \mathrm{d})^{\mathrm{a}}\end{array}$ & $\begin{array}{c}\text { Urine sample } \\
(\mathrm{dpm} / \mathrm{d})^{\mathrm{a}}\end{array}$ \\
\hline $10 / 14 / 98$ & Start & 0 & & \\
\hline $01 / 15 / 99$ & * & 93 & $5.78 E+0$ & \\
\hline $01 / 24 / 99$ & * & 102 & & $1.38 \mathrm{E}-1$ \\
\hline 02/12/99 & * & 121 & $8.07 \mathrm{E}+0$ & \\
\hline $02 / 21 / 99$ & * & 130 & & $4.33 E-2$ \\
\hline 03/07/99 & $*$ & 144 & & $8.76 E-2$ \\
\hline $03 / 10 / 99$ & * & 147 & $4.37 \mathrm{E}+0$ & \\
\hline 03/14/99 & * & 151 & & $1.89 E-1$ \\
\hline 03/18/99 & * & 155 & $5.78 \mathrm{E}+0$ & \\
\hline 04/18/99 & * & 186 & & $6.97 \mathrm{E}-2$ \\
\hline $04 / 21 / 99$ & * & 189 & $1.37 \mathrm{E}+0$ & \\
\hline $04 / 30 / 99$ & End & 198 & & \\
\hline
\end{tabular}

a Normalized result minus background contribution.

Table C-6. Summary of bioassay data from 1999 for Employee "H"

\begin{tabular}{||l|c|c|c|c|}
\hline Date & $\begin{array}{c}\text { Period of } \\
\text { intake }\end{array}$ & $\begin{array}{c}\text { Number of } \\
\text { days }\end{array}$ & $\begin{array}{c}\text { Fecal sample } \\
(\mathrm{dpm} / \mathrm{d})\end{array}$ & $\begin{array}{c}\text { Urine sample } \\
(\mathrm{dpm} / \mathrm{d})\end{array}$ \\
\hline \hline $11 / 01 / 98$ & Start & 0 & & \\
\hline $01 / 18 / 99$ & $*$ & 78 & & $1.63 \mathrm{E}-1$ \\
\hline $01 / 22 / 99$ & $*$ & 82 & $6.42 \mathrm{E}+0$ & \\
\hline $02 / 10 / 99$ & $*$ & 101 & & $5.37 \mathrm{E}-2$ \\
\hline $02 / 11 / 99$ & $*$ & 102 & $2.89 \mathrm{E}+1$ & \\
\hline $03 / 16 / 99$ & $*$ & 135 & $1.47 \mathrm{E}+0$ & $1.07 \mathrm{E}-1$ \\
\hline $03 / 23 / 99$ & $*$ & 142 & & \\
\hline $04 / 30 / 99$ & End & 180 & & \\
\hline
\end{tabular}

a Normalized result minus background contribution. 
Table C-7. Summary of bioassay data from 1999 for Employee "I"

\begin{tabular}{||c|c|c|c|c|}
\hline Date & $\begin{array}{c}\text { Period of } \\
\text { intake }\end{array}$ & $\begin{array}{c}\text { Number of } \\
\text { days }\end{array}$ & $\begin{array}{c}\text { Fecal sample } \\
(\mathrm{dpm} / \mathrm{d})\end{array}$ & $\begin{array}{c}\text { Urine sample } \\
(\mathrm{dpm} / \mathrm{d})\end{array}$ \\
\hline \hline $11 / 18 / 98$ & Start & 0 & & \\
\hline $01 / 17 / 99$ & $*$ & 60 & & $1.08 \mathrm{E}-1$ \\
\hline $01 / 20 / 99$ & $*$ & 63 & $2.50 \mathrm{E}+1$ & $8.46 \mathrm{E}-1$ \\
\hline $02 / 20 / 99$ & $*$ & 94 & & $1.42 \mathrm{E}-1$ \\
\hline $02 / 21 / 99$ & $*$ & 95 & $2.19 \mathrm{E}+1$ & \\
\hline $09 / 13 / 99$ & $*$ & 115 & $5.17 \mathrm{E}+0$ & $1.75 \mathrm{E}-1$ \\
\hline $04 / 06 / 99$ & $*$ & 139 & $4.65 \mathrm{E}+0$ & \\
\hline $04 / 07 / 98$ & $*$ & 140 & & \\
\hline $04 / 30 / 99$ & End & 163 & & \\
\hline
\end{tabular}

ârmalized result minus background contribution.

Table C-8. Summary of bioassay data from 1999 for Employee "J"

\begin{tabular}{||c|c|c|c|c||}
\hline Date & $\begin{array}{c}\text { Period of } \\
\text { intake }\end{array}$ & $\begin{array}{c}\text { Number of } \\
\text { days }\end{array}$ & $\begin{array}{c}\text { Fecal sample } \\
(\mathrm{dpm} / \mathrm{d})\end{array}$ & $\begin{array}{c}\text { Urine sample } \\
\text { (dpm/d) }\end{array}$ \\
\hline $10 / 01 / 98$ & Start & 0 & & $4.00 \mathrm{E}-1$ \\
\hline $01 / 09 / 99$ & $*$ & 100 & & \\
\hline $01 / 11 / 99$ & $*$ & 102 & $1.55 \mathrm{E}+1$ & $1.82 \mathrm{E}-1$ \\
\hline $01 / 29 / 99$ & $*$ & 120 & $1.14 \mathrm{E}+1$ & $1.25 \mathrm{E}-1$ \\
\hline $01 / 31 / 99$ & $*$ & 122 & & $1.22 \mathrm{E}-1$ \\
\hline $02 / 28 / 99$ & $*$ & 150 & & \\
\hline $03 / 01 / 99$ & $*$ & 151 & $1.61 \mathrm{E}+1$ & \\
\hline $03 / 28 / 99$ & $*$ & 178 & & \\
\hline $03 / 29 / 99$ & $*$ & 179 & $2.10 \mathrm{E}+1$ & \\
\hline $04 / 25 / 99$ & $*$ & 206 & & \\
\hline $04 / 30 / 99$ & End & 211 & & \\
\hline
\end{tabular}

a Normalized result minus background contribution. 
Table C-9. Summary of bioassay data from 1999 for Employee "K"

\begin{tabular}{|l|c|c|c|c|}
\hline Date & $\begin{array}{c}\text { Period of } \\
\text { intake }\end{array}$ & $\begin{array}{c}\text { Number of } \\
\text { days }\end{array}$ & $\begin{array}{c}\text { Fecal sample } \\
(\mathrm{dpm} / \mathrm{d})\end{array}$ & $\begin{array}{c}\text { Urine sample } \\
(\mathrm{dpm} / \mathrm{d})\end{array}$ \\
\hline \hline $10 / 13 / 98$ & Start & 0 & & \\
\hline $01 / 18 / 99$ & $*$ & 97 & & $4.62 \mathrm{E}-2$ \\
\hline $01 / 19 / 99$ & $*$ & 98 & $3.86 \mathrm{E}+0$ & \\
\hline $02 / 16 / 99$ & $*$ & 126 & $1.51 \mathrm{E}-1$ & $4.66 \mathrm{E}-2$ \\
\hline $02 / 17 / 99$ & $*$ & 127 & & $2.02 \mathrm{E}-1$ \\
\hline $03 / 01 / 99$ & $*$ & 139 & $6.14 \mathrm{E}-1$ & $5.68 \mathrm{E}-2$ \\
\hline $03 / 02 / 99$ & $*$ & 140 & & \\
\hline $03 / 30 / 99$ & $*$ & 168 & $1.77 \mathrm{E}+1$ & \\
\hline $04 / 30 / 99$ & End & 199 & & \\
\hline
\end{tabular}

aNormalized result minus background contribution.

Table C-10. Summary of bioassay data from 1999 for Employee "N"

\begin{tabular}{||l|c|c|c|c||}
\hline Date & $\begin{array}{c}\text { Period of } \\
\text { intake }\end{array}$ & $\begin{array}{c}\text { Number of } \\
\text { days }\end{array}$ & $\begin{array}{c}\text { Fecal sample } \\
(\mathrm{dpm} / \mathrm{d})\end{array}$ & $\begin{array}{c}\text { Urine sample } \\
(\mathrm{dpm} / \mathrm{d})\end{array}$ \\
\hline \hline $10 / 14 / 98$ & Start & 0 & & $1.81 \mathrm{E}-1$ \\
\hline $01 / 20 / 99$ & $*$ & 98 & $1.72 \mathrm{E}+1$ & $2.61 \mathrm{E}-1$ \\
\hline $02 / 18 / 99$ & $*$ & 127 & $3.55 \mathrm{E}+1$ & $1.27 \mathrm{E}-1$ \\
\hline $03 / 21 / 99$ & $*$ & 158 & $6.47 \mathrm{E}+1$ & \\
\hline $04 / 12 / 99$ & $*$ & 180 & $2.10 \mathrm{E}+1$ & $1.65 \mathrm{E}-1$ \\
\hline $04 / 15 / 99$ & $*$ & 183 & & \\
\hline $04 / 30 / 99$ & End & 198 & & \\
\hline
\end{tabular}

Normalized result minus background contribution. 


\section{APPENDIX D \\ SUMMARY OF 1999 PERSONAL AIR MONITORING DATA FOR SELECTED EMPLOYEES}

The air sampling data for Employee "A" from the first four months of 1999 are summarized in Table D-1. These air sampling data were obtained using the personnel air monitoring $(P A M)$ devices discussed in Section 8.4. The counts of the ${ }^{234} \mathrm{U}$ activity on the air filter of these devices and other data such as the air sampling time and air flow rate were used to determine the worker's exposure to enriched uranium aerosols in terms of the Derived Air Concentration $(D A C)$ for a Class Y aerosol of ${ }^{234} \mathrm{U}$ assuming an $A M A D$ of $1 \mu \mathrm{m}$ (see $10 \mathrm{CFR} 835$ ). The $D A C$-fraction and $D A C$-hour values in Table D-1 have been reduced by an appropriate respirator protection factor if a respiratory was worn by the employee during the exposure. A respiratory protection factor of 1 indicates that the employee was not wearing a respiratory; thus, no reduction was made in the $D A C$-fraction or $D A C$ hour values in Table D-1. The $D A C$ for a Class Y aerosol of ${ }^{234} \mathrm{U}$ is $2 \times 10^{-11} \mu \mathrm{Ci} / \mathrm{cm}^{3}$ (see $10 \mathrm{CFR}$ 835) and the DAC-hour for a Class $\mathrm{Y}$ aerosol is simply $2 \times 10^{-11} \mu \mathrm{Ci}-\mathrm{hr} / \mathrm{cm}^{3}$. To convert a $D A C$ hour to a ${ }^{234} \mathrm{U}$ activity intake, we use a value of $2 \times 10^{-11} \mu \mathrm{Ci}-\mathrm{hr} / \mathrm{cm}^{3}$ multiplied by a breathing rate of $1.2 \mathrm{~m}^{3} / \mathrm{hr}\left(1.2 \times 10^{6} \mathrm{~cm}^{3} / \mathrm{hr}\right)$ for light exercise (ICRP 1975) or $2.4 \times 10^{-5} \mu \mathrm{Ci}$, and to convert a $D A C$-hour to a dose, we use a value of $2.5 \mathrm{mrem}$ which follows from the definition of a $D A C$ (see 10 CFR 835). The total $D A C$-hour exposure to Employee "A" during the first four months of 1999 based on the PAM data is 29.1 (see Table D-2). Thus, the estimated total dose to Employee "A" for the first four months of 1999 assuming exposure to a Class Y aerosol of ${ }^{234} \mathrm{U}$ with an $A M A D$ of $1 \mu \mathrm{m}$ is 29.1 multiplied by $2.5 \mathrm{mrem}$ or $73 \mathrm{mrem}(0.73 \mathrm{mSv})$, and his estimated total intake of ${ }^{234} \mathrm{U}$ for the first four months of 1999 is 29.1 multiplied by $2.4 \times 10^{-5} \mu \mathrm{Ci}$ or $6.98 \times 10^{-4} \mu \mathrm{Ci}\left(2.58 \times 10^{1} \mathrm{~Bq}\right)$. 
Table D-1. Summary of 1999 air sampling data for Employee "A".

\begin{tabular}{|c|c|c|c|c|c|}
\hline Date & Respirator & $\begin{array}{l}\text { Protection } \\
\text { factor }\end{array}$ & $\begin{array}{c}\text { Sample time } \\
\text { (minutes) }\end{array}$ & $\begin{array}{c}\text { DAC } \\
\text { fraction }\end{array}$ & DAC-hour \\
\hline $1 / 04 / 99$ & Yes & 50 & 112 & 0.14 & 0.26 \\
\hline $1 / 04 / 99$ & No & 1 & 111 & $<0.06$ & $<0.12$ \\
\hline $1 / 06 / 99$ & Yes & 50 & 217 & 0.08 & 0.29 \\
\hline $1 / 07 / 99$ & Yes & 50 & 205 & 0.11 & 0.38 \\
\hline $1 / 08 / 99$ & No & 1 & 217 & $<0.03$ & $<0.12$ \\
\hline $1 / 11 / 99$ & Yes & 50 & 96 & $<0.07$ & $<0.12$ \\
\hline $1 / 11 / 99$ & No & 1 & 87 & $<0.08$ & $<0.12$ \\
\hline $1 / 11 / 99$ & Yes & 50 & 131 & 0.07 & 0.14 \\
\hline $1 / 12 / 99$ & Yes & 50 & 96 & $<0.07$ & $<0.12$ \\
\hline $1 / 12 / 99$ & Yes & 25 & 103 & 0.17 & 0.29 \\
\hline $1 / 13 / 99$ & Yes & 50 & 142 & 0.38 & 0.89 \\
\hline $1 / 13 / 99$ & Yes & 50 & 207 & 0.09 & 0.31 \\
\hline $1 / 14 / 99$ & Yes & 25 & 42 & 0.17 & 0.12 \\
\hline $1 / 14 / 99$ & No & 1 & 165 & 0.22 & 0.60 \\
\hline $1 / 15 / 99$ & Yes & 50 & 281 & 0.09 & 0.41 \\
\hline $1 / 19 / 99$ & Yes & 50 & 115 & 0.10 & 0.19 \\
\hline $1 / 19 / 99$ & Yes & 50 & 142 & $<0.05$ & $<0.12$ \\
\hline $1 / 20 / 99$ & Yes & 50 & 92 & 0.08 & 0.12 \\
\hline $1 / 20 / 99$ & Yes & 50 & 111 & 0.09 & 0.17 \\
\hline $1 / 21 / 99$ & Yes & 50 & 104 & 0.47 & 0.82 \\
\hline $1 / 21 / 99$ & No & 1 & 133 & 0.72 & 1.59 \\
\hline $1 / 21 / 99$ & Yes & 50 & 144 & 0.10 & 0.24 \\
\hline $1 / 22 / 99$ & Yes & 50 & 99 & 0.15 & 0.24 \\
\hline $1 / 25 / 99$ & Yes & 50 & 99 & 0.12 & 0.19 \\
\hline $1 / 26 / 99$ & No & 1 & 450 & 0.06 & 0.48 \\
\hline $1 / 27 / 99$ & No & 1 & 182 & $<0.04$ & $<0.12$ \\
\hline $1 / 27 / 99$ & No & 1 & 240 & 0.22 & 0.87 \\
\hline $1 / 28 / 99$ & No & 1 & 24 & 0.21 & 0.09 \\
\hline $1 / 28 / 99$ & No & 1 & 130 & 0.19 & 0.41 \\
\hline $1 / 28 / 99$ & Yes & 50 & 110 & 0.14 & 0.26 \\
\hline $1 / 29 / 99$ & Yes & 25 & 292 & 0.51 & 2.50 \\
\hline $2 / 01 / 99$ & Yes & 50 & 216 & 0.15 & 0.55 \\
\hline $2 / 01 / 99$ & Yes & 25 & 137 & 0.09 & 0.22 \\
\hline $2 / 02 / 99$ & Yes & 25 & 128 & 0.11 & 0.24 \\
\hline $2 / 02 / 99$ & Yes & 25 & 283 & 0.51 & 2.40 \\
\hline $2 / 03 / 99$ & Yes & 25 & 142 & 2.32 & 5.50 \\
\hline $2 / 04 / 99$ & No & 1 & 100 & 0.30 & 0.50 \\
\hline $2 / 08 / 99$ & Yes & 25 & 409 & 0.18 & 1.22 \\
\hline $2 / 09 / 99$ & Yes & 50 & 139 & 0.06 & 0 \\
\hline $2 / 09 / 99$ & Yes & 25 & 275 & 0.22 & 0.04 \\
\hline $2 / 10 / 99$ & Yes & 50 & 119 & 0.30 & 0.01 \\
\hline $2 / 10 / 99$ & Yes & 25 & 289 & 0.44 & 0.09 \\
\hline $2 / 12 / 99$ & Yes & 25 & 252 & 0.31 & 0.05 \\
\hline $2 / 15 / 99$ & Yes & 25 & 253 & $<0.03$ & 0 \\
\hline $2 / 16 / 99$ & Yes & 25 & 86 & 0.08 & 0 \\
\hline $2 / 16 / 99$ & Yes & 50 & 140 & 0.09 & 0 \\
\hline $2 / 17 / 99$ & Yes & 25 & 229 & 0.50 & 0.08 \\
\hline
\end{tabular}


Table D-1. Continued.

\begin{tabular}{|c|c|c|c|c|c|}
\hline Date & Respirator & $\begin{array}{c}\text { Protection } \\
\text { factor }\end{array}$ & $\begin{array}{c}\text { Sample time } \\
\text { (minutes) }\end{array}$ & $\begin{array}{c}\mathrm{DAC} \\
\text { fraction } \\
\end{array}$ & DAC-hour \\
\hline $2 / 18 / 99$ & Yes & 25 & 284 & 0.12 & 0.02 \\
\hline $2 / 19 / 99$ & Yes & 25 & 270 & 0.12 & 0.02 \\
\hline $2 / 22 / 99$ & No & 1 & 24 & 0.18 & 0.07 \\
\hline $2 / 22 / 99$ & Yes & 25 & 133 & 0.12 & 0.01 \\
\hline $2 / 23 / 99$ & Yes & 25 & 257 & 0.10 & 0.02 \\
\hline $2 / 24 / 99$ & Yes & 50 & 128 & $<0.05$ & 0 \\
\hline $2 / 24 / 99$ & No & 1 & 146 & 0.08 & 0.19 \\
\hline $2 / 25 / 99$ & Yes & 25 & 217 & $<0.03$ & 0 \\
\hline $2 / 25 / 99$ & No & 1 & 46 & $<0.15$ & $<0.12$ \\
\hline $2 / 26 / 99$ & Yes & 25 & 210 & $<0.03$ & 0 \\
\hline $3 / 01 / 99$ & No & 1 & 129 & $<0.05$ & $<0.12$ \\
\hline $3 / 01 / 99$ & Yes & 25 & 270 & 0.23 & 0.04 \\
\hline $3 / 02 / 99$ & No & 1 & 32 & 0.36 & 0.19 \\
\hline $3 / 02 / 99$ & Yes & 25 & 137 & 0.05 & 0 \\
\hline $3 / 02 / 99$ & Yes & 25 & 151 & $<0.05$ & 0 \\
\hline $3 / 03 / 99$ & Yes & 25 & 256 & 0.56 & 0.09 \\
\hline $3 / 03 / 99$ & Yes & 25 & 139 & 0.19 & 0.02 \\
\hline $3 / 04 / 99$ & Yes & 25 & 279 & 0.11 & 0.02 \\
\hline $3 / 04 / 99$ & Yes & 25 & 129 & 0.09 & 0.01 \\
\hline $3 / 05 / 99$ & Yes & 25 & 226 & 0.22 & 0.03 \\
\hline $3 / 08 / 99$ & Yes & 25 & 273 & 0.13 & 0.02 \\
\hline $3 / 09 / 99$ & Yes & 25 & 135 & 0.14 & 0.01 \\
\hline $3 / 09 / 99$ & Yes & 25 & 240 & 0.08 & 0.01 \\
\hline $3 / 10 / 99$ & No. & 1 & 125 & 0.15 & 0.32 \\
\hline $3 / 10 / 99$ & Yes & 25 & 233 & 0.13 & 0.02 \\
\hline $3 / 11 / 99$ & No & 1 & 106 & $<0.07$ & $<0.12$ \\
\hline $3 / 11 / 99$ & Yes & 25 & 119 & $<0.06$ & 0 \\
\hline $3 / 12 / 99$ & Yes & 25 & 110 & 0.31 & 0.02 \\
\hline $3 / 12 / 99$ & Yes & 50 & 110 & 0.14 & 0.01 \\
\hline $3 / 15 / 99$ & Yes & 25 & 124 & 0.34 & 0.03 \\
\hline $3 / 15 / 99$ & Yes & 50 & 116 & 0.53 & 0.02 \\
\hline $3 / 16 / 99$ & Yes & 25 & 144 & 3.12 & 0.30 \\
\hline $3 / 16 / 99$ & Yes & 50 & 122 & 0.22 & 0.01 \\
\hline $3 / 17 / 99$ & Yes & 50 & 199 & 0.14 & 0.01 \\
\hline $3 / 17 / 99$ & Yes & 25 & 144 & 0.05 & 0.01 \\
\hline $3 / 18 / 99$ & Yes & 50 & 115 & $<0.06$ & 0 \\
\hline $3 / 20 / 99$ & Yes & 25 & 125 & 0.28 & 0.02 \\
\hline $3 / 20 / 99$ & Yes & 25 & 114 & 0.74 & 0.06 \\
\hline $3 / 22 / 99$ & Yes & 25 & 169 & 0.14 & 0.02 \\
\hline $3 / 22 / 99$ & Yes & 50 & 279 & 0.14 & 0.01 \\
\hline $3 / 23 / 99$ & Yes & 25 & 229 & 0.23 & 0.03 \\
\hline $3 / 24 / 99$ & Yes & 25 & 269 & 0.76 & 0.14 \\
\hline $3 / 25 / 99$ & Yes & 25 & 120 & 0.76 & 0.06 \\
\hline $3 / 25 / 99$ & No & 1 & 86 & 0.20 & 0.29 \\
\hline $3 / 29 / 99$ & No & 1 & 85 & 0.09 & 0.13 \\
\hline $3 / 29 / 99$ & Yes & 25 & 74 & 1.14 & 0.06 \\
\hline $4 / 01 / 99$ & Yes & 25 & 86 & 0.13 & 0.01 \\
\hline
\end{tabular}


Table D-1. Continued.

\begin{tabular}{|c|c|c|c|c|c|}
\hline Date & Respirator & $\begin{array}{c}\text { Protection } \\
\text { factor }\end{array}$ & $\begin{array}{c}\text { Sample time } \\
\text { (minutes) }\end{array}$ & $\begin{array}{c}\text { DAC } \\
\text { fraction }\end{array}$ & DAC-hour \\
\hline $4 / 05 / 99$ & Yes & 25 & 214 & 0.04 & 0.01 \\
$4 / 06 / 99$ & Yes & 25 & 267 & 1.86 & 0.33 \\
$4 / 07 / 99$ & Yes & 25 & 276 & 1.14 & 0.21 \\
$4 / 08 / 99$ & Yes & 25 & 136 & 0.06 & 0.01 \\
$4 / 12 / 99$ & No & 1 & 162 & $<0.04$ & $<0.12$ \\
$4 / 13 / 99$ & Yes & 25 & 503 & 0.28 & 0.09 \\
$4 / 14 / 99$ & Yes & 25 & 161 & 0.57 & 0.06 \\
$4 / 14 / 99$ & Yes & 25 & 106 & 0.11 & 0.01 \\
$4 / 14 / 99$ & Yes & 25 & 141 & 0.41 & 0.04 \\
$4 / 15 / 99$ & Yes & 25 & 420 & 0.23 & 0.06 \\
$4 / 16 / 99$ & Yes & 25 & 95 & 0.60 & 0.04 \\
$4 / 19 / 99$ & Yes & 25 & 212 & $<0.03$ & 0 \\
$4 / 20 / 99$ & Yes & 25 & 77 & 1.95 & 0.10 \\
$4 / 20 / 99$ & No & 1 & 107 & 0.07 & 0.13 \\
$4 / 20 / 99$ & No & 1 & 125 & 0.06 & 0.13 \\
$4 / 21 / 99$ & Yes & 25 & 294 & 0.12 & 0.02 \\
$4 / 22 / 99$ & Yes & 25 & 101 & 0.11 & 0.01 \\
$4 / 22 / 99$ & Yes & 25 & 147 & 0.51 & 0.06 \\
$4 / 26 / 99$ & No & 1 & 125 & 0.15 & 0.32 \\
$4 / 26 / 99$ & Yes & 25 & 162 & 0.33 & 0.04 \\
$4 / 27 / 99$ & Yes & 25 & 144 & 1.04 & 0.10 \\
$4 / 27 / 99$ & No & 1 & 154 & 0.20 & 0.51 \\
$4 / 28 / 99$ & No & 1 & 83 & 0.12 & 0.16 \\
$4 / 29 / 99$ & Yes & 25 & 155 & $<0.04$ & 0 \\
$4 / 30 / 99$ & No & 1 & 215 & $<0.08$ & 0.27 \\
\hline
\end{tabular}

Table D-2. Cumulative $D A C$-hour values for first four months of 1999.

\begin{tabular}{|c|c|}
\hline Employee & DAC-hour \\
\hline \hline A & $29.1^{\mathrm{a}}$ \\
B & 72.3 \\
C & 36.7 \\
D & 7.9 \\
G & 7.6 \\
H & 18.1 \\
I & 22.4 \\
J & 34.7 \\
K & 36.3 \\
N & 19.6 \\
\hline
\end{tabular}

${ }^{\mathrm{a}} D A C$-hour for Class $\mathrm{Y}$ aerosols of ${ }^{234} \mathrm{U}$ with an $A M A D$ of $1 \mu \mathrm{m}$ and a value of $1.2 \times 10^{-11} \mu \mathrm{Ci}-\mathrm{hr} / \mathrm{cm}^{3}$. 


\section{APPENDIX E}

\section{ACTLITE CODE LISTING}

This appendix contains a listing of the ACTLITE code that was used in the calculation of the uranium intakes tabulated in this report. The code, written in FORTRAN, was compiled using the WATCOM $^{\mathrm{TM}}$ compiler from Sybase, Inc., and run within a DOS window on a PC with a Windows $95^{\mathrm{TM}}$ operating system. Verification of ACTLITE's calculation was carried out by comparing its output with values derived using ORNL's DCAL code system and with values published by the ICRP and others.

Estimates of the intake rates $\left\langle\dot{I}_{u}>\right.$ and $\left\langle\dot{I}_{j}>\right.$ are calculated for both urinary and fecal excretion, respectively, as:

$$
<\dot{I}_{u}>=\frac{\sum_{i}^{N_{u}} \dot{A}_{u}\left(t_{i}\right)}{\sum_{i}^{N_{u}} E_{u}\left(t_{i}\right)}
$$

and

$$
\left\langle\dot{I}_{f}\right\rangle=\frac{\sum_{i}^{N_{f}} \dot{A}_{f}\left(t_{i}\right)}{\sum_{i}^{N_{f}} E_{f}\left(t_{i}\right)}
$$

where $\dot{A}_{u}\left(t_{i}\right)$ and $\dot{A}_{(}\left(t_{i}\right)$ represent the measured activity excreted per day at timet $t_{i}$ in the urine and feces and $E_{u}\left(t_{i}\right)$ and $E_{f}\left(t_{i}\right)$ are the expected excretion rates in urine and feces at time $t_{i}$ as predicted by the models given a unit intake rate. The $\chi^{2}$ values for the fit of the expected urinary excretion rates to the observed urinary excretion rates were calculated as

$$
\chi^{2}=\sum_{i}^{N_{u}} \frac{\left[\dot{A}_{u}\left(t_{i}\right)-<\dot{I}_{u}>E_{u}\left(t_{i}\right)\right]^{2}}{<\dot{I}_{u}>E_{u}\left(t_{i}\right)} .
$$

A corresponding equation applies to the fecal data. The above equation for the intake rate is based on a weighted least square fit of the excretion model to the data. The observations are weighted assuming their variance is proportional to the model predictions (Skrable et al. 1994). The $\chi^{2}$ values provide a measure of the goodness of fit, but they are of limited utility in deciding whether to base the recorded estimated intake on the urine or on the fecal data. 
The ACTLITE code also calculates the lung burden $q_{\text {lung }}(t)$ of uranium as a function of time for a unit intake rate. The predicted lung burden at the time of an measurement, $\left\langle q_{\text {lung }}(t)\right\rangle$, is computed as

$$
<q_{\text {lung }}(t)>=f_{235}<\dot{I}>q_{\text {lung }}(t) \text {. }
$$

The quantity $f_{235}$ represents the fraction of the uranium activity associated with ${ }^{235} \mathrm{U}$ which is the uranium isotope consider in the in vivo measurements. This equation was applied in deriving the values tabulated in Table 8.

The committed effective dose, $E(50)$, is computed as

$$
E(50)=\langle\dot{I}\rangle t e(50)
$$

where $\langle\dot{I}\rangle$ is the estimated intake rate, $t$ the duration of the intake, and $e(50)$ is the committed effective dose coefficient (see Table 4). The commitment period is taken to be 50 years; thus, the dose assigned to an intake in the period $t$ is the dose expected to be delivered in a fifty year period following the intake. 
Program ACTLITE

An age-independent, parent-only, striped-down version of ACricAl An use in Y-12 bioassay calculations. K. F. Eckerman 05/10/99.

impl icit integer ( $i-n)$

include 'iolist.cmn'

character"128 ar

character $* 8$ filei, caset

real*8 y, yw, a, zero

, delt3, delt 4 , delts

dimension sdate(5), edate(5)

dimension exuf(murite, 3), a(2*mcomp), itimeu( 30$)$, it imet (30),

cormon/timit/ delt1: delt2, del t 3 , del 14 , delts,

common/iconds/y(mcomp) yw (mcomp)

equivalence $(y(1), a(1))$, ( $y w(1)$, a(meomp +1$)$

parameter (zero = $0.0 d 0)$

(1, ACTLITE: :",t11, "Activity calculations '", $/ 111$,

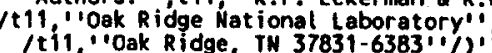

get the input file names from the command line

numarg $=$ iargc( $)$

write $(* ;)$ iUsage: ACILIIE filel w/o extensions. Filel,

urite(**) :

blassay data file. The output files'

write $(*, *)$ ? are nol

el stop

narglen $=$ igetarg( 1 , arg

filei = arg(i:narglén) $\quad$ bioassay data file

* Inquire if tiles exist

inquire (file=filel(: tentrim(filel)) // '.dat', exist = ex) if (.not. ex) then

write(*,*) Error: The date file '. filel(: lentrim(file1)) // writeida, $\because$ does not exist. write
write( $(*, *)$

end if

calculate some machine constants

call epsiton

open the $\log$ file

open(olog, file=filel(: (entrim(file1)) // '.log')
- read the time step information to be used by the solver

call timin

open(39, flle=file1(:lentrim(file1)) // '.dat') I open data file $n+=1$

do while (nit ine. O)

- call datrec(itimeu, umeas, it imef, fmeas, itimer, sdate,

uritedate, caset, iyearo, nu, nf, nr, ns, ne)

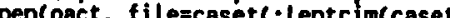

) /('euf')

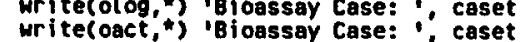

do iset $=1$, ns $\quad 1$ Do over the start/stops

lyear $=($ iset -1$)+$ i year 0
iendyr $=$ juldayo $(12,31$, iyear $)$

do $\begin{aligned} & i=1,2^{*} \text { mcomp } \\ & a(i)=\text { zero }\end{aligned}$

do $i=1$, mcomp

isorlst $(i, 0)=0$

do $i=1,0$

irmatrix $(i, j)=0$

end do

call moddat (' utypesc5')

1 1st assume type

(1)

$\begin{array}{ll}\text { call trace } & \text { process the model and } \\ \text { call comprake } & \text { compartment definitions }\end{array}$

Year: '? iyear

writecolog, ' ( $"$ " Number of compartment $=1,(i 4)$ ') ncomp

call compute(exuf, edate, sdate, iset) I do the computations

jpath $=1$

I process the results...

if (nu $=$ sdate( iset)

I if we have urine data then ... call intakes(exuf, umeas, itimeu, iyear, istart, zus,

end if

dose $=0.01133 *$ zus * real (edate( ( set) - istart)

write(oact, $")$ 'Dose (mrem) $=1$, dose

if (nf . ot. 0 ) then 1 if we have feces data then ... call intakes(exuf, fmeas, itimef, iyear, istart, $2 f s$,
chif, jpath, nf)

end if 0.01133 * $2 \mathrm{fs}$ * real(edate(iset) - istart) if (2us/2ts." 'Dose (mrem) $=1$, dose zintake 2 if

se

sumEus $=0.0$

$\Rightarrow$

do $i=1$ if

if (it imeu(i).gt. istart .and. itimeurine and fecal samples.

itm $=$ it imeu(i) - istart
sumeus = surieus + exuf(itm, 1$)$ lif urine : fecal ratio for $s$ is assumed.

If urine: fecal ratio greater than 1.05 then assume some is is present

$m, 1)$ 


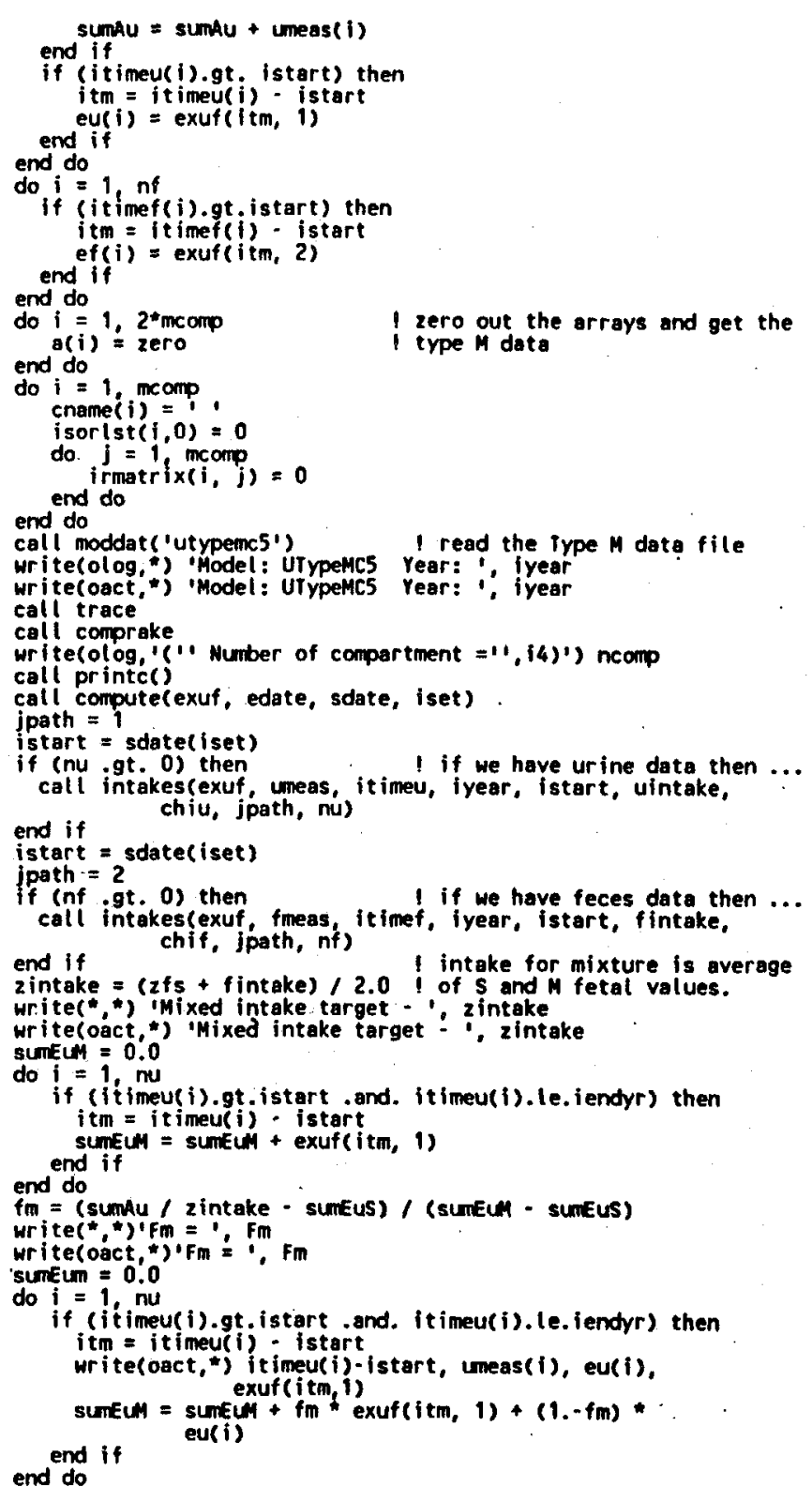

zint toke = sumAu/sumEum

writer", intake $=$ zintake

uri teloact, ")'Intake $=1$, zintake

if (iset .eq. 1 .and. ns .gt. 1 .and. $f m$.eq. 0.0 ) then write(oact, $"$ ) 'Correct ing future measurments:' write(oact, ") 'Urine:'

do $i=1, \mathrm{mu}$

if (it imeu( (i) -gt; sdate( 2$)$ ) then

$i_{\mathrm{tm}}=$ it imeu( $i$ - - sdate(i)

if (umeas (i) (it 0 zintake "exuf(itm, 1)

uriteloact (i4 i4 ipe umeas $(i)=0.0$

:

end if

end do

do

if (it imef(i) gt. sdate(2))

If (fmeas (i) $1 \mathrm{t}, 0.0$ ) fmeas (i) $=0.0$

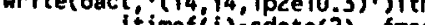
end if

elseif (iset .eq. 1 .and. ns .gt. 1) then

write(oact, ${ }^{*}$ ) 'Correcting future measurments'

writeest, thrine:

do $i=1$, nu

(it imeu(i) $=$ gt sdate(imeu(i) - sda) then

umeas $(i)=$ umeas(i) - zintake * $(\mathrm{fm} * \operatorname{exuf(itm,~1)+~}$

if cumeas (i) $(1 .-\mathrm{fm}) *$ eu(i))

if (umeas (i) $(t, 0.0)$ uneas $(i)=0.0$ end if

end do

urite(aact,")' 'feces: :

do $i=1$, nf

(it imef(i) gt sdate(2)) then

fmeas $(i)=$ fmeas(i) - zintake * (fm*exuf(itm, 2)*

if (fmeas (i) $1 t, 0.0)$ fmeas $(i)=0.0$

write(oact, '(i4, i4, 1 p3e10,3)' it tm,

end if end if

if (iset .eq 2) then 1 , i year)

else istart = sdate(iset)

dose = zintake " real(edate( iset) - istart)

$((1.0-\mathrm{fm}) * 0.01133+\mathrm{fm}=0.0035$

write(oact ' (''Total Intake (UCi)= '', 1PE9.2)') zintake *

write(oact, $")$ 'Dose (mrem) $=4$, dose

if (nr ${ }^{-9 t}$ ) then ${ }^{\prime}$ if we have lung measurements write(oáct, ") " Lung burden estimates: 

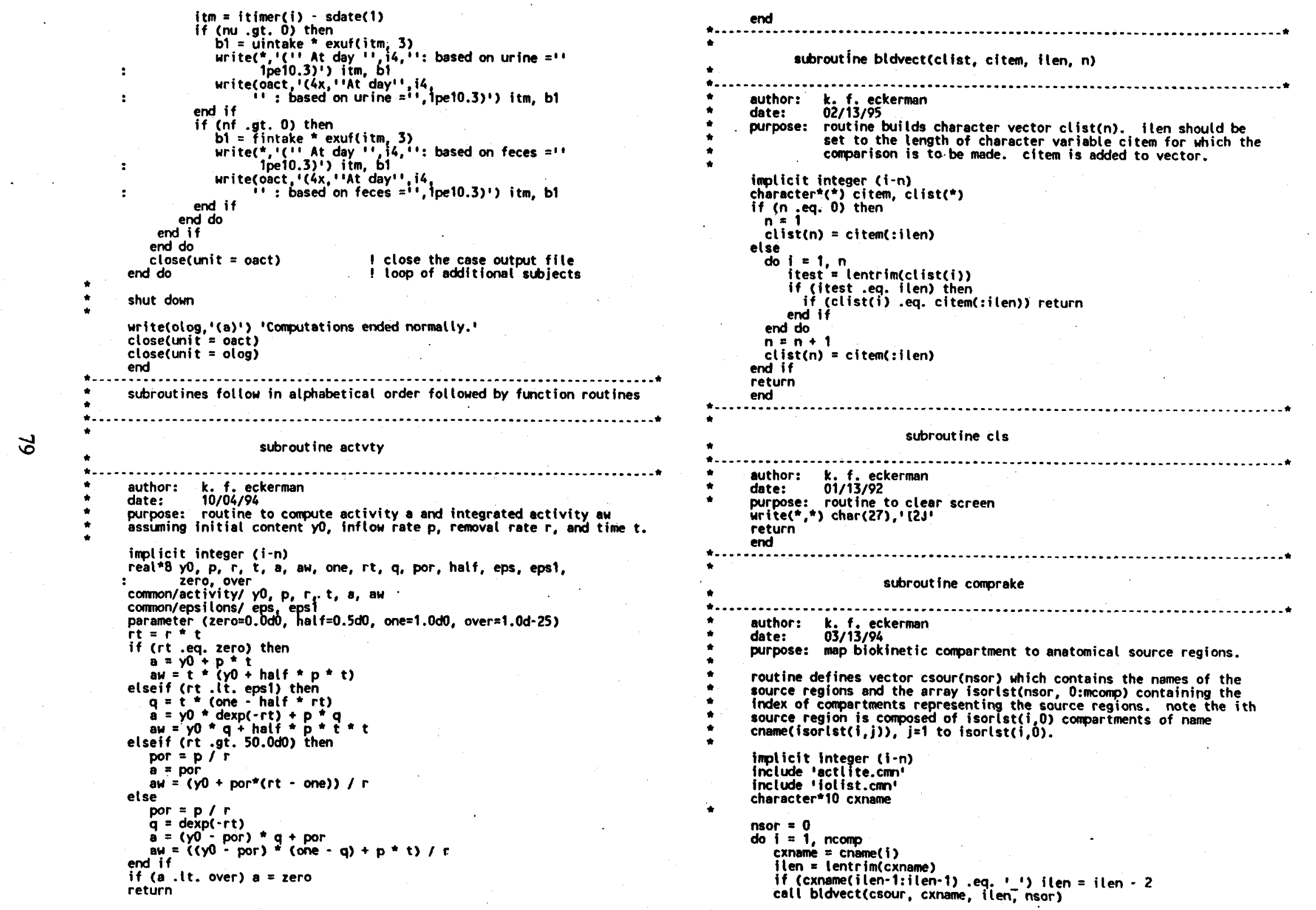


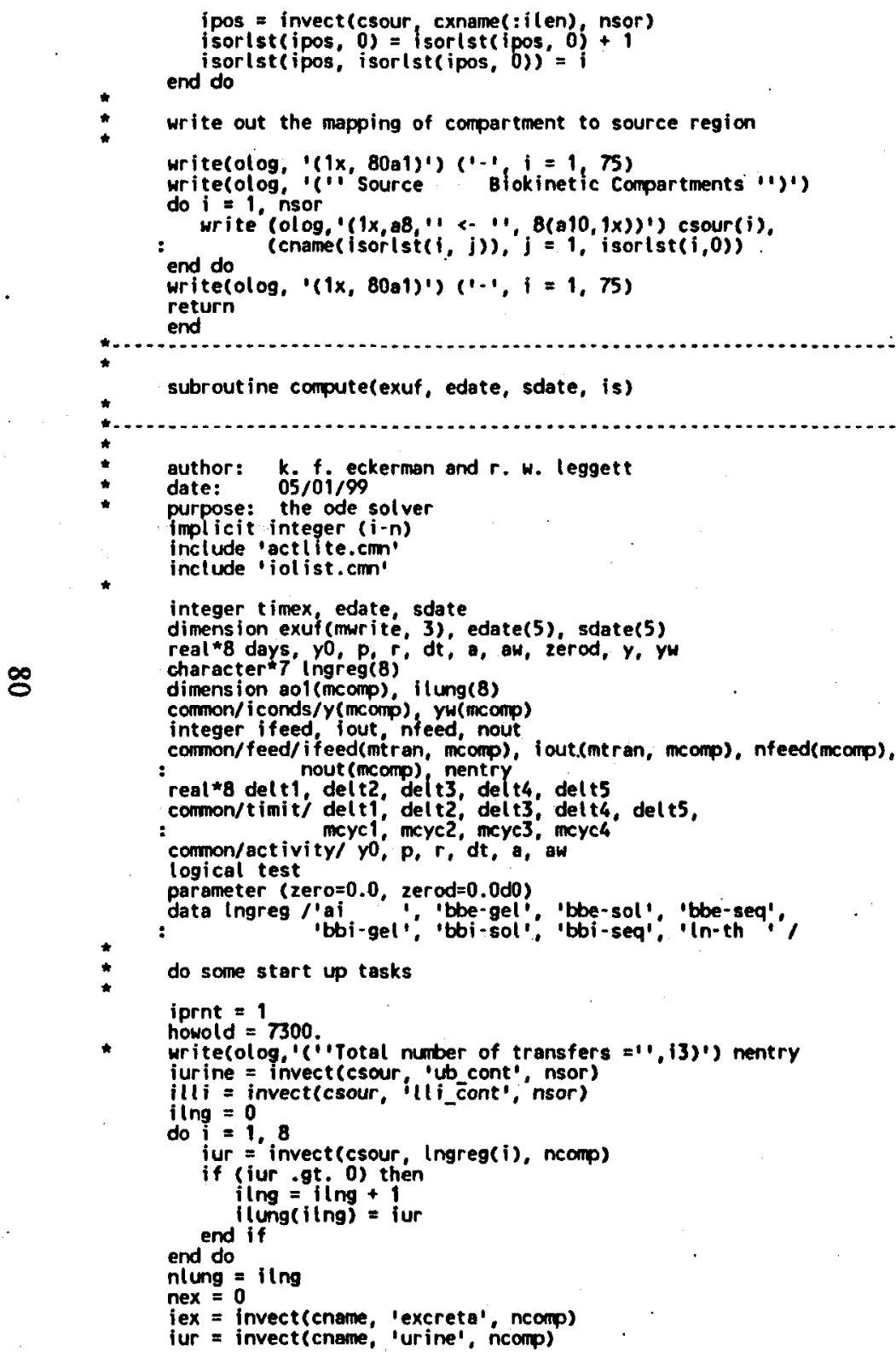

ifc = invect (cname, :feces', ncomp)

if (iur ne. o) nex $=$ nex +1

if (iex .ne. of nex $=$ nex +1
if (ifa. ne. o) nex $=$ nex +1

begin calculations: 1st set the initial conditions

\section{days $=$ zerod
do $i$ comp $=1$}

\section{if (icomp) $=$ dble(ao(icomp) . ne. 0 .) then}

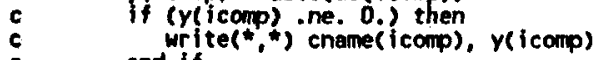

$$
\text { end do }
$$

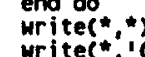

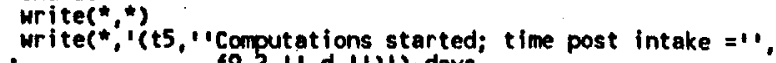

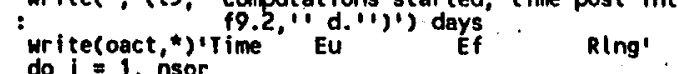

do $j=$ i nsor

do $i$ comp $=1$, isortst $(j, 0)$ end do

aot $(j)=\operatorname{aot}(j)+y(i$ sorlst $(j, i$ comp $))$

start timer and begin the cycling through the compartment

\section{itme $=$ timex $($ )
ptime $=1.0 d 0$}

texp $=$ able(edate(is) - sdate(is))

do 1000 icycle $=1,100000$

exhaust $=$ zero
if (icycle. (e. mcyc1) then
$d t=d$ del $i 1$.

elseif (icycle .le. mcycz) then

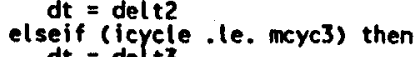

$\begin{aligned} d t & \text { delt } \\ \text { elseif (icycle . le. mcyc4) then } & \end{aligned}$

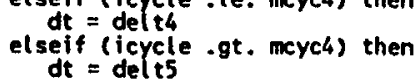

end if $=$ del to

elapsed time since start of. intake
do 750 icomp $=1$, ncomp
I loop over the compartments

set initial condition $r 0$ and compute inflow $p$ to compartment.

1. inflow from outside the system if $\mathrm{pO}(\mathrm{icomp}) \longleftrightarrow 0$, and

yo $=y$ (icomp)

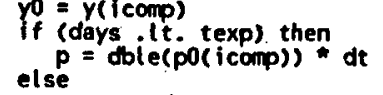

else $=$ zerod

do $i=1$, nfeed(icomp)

jcomp = ifeedd $i$ icomp

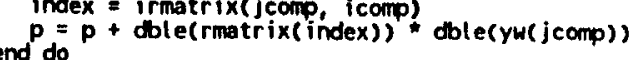

$e_{p=p}=d^{2} d t$

$p=p$
if
$\left(y 0^{\prime}\right.$. ne. zerod .or. $p$.ne. zerod) then 
- determine total removal constant from icomp.

if (icomp .eq. iex or. icomp .eq. iur .or $r=$ zerod. $i f($ ) then else

end if $r$

do $i=1$, nout(icomp)

$r=r+d b l e(r m a t r i x(i o u t(i, i$ comp) $))$

end do actrty

else

$a=$ zerod

end if

Save the activity, cumulative activity, and nuclear

transformation for current time step.

$y$ (icomp) $=a$

if (icomp. Le. ncomp-nex) then

exhaust $=$ exhaust +

cont inue

end of the icomp loop

increment howold to the right hand of the time period.

howold = howold $+d t$

if (days - .gt. ptime-0.00001) test $=$.true.

ptime $=$ ptime +1.000 write ${ }^{*}, "(1 \mathrm{ht}, 45, \because$ Computations started; time post "

add up activities in compartments of source region using isorlst array defined in rout ine comprake

do $j=1$, nsor

ao1 (j) = zero

isorlst(l of

ao1 $(j)=\operatorname{sol}(j)+y(i \operatorname{sor}(s t(j, i$ comp $))$

end do to

sumr $=0.0$

$\begin{array}{ll}\text { do } j & =1,0 \\ & =1 \text { nlung }\end{array}$

sumr $=$ sumr + ool(itung $(j))$

exuf(iprnt, 1$)=12$; *oof (iurine)

xuf( prnt, 2$)=001(11$

urite(oact, ' $(i 4,1$, ip3e11.4)') iprnt, (exuf(iprnt, j), $j=1,3$ )

iprnt $=$ iprnt +1 (exhaust .eq. zero) then

write(olog, '(" Compartments are exhausted, quit."')')

Iseif (days

write(olog. 9 . tend-real (sdate(is)-1)) then

goto 1001

end if

$f$ (howold .gt. 36500.) then

writec ${ }^{*}, i+5, "$ Attained age > $100 \mathrm{y}$; computations" "

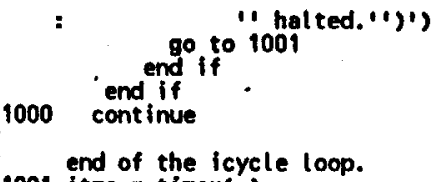

001 end of the icycle loop.

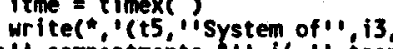

11 comprements $11,14,1$ transfers solved in $(100 s)=11$, is

:'(1')' ncomp, ntrans, it the

return

subrout ine datreclitimeu, umeas, itimef, fmea

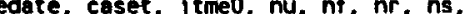

author: $k . t$. eckerman

purpose: read the bioassay date records

implicit integer $(i-n)$

dimension itimeu(30), it imef(30), umeas (30), fmeas (30), it imer (30) dimension sdate( 5 ), edate(5)

character $\$ 80 \mathrm{ls}$

character $\$ 8$ case

tend $=0.0$

nu $=0$

$\mathrm{nr}=\mathrm{O}$

$n s=$
ne $=0$

read(39, '(ABO)') Ls

caset $=$ L $($ s $(: 8)$

read(39; ( $(280)$ '?' (Ls), iy

itmeo $=1900+$ iy

do while (Ls::3) ne. 'END')

if (Ls(17:21) .eq. 'start') then

ns = ns +1

read (Ls $(: 2) \cdot(12) '$ ') mm

read (Ls(1:8): ( (i2) $)$, iy

sdate(ns) = juldayo(mm, id iy)
el se if (Ls(17: 19). eq. 'End's then

ne $=$ ne +1

read (Ls(:2), '(i2)')

read (Ls( $4: 5)^{\circ}$. (ii) (i) id

iy $=1900+$ iy

edate(ne) = juldayo(mm, id, iy)

(Ls(33:39) .ne. ' I) then

$n f=n f+1$
read(Ls(33:39), ( $(f 7.0)$ ') fmeas (nf)

read (Ls(:2), (i2) ' ; nm

read (Ls(4:5), '(i2)') id

$i y=1900+$

timef $(n f)=$ Julday $0(m m$, id, iy $)$ 


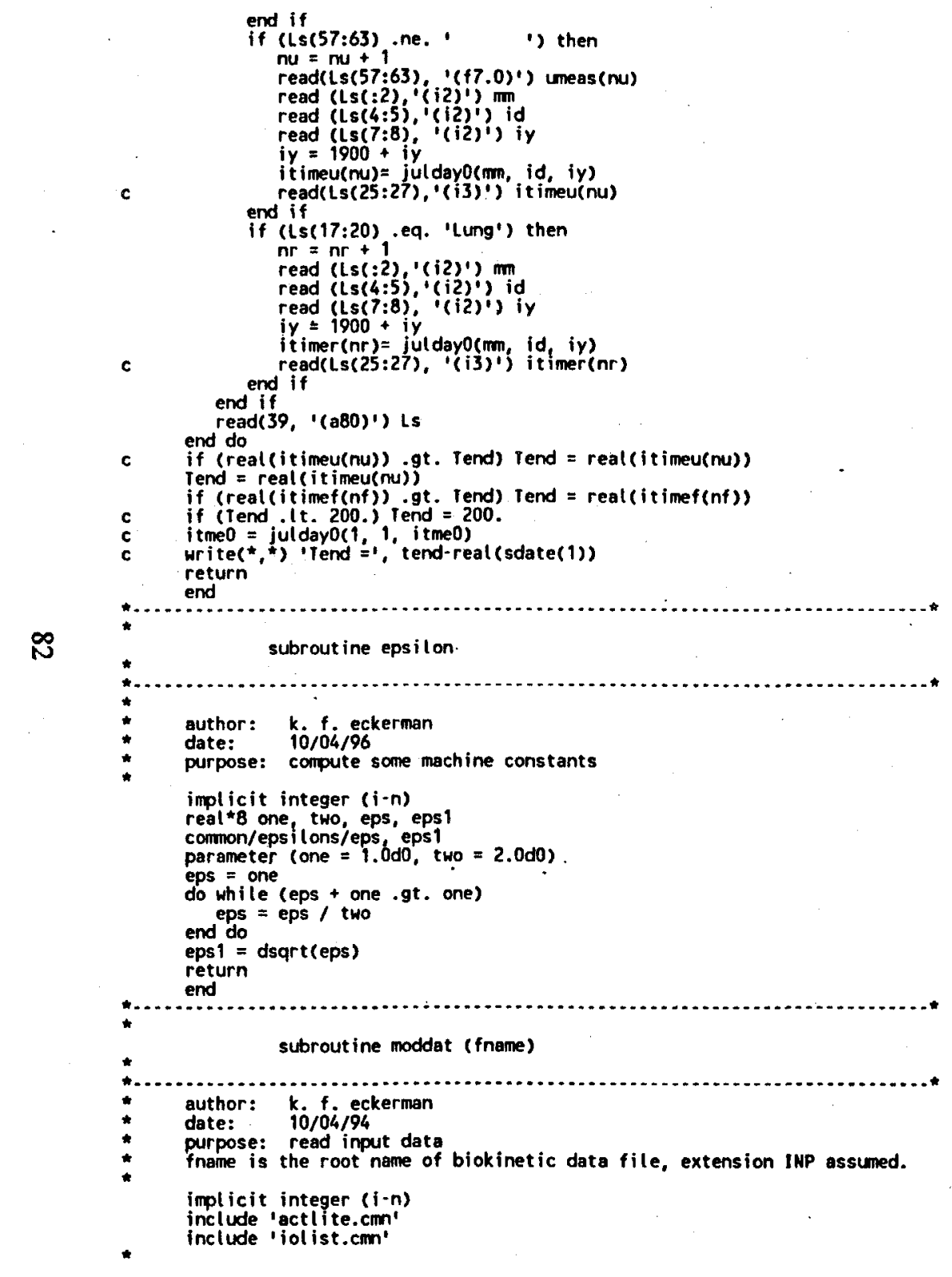

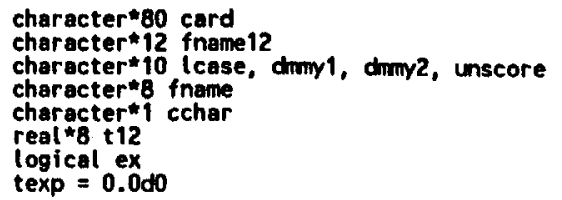

if (lentrim(cname(mcomp-2)) .gt. 0) then move excretion compartments ncomp = ncomp + 1 chame(ncomp) $=$ cname (mcomp-2)

if (lentrim(cname(mcomp-1)) .gt. 0) then ncomp $=$ ncomp + cname (ncomp) $=$ cname $($ mcomp -1$)$ end if if $($ mcomp-1) $=1$

if (lentrim(cname(mcomp)) .gt. 0) then first read through file to
assemble array of compartments. up from end of list. 
cname (ncomp) $=$ cname (mcomp)

end if

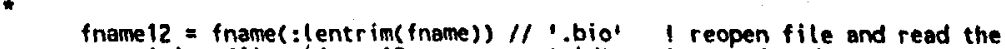
openc(igit, file =' fnamel2, status = old') Iransfer data.

$$
\text { rad }=0.000
$$

read(igit, '(a80)i') card

do thile (card $(: 3)$. ne. 'com's

(card(:5) .eq. 'THALF') then

read $=0.693147100 /$ tid 12

elseif (card(:4) . eq. 'TEXP.) then

read(card ' $\left.(5 x, e 16.0)^{\prime}\right)$ ' exp

el seif (card : 4 ) . eq. 'TENO') then

read(card, ' $\left(5 x\right.$, ei $\left.^{16.0} .1\right)$ iend

read( igit, ' (a80)') card

end do

read(igit ' (a80)') card

do while (card(:5) ne. 'END L')

do $i=1,100$ card $i: i)=1$

end do

I blank out the 1st 10 spaces

$n=$ lentrim(card)

do $i=11, n$

cchar $=\operatorname{card}(i: i)$

card $(i-10: i-10)=$ cchar

$\infty$

read(card, $*) x_{2}$

dimy $1=$ unscoré ( $Y_{\text {case }}(d m m y 1)$ )

i1 $=$ lentrim(dnmy 1 )

ip = invect (cname, dmmy1, ncomp)

po(ip) $=x$

read(igit.' (a80)') card

readkigit, '(a10)') dnmyl
ntrans $=0$

read(igit, '(a80)') card

(ceards:3) . ne. 'EOF'

read(card, ' ( a10,2x;
nt rans $=$ ntrans :

rmatrix(ntrans) $=$

dmmy1 = unscore ( ( case (dmmy1))

if $=$ invect (cname, dimy1, ncomp)

$i 2=$ invect (cname, dint, ncomp)

irmatrix(i1, 12$)=$ ntrans

end do

lose(unit $=$ igit)

write(", '(" Thalf (d) $=11,1$ pe11.4)") t12

read transfer rates between the compartments. Neran is number of

write( ${ }^{\prime},\left((6(3 x, a 10))^{\prime}\right)$ (ename(i), $i=1$, ncomp)

return

subrout ine printc

subroutine trace

date: $k$. f. eckerman

purpose: determine the interconnection of compartments so that the computations need only consider the feeder compartments
al so compartments with nonzero removal are ident ified.

implicit integer ( $(i-n)$
include 'actlite.crn'

integer if feed, iout, nfeed, nout 
$:^{\operatorname{co}}$

cormon/feed/i feed(mtran, mcomp), iout (mtran, mcomp), nfeed(mcomp),

this block establishes information needed to determine the removal coefficlents from each compartment ine matrix iout ( $j$, $j$ ) contains the the number of nonzero removal coefficients from the $j$ th compartment is nout (j).

nentry $=0$ icomp $=1$, ncomp

$n=$

index $=1$, ncomp

if (index. ne. 0 ) then

$n=n+1$

$f$ (n . gt. mtran) then

witecolog, '( 11 ' The number of outflows from '", a10,

writecolog, ' ( 1 ', Fatal error, please check biokinetic' ".

writes". " $("$ " the number of outflows from "', a10,

writes", ' ("I Fatal error, please check biokinetic "'

stop 1

iouten

out $(n$, icomp) $=$ index

end do

neutry * This block establ ishes information needed to determine the inflow feeding the ith compartment. The rmatrix of the ith compartment the $j$ th compartment is nfeed $(j)$.

\section{do jcom}

$n=0=1$, ncomp

do icomp $=1$, ncomp

index = irmatrix (icomp, jeomp)

if $n=n+i$

$=n+i$

writecolog, '(') The number of inflows into $" 1,10$,

writecolog, ' ( 1, Fatal error, please check biokinetic' "

writec", ' $" . '$ The number of inflows into "," 810,

writef*, ' ( $"$ "' Fatal exroeds mt please check biokinetic'"

" tiles."i)"

: stop 1

end if

ifeed(n, jcomp) $=$ icomp

nfeed ( jcomp) $=n$

end do

return

$*$ integer function invect(clist, citem, $n$ )

author: k. f. eckerman

purpose: function returns the index of citem in the array $\mathrm{clist}(\mathrm{m})$. if eiten is not in clist a zero is returned.

implicit integer $(i-n)$

character*(*) citem, clist(*)

if (n .eg., 0$)$ then stop 1

ilen $=$ lentrim(citem)

do $i=1$,

itest $=$ lentrim(clist(i)

(clist(i). eq. citem(: ilen)) then$$
\text { invect }=
$$

- invect $=0$

invect
end if
return

end

integer function julday $0(\mathrm{~mm}$, id, irys)

return 0 when item is not

\section{author: from Numerical Recipes}

date: 1996

compute Jul i an days.

Rout ine computes the JULIAN day given the month (MM), day (ID) and year (IYYY), The rout ine was obtained from: NUMERICAL RECIPES by Camberidge University Press, 1986, (FORTRAN version).
Cing

implicit integer $(i-n)$

$(10+12 * 1582))$

if (ivy .eq, of iyy, jy, jo

write $(*,+)$. There is no year zero.'

stop 1

if (imy $1 \mathrm{t}, 0$ ) iry $=i m y+1$

iv $=$ irry

else

$j_{j m}=i m y-1$

juldayo $=\operatorname{int}(365.25 * j y)+\operatorname{int}\left(30.6001^{*} j \mathrm{~m}\right)+i d+1720995$

If $\left(i d+3 i^{*}\left(\mathrm{~mm}^{2}+12^{\star}\right.\right.$ iy $\left.y\right)$. ge. igreg) then

ja $=\operatorname{int}(0.01 * j r)$

end if 


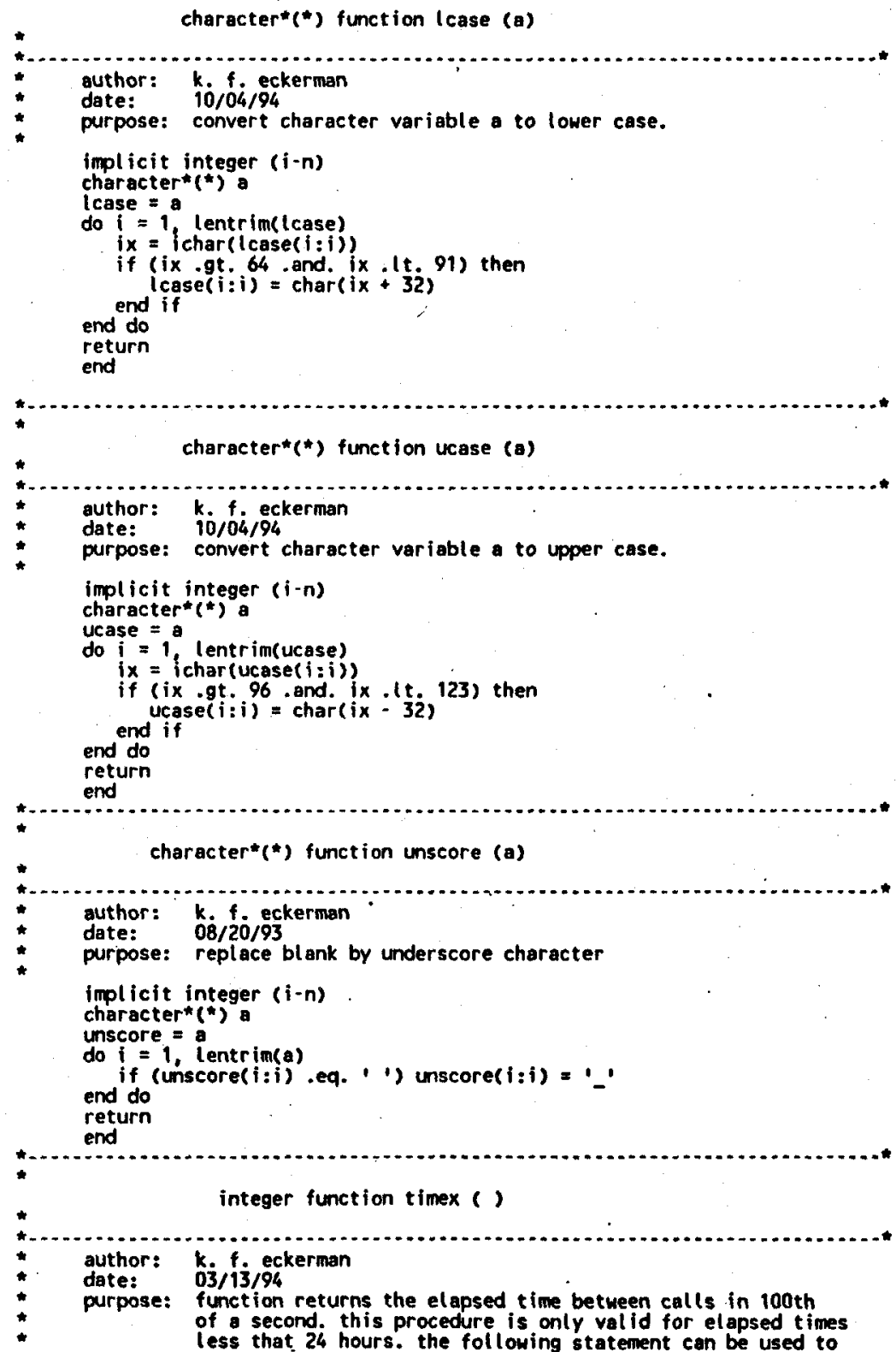

* print the elapsed time after the second call to timex:
write( $*,(11$ elapsed time $(100 \mathrm{~s})=11,18) !)$ timex( $)$

implicit integer $(i-n)$

integer*2 $\mathrm{hr}$ imin, isec, i100s

integer* 4 idelt, itold, isecd, itme

parameter(isecd $=8640000$ )

save first, itold

data first / true.

call gettim(ihr imin, isec, $i 100 \mathrm{~s})$
itme $=i 100 \mathrm{~s}+100 *($ isec $+60 *($ imin $+60 * i \mathrm{hr}))$

* if first set idelt to zero, first to false, store itme as

if (first) then

idelt $=0$

first $=$ ifalse.

else (itme .tt. itold) then

if current time is less than time of previous call.

idelt $=$ itme + isecd - itold

else $i d e l t=i$ tme $-i$ told

itold = itme

timex = idelt

return

return

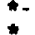

- subroutine intakes(exf, u, it, iyr, istart, uin, chi, jpath, n)

- author: k. f. eckerman

date: $06 / 12 / 99$
purpose: compute intake rat

implicit integer $(i-n)$

include 'actlite.cmn'

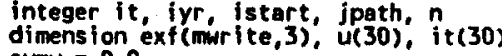

sumu $=0.0$
sume

iendyr $=$ juldaro( 12,31 , iyr)

if (jpath. eq. 1) then

write(oact,"), Urine samples:

end if if (oact,*) ' Fecal samples:"

write(oact, *) \& Day $A(t) \quad$ Eu(t)'

if (it (i) .gt. istart ,and. it(i) . le. iendyr) then

$i \operatorname{tm}=i t^{(i)}$ - istart

sum $=$ sum $+u(i)$

sume = sume + ext(itm,jpath) 


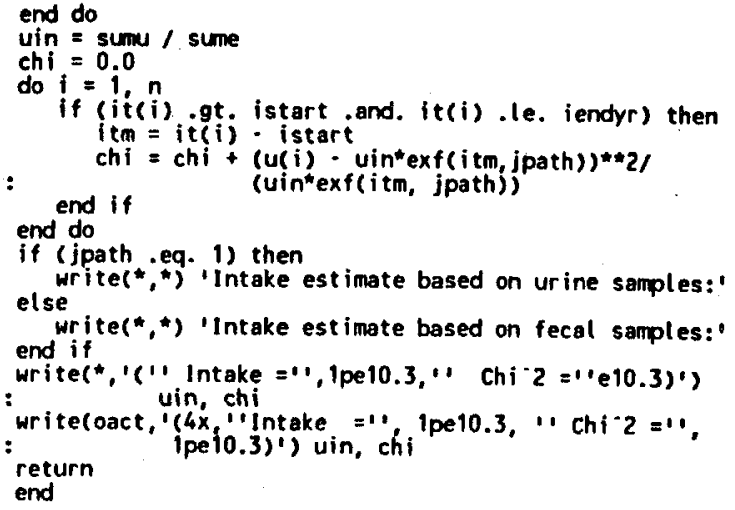




\section{APPENDIX F}

\section{URANIUM BIOKINETIC DATA FILES}

This appendix lists the uranium biokinetic data files used by ACTLITE for Type $\mathrm{S}$ uranium (see page 88) and Type $M$ uranium (see page 89). The files give the values of the transfer coefficients which define the rate at which material is transferred from one compartment to another in the lung, gastrointestinal, and systemic models. The deposition values for an aerosol with an $A M A D$ of $5 \mu \mathrm{m}$ are also given in the files. 
This file is UTypesC5.INP. This case is an inhatation of stable $U$ as Type $S$ material; AMAD - 5 micron.

$\begin{array}{lll}\text { COMPARTMENTS A(0) } \\ \text { AI-1 } & 0.0 & 1.596 \mathrm{E}-02 \\ \text { AI-2 } & 0.0 & 3.191 \mathrm{E}-02 \\ \text { A1-3 } & 0.0 & 5.319 \mathrm{E}-03 \\ \text { bbe-gel } & 0.0 & 6.569 \mathrm{5}-03 \\ \text { bbe-sol } & 0.0 & 4.384 \mathrm{E}-03 \\ \text { bbe-seq } & 0.0 & 7.721 \mathrm{E}-05 \\ \text { BBi-gel } & 0.0 & 1.171 \mathrm{E}-02 \\ \text { BBi-sol } & 0.0 & 5.921 \mathrm{E}-03 \\ \text { BBi-seq } & 0.0 & 1.243 \mathrm{E}-04 \\ \text { ET2-sur } & 0.0 & 3.989 \mathrm{E}-01 \\ \text { ET1-sur } & 0.0 & 3.385 \mathrm{E}-01 \\ \text { ET2-seq } & 0.0 & 1.996 \mathrm{E}-04 \\ \text { END LIST } & & \end{array}$

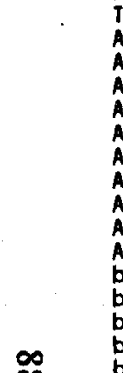

ANSFR

1 ( $>$ bbe-gel $(/ d)$

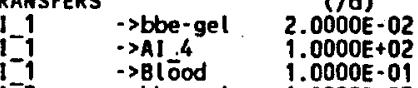

$\rightarrow$ bbe-gel 1.0000E-03

$1.0000 E+02$

$\rightarrow$ bbe-gel

$\rightarrow>$ N Th 2.0000 - Th -05

$\rightarrow>A 16$ 1.000E+02

$2.0000 E+00$
$->B B i-g e l$

abe-gel $>$ bbe-gel_t $1.0000 E+02$

bbe-gel $>$ Blood - 1.0000E-01 $\rightarrow$ BBi-gel 3.0000E-02 >Bbe-sol_t 1.0000E+02 $\rightarrow \rightarrow \mathrm{LlOOd}$ Th - >bbe-seq $1.0000 E+02$ $\rightarrow$ Blood 1.0000E-0 - $>E T 2$-sur
$\rightarrow B B$ i-gel_t $1.0000 E+01$ $\rightarrow>8 B$ i-gel_t 1.0000E+02 ->ET2-sur 3.0000 -02 $\rightarrow$ BBi-sol t $1.0000 E+02$ $\rightarrow$ Blaod - 1.0000E-0 $\rightarrow$ LN-Th 1.0000E-02 $\rightarrow 8 B B i-\operatorname{seq}$ t $1.0000 E+02$ $\rightarrow B$ 1.0000E-0 $\rightarrow$ Blood 1.0000 -01 $\rightarrow$ St Cont 1.0000E+02 $\rightarrow$ - ET2-sur_t 1.0000E+02 $\rightarrow>B$ lood 1.0000 -0 $\rightarrow \rightarrow$ TE-ET $1.0000 E-03$ $\rightarrow$ Blood $\rightarrow$ LN-ET t $1.0000 E+02$ $\rightarrow$ Bloor 1.0000E-01 - Excreta 1.0000E+00 $\rightarrow>$ bbe-gel_t 2.0000E-02 $\rightarrow$ blood t $\rightarrow$ Btood 1.0000 E-04 $\rightarrow$ bbe-gel t 1.0000E-04 $\rightarrow$ LN-Th $t$ 2.0000E-05 $1.0000 E-04$ Abe-gel_t $>2881-g e l$ t $2.0000 E+00$

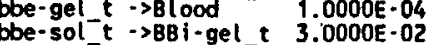

- Delimiter for end of block
<- Delimiter for initial condition block

transfer data

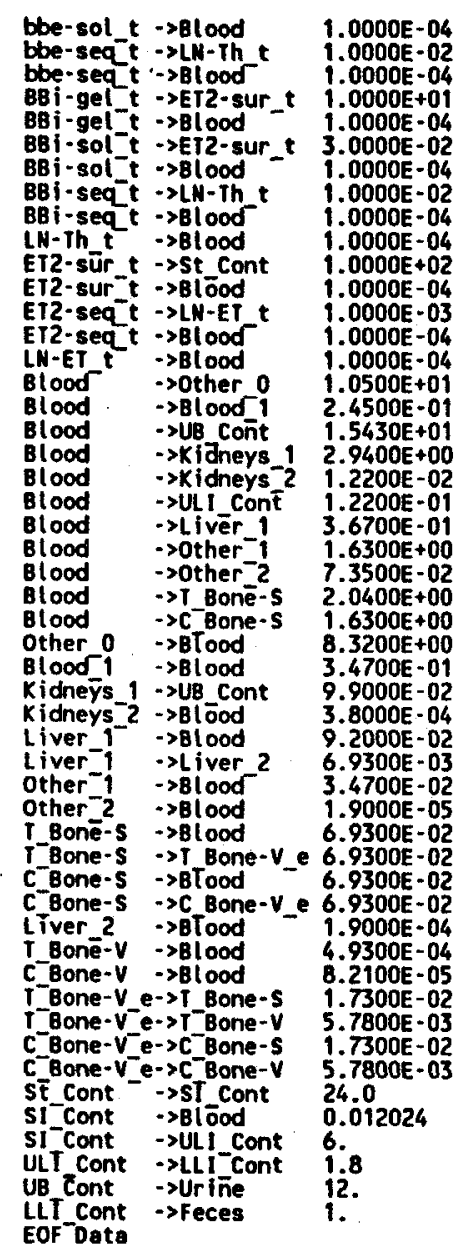

$<-f 1=0.002 ; 6 * f 1 /(1-f 1)$ 
This file is UTypeMC5.INP. This case is an inhalation of stable $U$ as Type M material: AMAD. 5 micron.

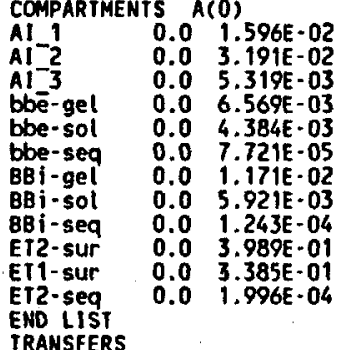

Al-1 $\rightarrow$ bbe.gel $(/ d)$

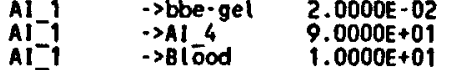
$>$ bbe-gel 1.0000E-0 $\rightarrow>A 159.0000 E+0$ $\rightarrow$ B $1.0000 E+0$ $\rightarrow$ L $\rightarrow$-Th $\rightarrow$ Al 6 9.0000E+0 $\rightarrow \rightarrow B$ iond $>$ BBi-gel $2.0000 E+00$ >bbe-gel_t $9.0000 \mathrm{E}+0$ T.0000E+0 (1) 1.0000E-02 $>$ bee-seq $9.0000 \varepsilon+0$ $\rightarrow$ Blood $1.0000 E+0$ $>$ BBi-gel t g.0000e+0 $\rightarrow$ Blood $1.0000 E+0$ - BET2-sur 3.0000E-0 >B8T-SOL_t 9.0000E+O $\rightarrow$ >lood $\rightarrow$ i. $\rightarrow$ Blood $1.0000 \mathrm{E}+0$ $\rightarrow$ LLF-Th t 9.0000E+0 $\rightarrow$ Blood $1.0000 E+0$ $\rightarrow$ Sont 1.0000 t02 $\rightarrow$ Blood_t $9.0000 E+0$ $\rightarrow$ LL-ET 1.000E+0 ->EI2-seq $9.0000 E+0$ ->Blood 1.0000e+0 $\rightarrow$ LLNETt $9.0000 E+0$ $\rightarrow$ Blood $1.0000 E+0$ $\rightarrow$ bbe-gel t $2.0000 E-02$ $\rightarrow$ Blood - 5 .0000E-03 $>$ bbe-gel_t 1.0000E-03 $>$ Blood 5.0000E-03 $266 \mathrm{e} \cdot \mathrm{gel} t \mathrm{t} 1.0000 \mathrm{E} \cdot 04$

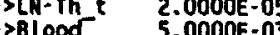
(2) Abé-gel_t $\rightarrow>B B i-g e l+t \quad 2.0000 E+00$

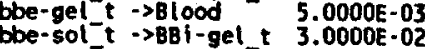

$<+\$ 1=0.002 ; 6 *+1 /(1-41)$

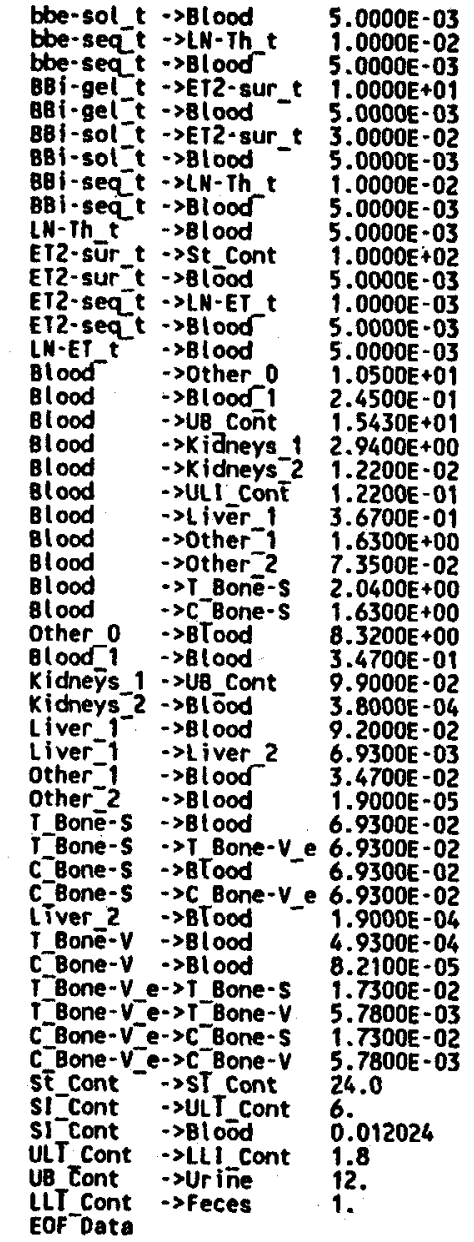

<- Delimiter for initial condition block

- Delimiter for end of block

- Delimiter for start of transfer data 


\section{APPENDIX G}

\section{ANALYSIS OF INTAKE CONTRIBUTIONS FROM TYPE M AND S URANIUM}

Experience indicates that inhalation exposures at the Y-12 Plant may involve both soluble and insoluble uranium. As discussed in Appendix E , the uranium intake rates $\left\langle\dot{I}_{u}>\right.$ is calculated for both urinary and fecal excretion using an equation of the form:

$$
<\dot{I}_{u}>=\frac{\sum_{i}^{N_{u}} \dot{A}_{u}\left(t_{i}\right)}{\sum_{i}^{N_{u}} E_{u}\left(t_{i}\right)},
$$

where $\dot{A}_{u}\left(t_{i}\right)$ represent the measured activity excreted per day at time $t_{i}$ in the urine, $E_{u}\left(t_{i}\right)$ is the expected excretion rate at time $t_{i}$ in urine per unit intake rate as predicted by the mathematical models, and $N_{u}$ is the number of bioassay measurements during the period of interest. For exposure to a mixture of Type $M$ and $S$ uranium, Eq. (G-1) becomes

$$
<\dot{I}_{u}>=\frac{\sum_{i}^{N_{k}} \dot{A}_{u}\left(t_{i}\right)}{\sum_{i}^{N_{k}}\left[f^{M} E_{u}^{M}\left(t_{i}\right)+f^{s} E_{u}^{s}\left(t_{i}\right)\right]},
$$

where $f^{M}$ and $f^{S}$ represent the fraction of the intake attributed to Type $M$ and Type $S$ uranium, respectively. A similar equation can be written for fecal excretion. Fecal excretion of Type $M$ and $S$ uranium is primarily a consequence of mechanical processes within the respiratory tract which transfer the deposited uranium to the GI tract. Although the mechanical processes act in competition with the absorption rates in the new lung model (ICRP 1994a), the mechanical removal rates dominate the clearance of Type $M$ and $S$ uranium. Thus, the estimated intake rates based on fecal excretion are largely independent of absorption Type. The separation of the clearance processes is a major feature of the new lung model.

Assume that both fecal and urine bioassay data are available for a worker chronically exposed to Type $M$ and $S$ uranium. As noted above, similar estimates of the intake rate will be indicated by the fecal samples regardless of the absorption type. This can be seen graphically in Fig. 2 of the text and 
is also evident in the figures of Appendix B (see, for example, Figs. B-2, B-3, B-4, B-12, and B-13). If the exposure involves only Type $S$ uranium, then the urinary excretion data and the fecal excretion data should yield similar estimates of the intake (see, for example, Fig. B-1 and B-7). If the intake rates derived from the urinary excretion data, assuming Type $S$ uranium, are numerically larger than those based on the fecal data, then the exposure may involve a mixture of Type $M$ and $S$ uranium.

If the intake rate derived from the urine samples $\left\langle\dot{I}_{u}^{S}\right\rangle$ is greater than the value indicated by the fecal samples $\left\langle\dot{I}_{f}^{S}\right\rangle$, then we seek the fraction of the intake rate attributable to Type $M$ uranium, such that the intake rate estimated for the mixture based on the urinary data might agree with that indicated by the fecal data. We set the left-hand side of Eq. G-2 to the average value of the intake rate derived from the fecal excretion $<\dot{I}>$ assuming either Type $\mathrm{M}$ and $\mathrm{S}$ uranium, that is

$$
<\dot{I}>=\left(\left\langle\dot{I}_{f}^{S}\right\rangle+\left\langle\dot{I}_{f}^{M}\right\rangle\right) / 2
$$

and solve for $f^{M}$ noting that $f^{M}+f^{S}=1$. The resulting expression for $f^{M}$ is

$$
f^{M}=\frac{\frac{1}{\langle\dot{I}>} \sum_{i}^{N_{x}} \dot{A}_{u}\left(t_{i}\right)-\sum_{i}^{N_{u}} E_{u}^{S}\left(t_{i}\right)}{\sum_{i}^{N_{u}} E_{u}^{M}\left(t_{i}\right)-\sum_{i}^{N_{u}} E_{u}^{S}\left(t_{i}\right)}
$$

and $f^{S}=1-f^{M}$. If the intake rate derived from the urine samples $\left\langle\dot{I}_{u}^{S}\right\rangle$ is less than the value indicated by the fecal samples $\left\langle\dot{I}_{f}^{S}\right\rangle$ (see, for example, Figs. B-11 and B-15), then we simply take the average of these two values as the intake rate and assume the exposure was due entirely to Type $S$ uranium (i.e., $f^{S}=1$ and $f^{M}=0$ ). 


\section{INTERNAL DISTRIBUTION}

1. K. M. Bailey

2. J. H. Barker

3. J. S. Bogard

4. R. S. Bogard

5. D. P. Bryant

6. T. R. Butz

7. W. W. Day

8. T. J. Denton

9-13. K. F. Eckerman

14. C. A. England

15. L. A. Felton

16. B. R. Fortune

17. B. T. Gose

18. F. P. Gustavson

19. N. C. Jessen

20. G. D. Kerr

21. D. C. Kocher
22. R. W. Leggett

23. R. C. Mann

24. D. A. McLaughlin

25. R. W. Oliver

26. R. N. Ortiz

27. R. R. Redmond

28. D. P. Rowan

29. A. Simanis

30-34. L. M. Snapp

35. R. E. Swaja

36. J. M. Thomas

37. R. Van Hook

38. S. A. Watkins

39. S. A. Wical

40. Central Research Library

41-42. Laboratory Records ( 1 - OSTI)

43. Y-12 Central Files

\section{EXTERNAL DISTRIBUTION}

44. C. H. Booker, U.S. Department of Energy, P.O. Box 2001, MS SE-32, Oak Ridge, Tennessee 37830.

45. M. D. Henderson, U.S. Department of Energy, P.O. Box 2001, MS SE-32, Oak Ridge, Tennessee 37830.

46. D. K. Hoag, U.S. Department of Energy, P.O. Box 2001, MS SE-32, Oak Ridge, Tennessee 37830 . 